\title{
Simulation and Modeling Capability for Standard Modular Hydropower Technology
}

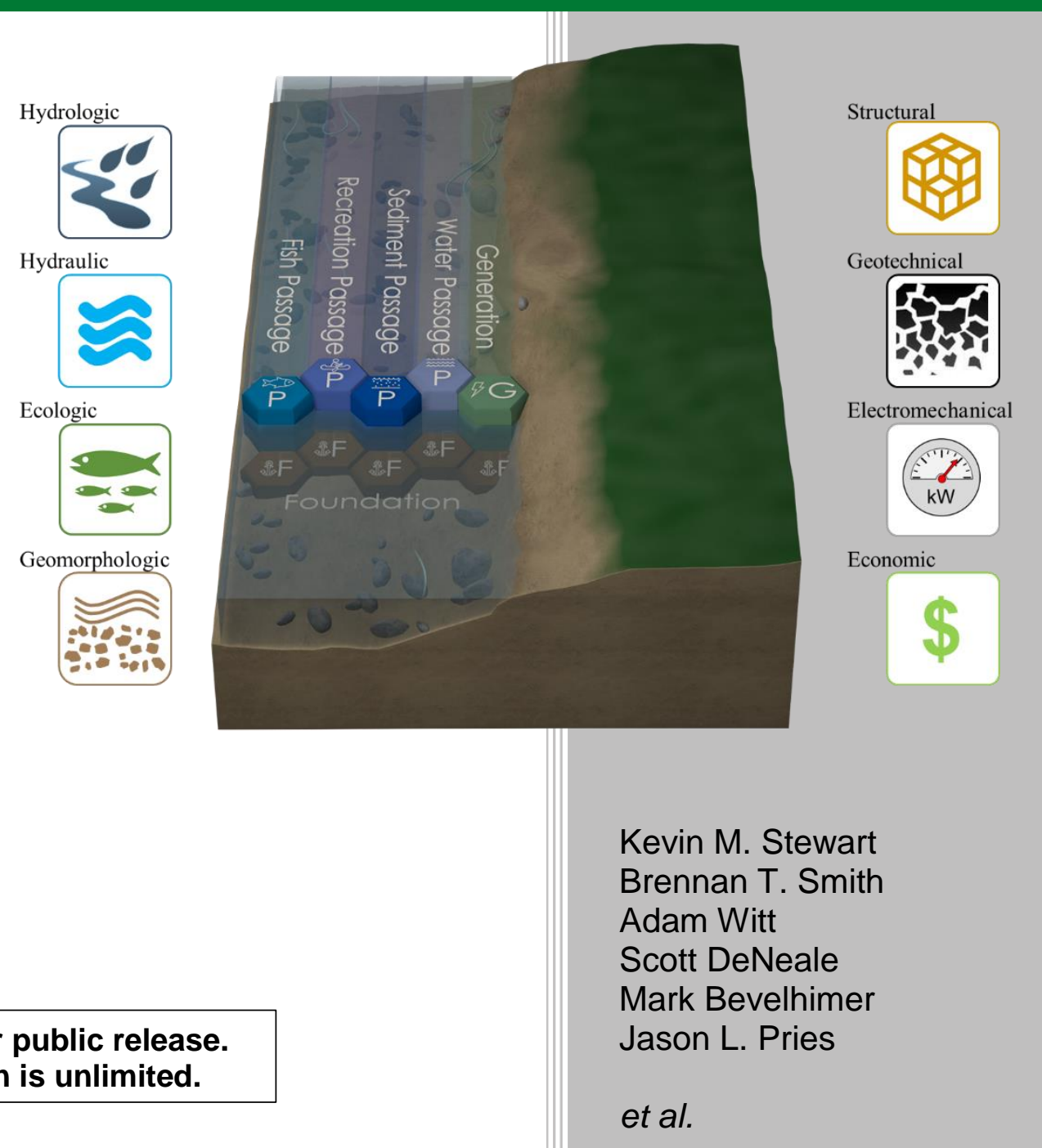




\title{
DOCUMENT AVAILABILITY
}

Reports produced after January 1, 1996, are generally available free via US Department of Energy (DOE) SciTech Connect.

Website http://www.osti.gov/scitech/

Reports produced before January 1, 1996, may be purchased by members of the public from the following source:

\author{
National Technical Information Service \\ 5285 Port Royal Road \\ Springfield, VA 22161 \\ Telephone 703-605-6000 (1-800-553-6847) \\ TDD 703-487-4639 \\ Fax 703-605-6900 \\ E-mail info@ntis.gov \\ Website http://classic.ntis.gov/
}

Reports are available to DOE employees, DOE contractors, Energy Technology Data Exchange representatives, and International Nuclear Information System representatives from the following source:

Office of Scientific and Technical Information

PO Box 62

Oak Ridge, TN 37831

Telephone 865-576-8401

Fax 865-576-5728

E-mail reports@osti.gov

Website http://www.osti.gov/contact.html

This report was prepared as an account of work sponsored by an agency of the United States Government. Neither the United States Government nor any agency thereof, nor any of their employees, makes any warranty, express or implied, or assumes any legal liability or responsibility for the accuracy, completeness, or usefulness of any information, apparatus, product, or process disclosed, or represents that its use would not infringe privately owned rights. Reference herein to any specific commercial product, process, or service by trade name, trademark, manufacturer, or otherwise, does not necessarily constitute or imply its endorsement, recommendation, or favoring by the United States Government or any agency thereof. The views and opinions of authors expressed herein do not necessarily state or reflect those of the United States Government or any agency thereof. 
Environmental Sciences Division

\section{Simulation and Modeling Capability for Standard Modular Hydropower Technology}

Kevin M. Stewart, Oak Ridge National Laboratory Brennan T. Smith, Oak Ridge National Laboratory Adam Witt, Oak Ridge National Laboratory Scott DeNeale, Oak Ridge National Laboratory Mark Bevelhimer, Oak Ridge National Laboratory Jason L. Pries, Oak Ridge National Laboratory Timothy A. Burress, Oak Ridge National Laboratory Shih-Chieh Kao, Oak Ridge National Laboratory Miles Mobley, Oak Ridge National Laboratory Kyutae Lee, Oak Ridge National Laboratory Shelaine Curd, Oak Ridge National Laboratory Achilleas Tsakiris, The University of Tennessee-Knoxville Christian Mooneyham, The University of Tennessee-Knoxville Thanos Papanicolaou, The University of Tennessee-Knoxville

Kivanc Ekici, The University of Tennessee-Knoxville Matthew Whisenant, The University of Tennessee-Knoxville Timothy Welch, US Department of Energy Daniel Rabon, US Department of Energy

Revision 0

Date Published: August 2017

Prepared by

OAK RIDGE NATIONAL LABORATORY

Oak Ridge, TN 37831-6283

managed by

UT-BATTELLE, LLC

for the

US DEPARTMENT OF ENERGY

under contract DE-AC05-00OR22725 



\section{CONTENTS}

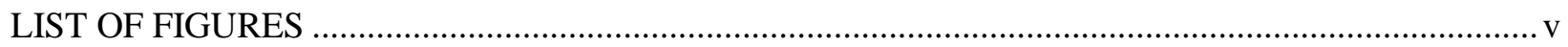

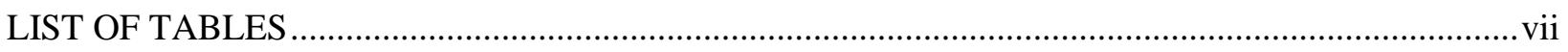

ABBREVIATIONS, ACRONYMS, AND INITIALISMS ................................................................. ix

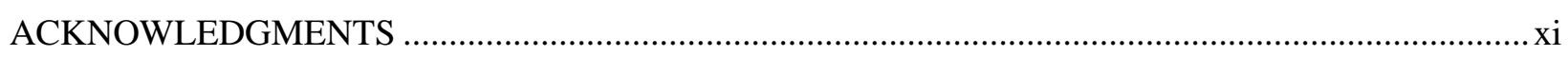

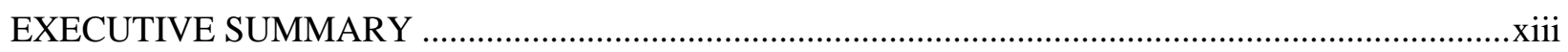

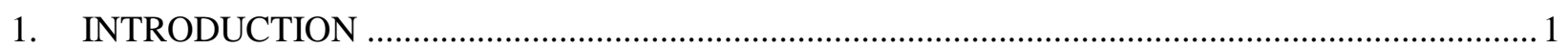

1.1 DEFINITION OF MODEL AND SIMULATION ....................................................... 1

1.2 CAPABILITY ASSESSMENT ASSUMPTIONS AND EXPECTATIONS ........................... 3

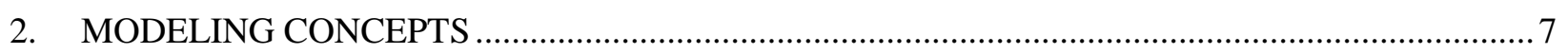

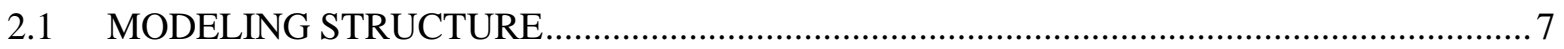

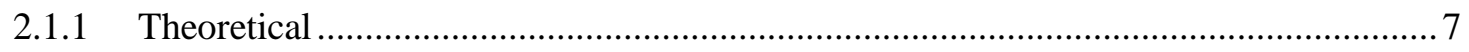

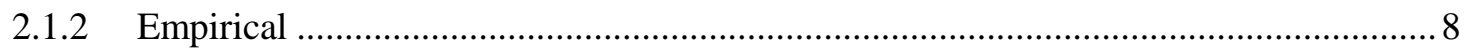

2.2 MODELING IMPLEMENTATION: SCALES OF IMPORTANCE …............................ 8

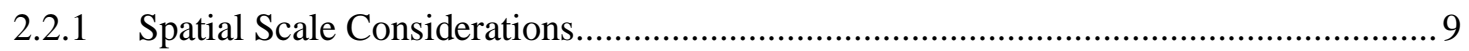

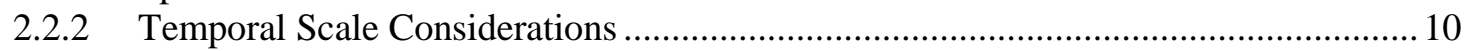

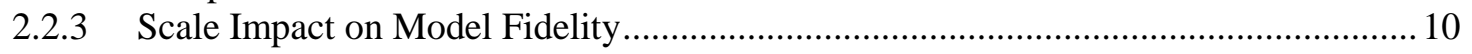

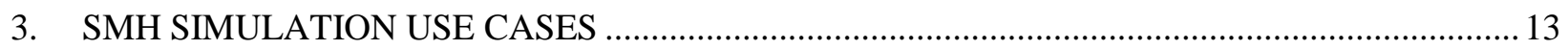

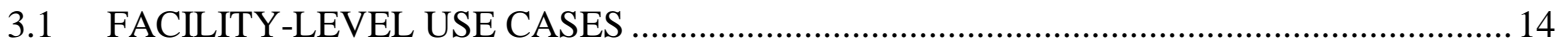

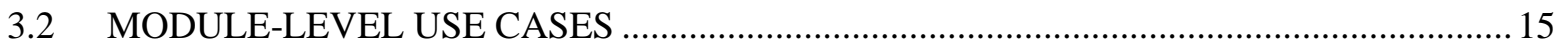

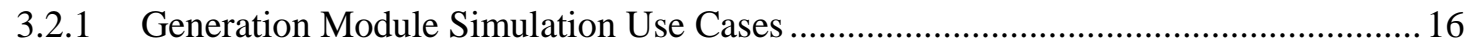

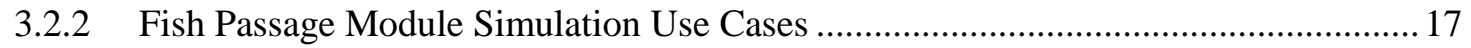

3.2.3 Sediment Passage Module Simulation Use Cases .................................................... 18

3.2.4 Recreation Passage Module Simulation Use Cases .................................................. 19

3.2.5 Water Passage Module Simulation Use Cases ....................................................... 20

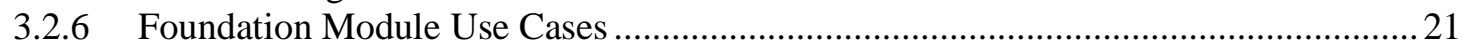

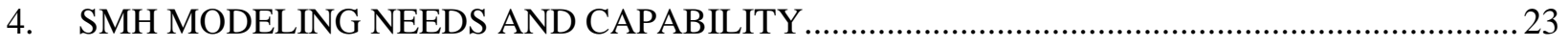

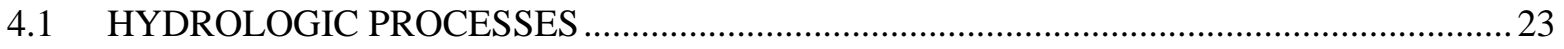

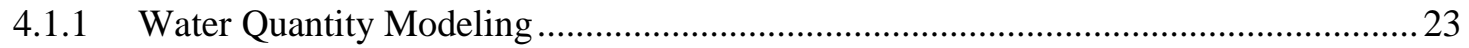

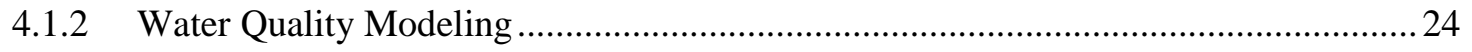

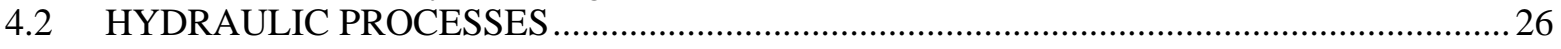

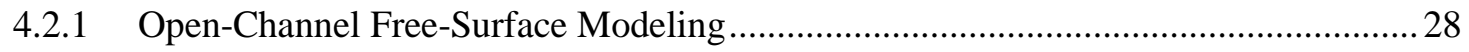

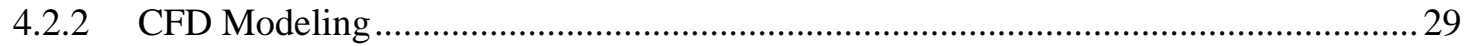

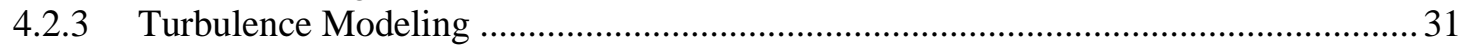

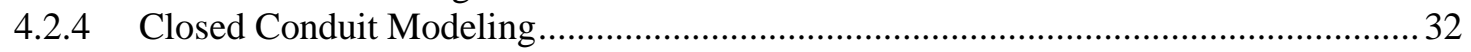

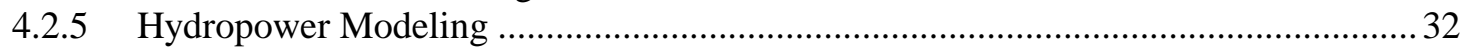

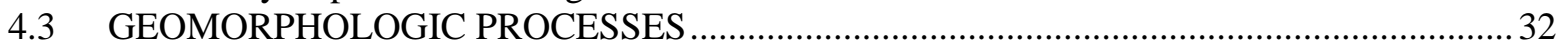

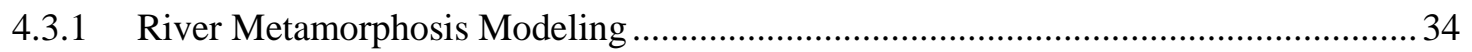

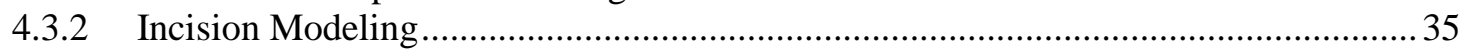

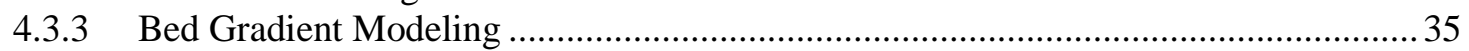

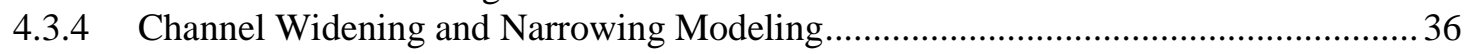

4.3.5 Modeling of Textural Changes and Bedform Development....................................... 36

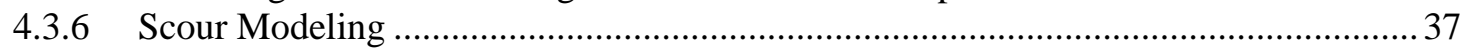

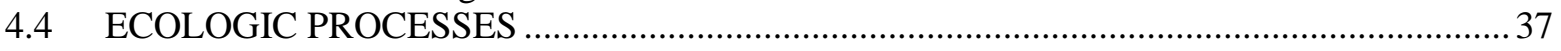

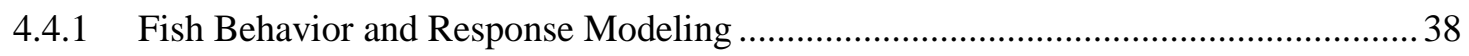

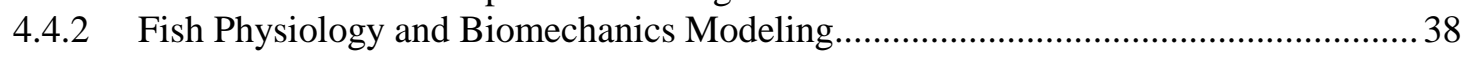




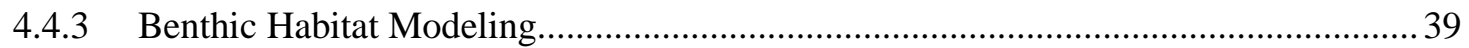

4.4.4 Cumulative Effects/Population-Level Response Modeling .........................................39

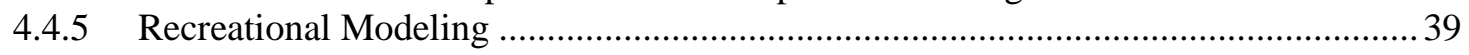

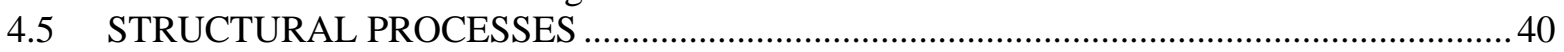

4.5.1 Structural Dynamics and Fracture Mechanics Modeling ........................................... 40

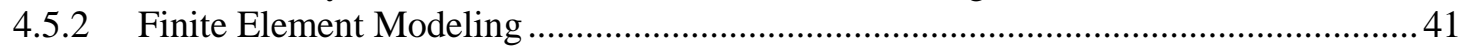

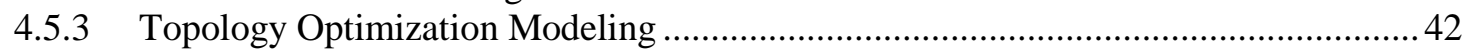

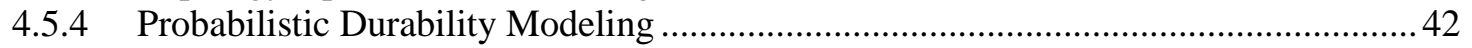

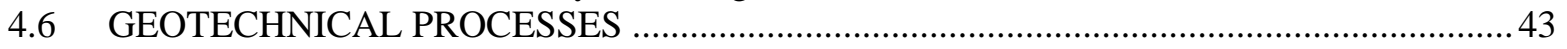

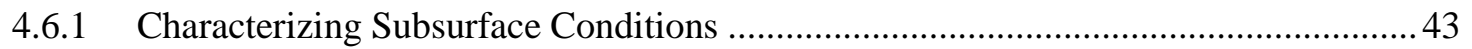

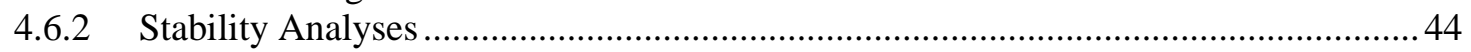

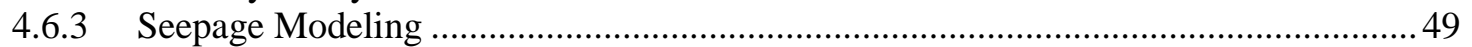

4.6.4 Sediment Consolidation and Fluidization Modeling ................................................. 49

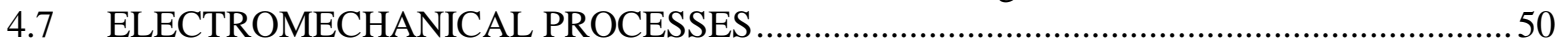

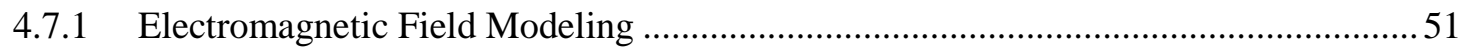

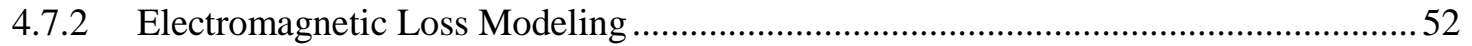

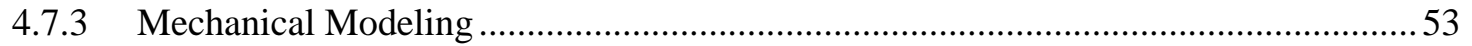

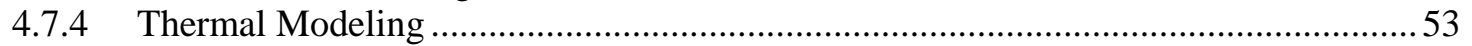

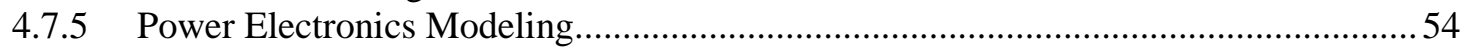

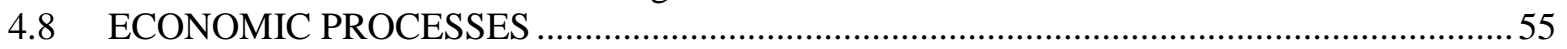

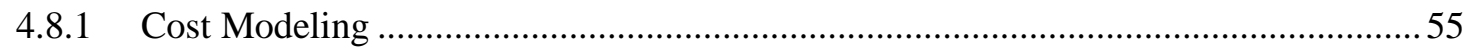

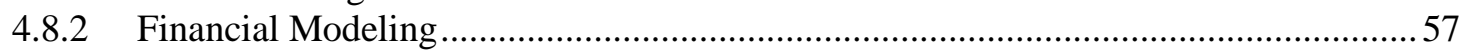

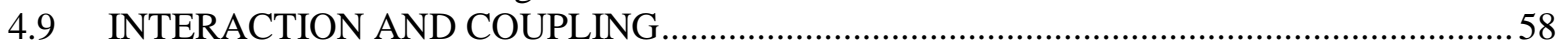

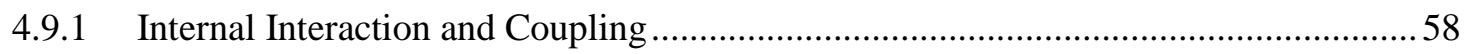

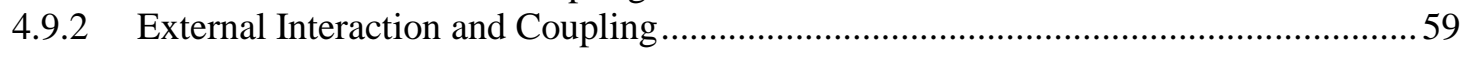

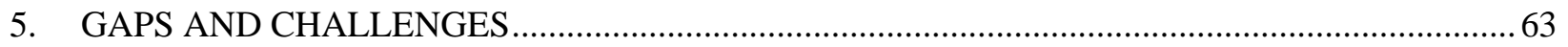

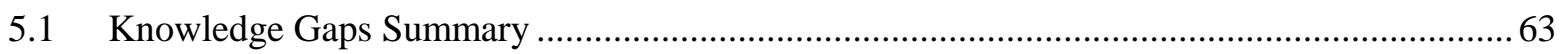

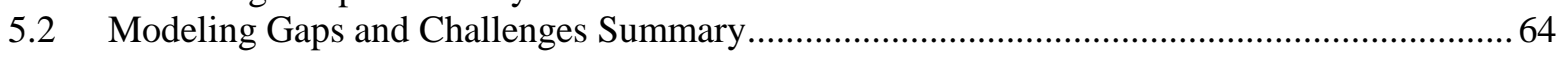

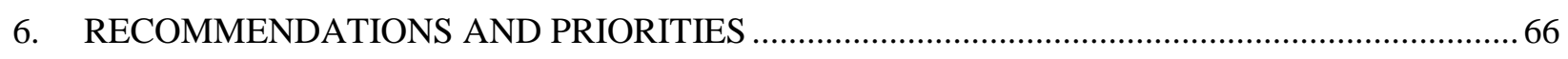

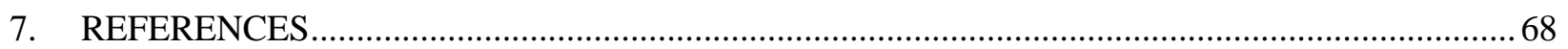

APPENDIX A. TOPIC DISCUSSION OF KNOWLEDGE GAPS AND MODELING GAPS

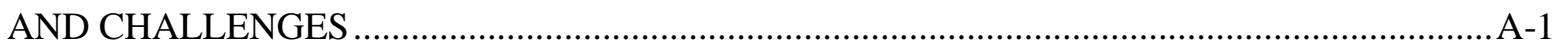




\section{LIST OF FIGURES}

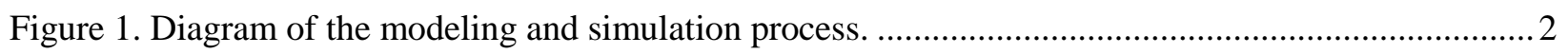

Figure 2. Schematic of the approach used to assess modeling and simulation capabilities........................ 5

Figure 3. Schematic of the spatial and temporal scales of the domain hierarchy used for SMH............... 9

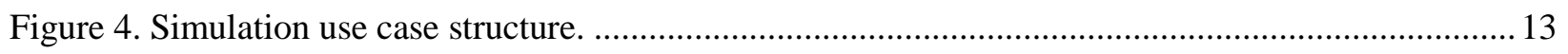

Figure 5. Characteristic spatial and time scales of key river geomorphic processes (after Knighton 1998).

Figure 6. Geometry of structure-foundation system, showing driving, structural, and resisting

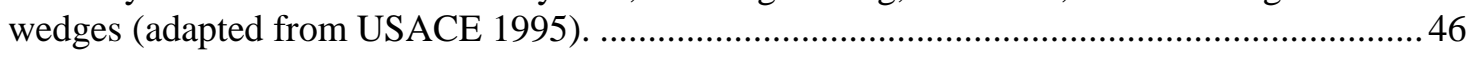

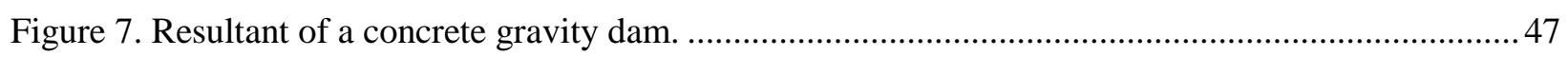

Figure 8. Generic geometry and loading conditions of a concrete gravity dam (USACE 1987)..............48

Figure 9. Interactions of the geomorphologic processes among themselves and with the hydraulic and geotechnical processes. 



\section{LIST OF TABLES}

Table 1. Example SMH facility-level simulation use cases............................................................. 15

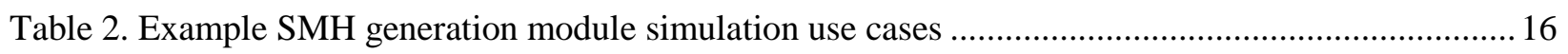

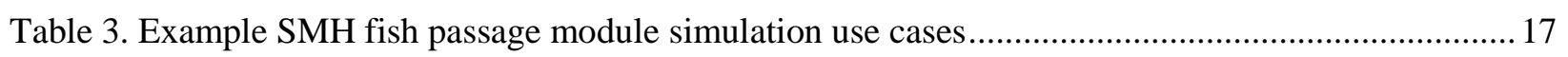

Table 4. Example SMH sediment passage module simulation use cases .............................................. 18

Table 5. Example SMH recreation passage module simulation use cases............................................. 19

Table 6. Example SMH water passage module simulation use cases ....................................................20

Table 7. Example SMH foundation module simulation use cases ........................................................2 21

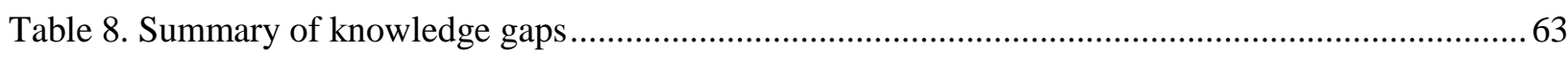

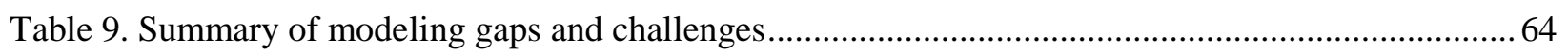

Table 10. Summary of recommended simulation and modeling capability research priorities ..................66 



\section{ABBREVIATIONS, ACRONYMS, AND INITIALISMS}

1D one-dimensional or one dimension

2D two-dimensional or two dimensions

3D three-dimensional or three dimensions

$\begin{array}{ll}\text { AC } & \text { alternating current } \\ \text { BCR } & \text { benefits-cost-ratio } \\ \text { CAD } & \begin{array}{l}\text { computer aided design } \\ \text { computational fluid dynamics }\end{array} \\ \text { CFD } & \text { conterminous US variable infiltration capacity } \\ \text { CONUS-VIC } & \text { detached-eddy simulation } \\ \text { DES } & \text { direct numerical simulation } \\ \text { DNS } & \text { dissolved oxygen } \\ \text { DO } & \text { US Department of Energy } \\ \text { DOE } & \text { Exemplary Design Envelope Specification }\end{array}$

FEA finite element analysis

FEM finite element modeling

FS factor of safety

FSI fluid-structure interaction

GLM General Lake Model

GM generation module

GUI graphical user interface

HB harmonic balance

HEC-HMS Hydrologic Engineering Center Hydrologic Modeling System

HEC-RAS Hydrologic Engineering Center-River Analysis System

HSPF Hydrological Simulation Program-Fortran

ICC initial capital costs

IDEA integrated design and economic assessment

IGV inlet guide vane

iRIC International River Interface Cooperative

IRR internal rate of return

LCOE levelized cost of energy

LES large-eddy simulations

NHDPlus National Hydrography Dataset Plus

NPV net present value

NSD new stream-reach development

NSE Navier-Stokes equations

NSF National Science Foundation

NWIS National Water Information System

O\&M operations and maintenance

ORNL Oak Ridge National Laboratory

PMG permanent magnet generator

POD proper orthogonal decomposition

RANS Reynolds-Averaged Navier-Stokes

RD\&D research, development and demonstration

ROM reduced-order model 
SAC-SMA Sacramento Soil Moisture Accounting

SBES simulation-based engineering science

SMH Standard Modular Hydropower

SWMM Storm Water Management Model

TOM topology optimization modeling

URANS Unsteady Reynolds-Averaged Navier-Stokes

USGS US Geological Survey

VIC variable infiltration capacity 


\section{ACKNOWLEDGMENTS}

The authors would like to acknowledge and express their appreciation to all the following individuals and programs for their review, comments, and support of this report and support of Standard Modular Hydropower research efforts.

\section{Oak Ridge National Laboratory}

- Patrick O’Connor, Energy Analyst

- Deborah Counce, Technical Writer/Editor

- Kathy Jones, Electronic Media Specialist

- Rose Raney, Technical Writer/Editor

- Priscilla Henson, Publications Manager

- Andy Sproles, Graphic Artist

- Douglas Edwardson, Web Developer

- Missy Miller, Administrative Assistant

\section{McKeown and Associates LLC}

- $\quad$ Alisha R. Fernandez

\section{Knight Piésold and Co.}

- Norman Bishop

\section{Small Hydropower Stakeholders}

The authors would like to thank the many stakeholders with whom we have engaged to elicit feedback on the opportunities and challenges associated with developing and deploying standard modular hydropower technologies. Ongoing engagement with these technology innovators, commercial service/equipment providers, project developers, and environmental stewards has yielded insight into the myriad perspectives and experiences that shape the current hydropower landscape and inform standard modular hydropower research. 



\section{EXECUTIVE SUMMARY}

Grounded in the stakeholder-validated framework established in Oak Ridge National Laboratory's SMH Exemplary Design Envelope Specification, this report on Simulation and Modeling Capability for Standard Modular Hydropower (SMH) Technology provides insight into the concepts, use cases, needs, gaps, and challenges associated with modeling and simulating SMH technologies.

The SMH concept envisions a network of generation, passage, and foundation modules that achieve environmentally compatible, cost-optimized hydropower using standardization and modularity. The development of standardized modeling approaches and simulation techniques for SMH (as described in this report) will pave the way for reliable, cost-effective methods for technology evaluation, optimization, and verification.

By identifying priority simulation use cases, a suite of modeling capabilities is documented for evaluating, predicting, and optimizing the safety, performance, reliability, and cost of SMH facilities, individual SMH modules and module combinations. The current gaps and challenges associated with simulating critical SMH processes highlight opportunities to improve the state of hydropower modeling with a goal of increasing small hydropower development while maintaining the power and function of the natural stream.

While simulation use cases are identified at a facility or module level, modeling needs are identified in terms of the physical processes that affect the stream environment, SMH structures, and socioeconomic features. These processes are separated into eight categories as follows:

1. Hydrologic processes

2. Hydraulic processes

3. Geomorphologic processes

4. Ecologic processes

5. Structural processes

6. Geotechnical processes

7. Electromechanical processes

8. Economic processes

In addition to individual processes, many of the important needs associated with SMH technology modeling involve the interaction and coupling of multiple processes through one or more models. This document describes some of the currently available tools and techniques that support SMH modeling capabilities and describes some key gaps and challenges. Recommendations and priorities for targeted research and development are also identified, based on those simulation and modeling gaps and challenges that are most critical to achieving broad SMH deployment.

This document represents Revision 0 of the SMH Simulation and Modeling Capability and will be updated periodically. 



\section{INTRODUCTION}

As the nation's largest source of renewable energy generation ${ }^{1}$, hydropower provides a reliable, lowemission source of electricity. Within the United States, much of the energy-dense hydropower resource has already been developed. Opportunities for hydropower growth are generally limited to the traditionally higher-cost, environmentally constrained development of new stream-reaches and nonpowered dams.

The US Department of Energy's (DOE) Hydropower Vision report (DOE 2016) highlights an opportunity to sustainably expand the hydropower fleet through environmentally compatible new stream-reach development (NSD). In particular, successful NSD projects must ensure that existing stream-reach functions are protected. Under the Vision's Combined Environmental Consideration scenario, in which environmentally sensitive locations are avoided, $1.7 \mathrm{GW}$ of NSD growth occurs through 2050. Through a combination of advanced technology and low-cost financing to support NSD, the Vision estimates an additional $15.5 \mathrm{GW}$ of NSD potential could be realized. It is hypothesized that the gap in these two scenarios can be bridged with "new-even transformative-hydropower technologies and project designs capable of avoiding or minimizing adverse environmental and social impacts"

Consistent with key features of the Vision Roadmap for unlocking undeveloped NSD potential (DOE 2016), DOE and Oak Ridge National Laboratory (ORNL) have developed the groundwork for a new class of small hydropower development called Standard Modular Hydropower (SMH). SMH focuses on stream functionality, standardization, and modularity as primary pathways to achieving environmentally compatible, cost-optimized hydropower project development.

As envisioned, successful SMH technology innovation and development must rely on a communal understanding of how environmentally compatible, cost-optimized hydroelectric energy production can be compatible with and even enhance the existing uses and function of natural streams. Consequently, engagement with industry stakeholders and key interest groups is essential in shaping SMH concepts and identifying research, development, and demonstration (RD\&D) opportunities, gaps, and challenges.

This report, Simulation and Modeling Capability for Standard Modular Hydropower Technology (Stewart et al., 2017), is preceded by two key SMH research planning documents:

- The SMH Multi-Year Research Plan (Smith et al. 2017) provides the context, background, and vision for SMH RD\&D activities.

- The SMH Exemplary Design Envelope Specification (EDES; Witt et al. 2017) provides a framework for technology-neutral conceptual SMH design that conforms to module-specific objectives, requirements, and constraints.

The groundwork being laid through the DOE/ORNL research efforts offers guiding principles for achieving broad small hydropower development in a sustainable way. With the SMH EDES (Witt et al. 2017) and stakeholder perspectives serving as a framework, this report describes the needs, capabilities, gaps, and challenges associated with modeling (i.e., predicting) the effectiveness of conceptual SMH designs and simulating the trade-offs associated with various design considerations.

\subsection{DEFINITION OF MODEL AND SIMULATION}

Modeling and simulation are used throughout a wide array of disciplines to develop and assess representations of processes or systems to predict outcomes in support of decision making and enhancing

\footnotetext{
${ }^{1}$ https://www.eia.gov/energyexplained/index.cfm?page=renewable_home
} 
understanding of how systems function (knowledge gain). Although the terms are often used interchangeably, "modeling" and "simulation" represent distinct processes and should be viewed as such, especially in developing new methodologies, technologies, or applications. The following definitions offer clarity in how to distinguish these concepts:

- Reference: some real or imagined system ${ }^{2}$ (set of connected things), entity (distinguishable "something" with a distinct existence as a particular unit about which the simulation keeps information), phenomenon (an observable occurrence or circumstance), or process (series of actions to achieve a particular outcome)

- Model: a logical representation of a system, entity, phenomenon, or process ${ }^{3}$

- Modeling: the interpretation, development, and refinement of reality into a model

- Simulation: a method of implementing a model or series of models over time in which the behavior of a system can be predicted by changing variables and the results can be used for making decisions ${ }^{4}$

As stated in Loper and Register (2015),

A model is characterized by three essential attributes: reference, purpose, and costeffectiveness. A model has a referent, some real or imagined system. A model should have some cognitive purpose with respect to its referent; it is impossible to evaluate or intelligently use a model without understanding its purpose. It should be more costeffective $e^{5}$ to use the model for this purpose than to use the referent itself; it may be impossible to use the referent directly, or using the referent would be dangerous, inconvenient, or expensive.

A basic illustration of the modeling and simulation process is provided in Figure 1.
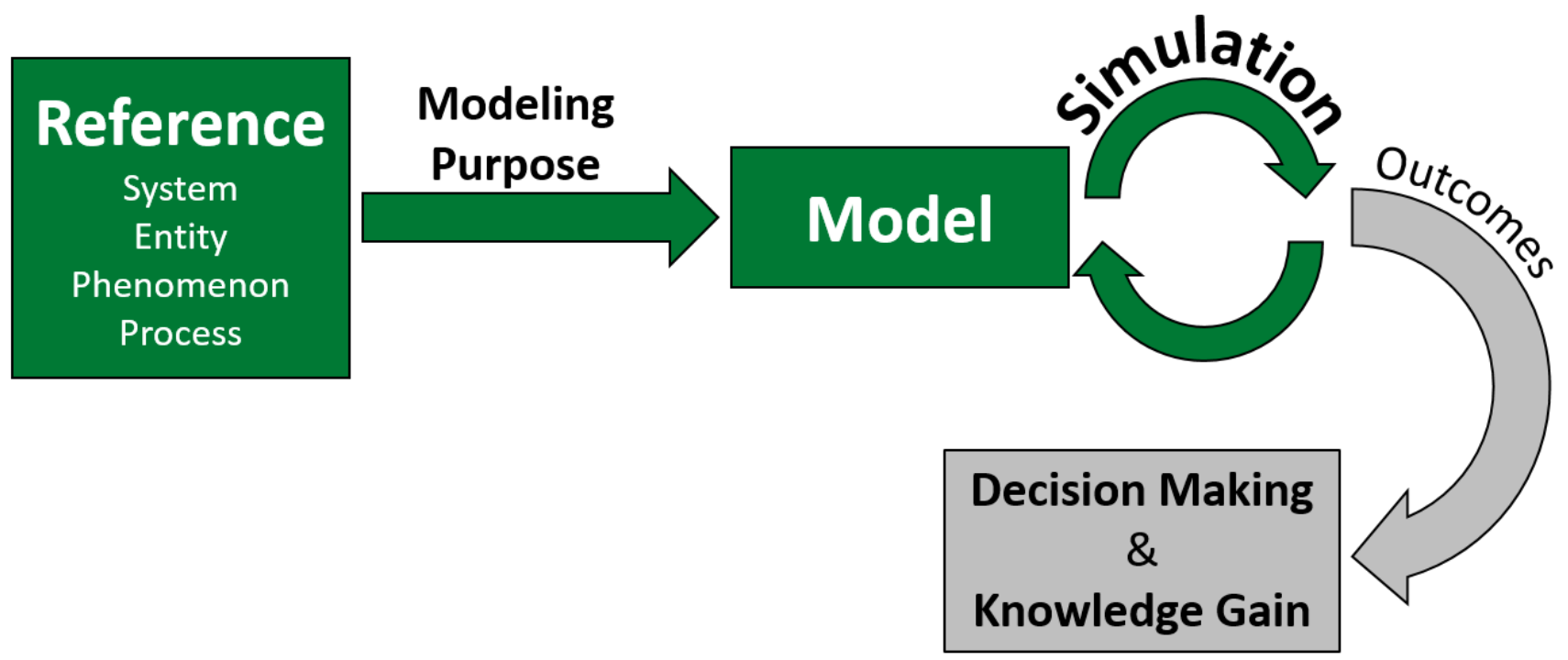

Figure 1. Diagram of the modeling and simulation process.

\footnotetext{
${ }^{2}$ Loper and Register 2015.

${ }^{3}$ Loper and Register 2015.

${ }^{4}$ Modified from Loper and Register 2015.

${ }^{5}$ Cost may refer to money, time scales, resources, risk, etc.
} 
Advances in computing technologies have enabled increased modeling precision and improved simulation performance. Successful modeling and simulation applications have shaped nearly all aspects of society, from science, engineering, and mathematics to politics, business, and economics.

Within the realm of engineered systems, the term "simulation-based engineering science" (SBES) has been used to define the multidisciplinary fusion of knowledge and techniques from engineering fields (e.g., electrical, mechanical, civil, chemical, aerospace, nuclear, biomedical, materials science) with knowledge and techniques from science fields (e.g., computer science, mathematics, physical sciences, social sciences) (NSF 2006). A National Science Foundation (NSF) Blue Ribbon Panel describes SBES as "a new paradigm that will be indispensable in meeting the scientific and engineering challenges of the twenty-first century" (NSF 2006). The NSF panel concludes that the United States is approaching a significant expansion in modeling and simulation capabilities for a nearly limitless array of phenomena and identifies several key implications. In summary, modeling and simulation will:

- Enable the exploration of previously unattainable analyses, measurements, and methodologies and may replace empirical assumptions with science-based computational models.

- Support wide-reaching applications for modern technologies and establish the groundwork for new and emerging technologies.

- Reduce design and manufacturing trial-and-error and design cycles using a more scientific basis.

- Improve predictive outcomes and optimize solutions before developing final designs or decisions.

- Expand capabilities to simulate length and time scales, multiple processes, and uncertainties.

- Provide tools and methods across all engineering disciplines to advance optimization, control, uncertainty quantification, verification and validation, design decision-making, and real-time response.

Consequently, momentum is gathering to improve modeling and simulation capabilities across all disciplines for spurring technology innovation in the face of twenty-first century issues and needs.

\subsection{CAPABILITY ASSESSMENT ASSUMPTIONS AND EXPECTATIONS}

Because most of the US hydropower fleet was developed over 30 years ago, the advent of sophisticated modeling and simulation techniques has not garnered as much attention in the hydropower industry as in other, newer renewable energy sectors (e.g., wind and solar) that have grown largely out of the successful application of advanced simulation-based design. Many older hydropower facilities were not subjected to regulatory review and were developed without awareness of the many environmental and social concerns that drive current regulation.

Currently, traditional hydropower development is typically preceded by site-specific design and assessment and uses custom equipment and structures. This approach largely results from a desire to maximize a site's energy production while ensuring proper regulatory compliance. In contrast, SMH technologies aim to reduce site-specific needs by leveraging advanced technologies (e.g., new powertrain designs, additive materials and manufacturing, power electronics); modular design concepts; and standardized approaches to simulation, design, and assessment. Conceptually, SMH facilities do not mimic traditional dams and may capitalize on only a fraction of a site's available energy potential as a result of minimized disruption of the natural environment. This novel approach to technology and design solutions demands an accompanying suite of modeling and simulation capabilities for accurate prediction and simulation interactions across hydropower systems and stream environments to improve design, performance, safety, environmental compatibility, reliability, manufacturability, and cost.

This report summarizes the needs, capabilities, gaps, and challenges associated with SMH modeling and simulation. The expectations and assumptions of this report and its content are as follows: 
- The existing model and simulation capabilities presented herein are based on professional use and knowledge gained through industry and academic experience. Whereas not all commercial and academic software tools and applications are contained herein, those included are representative of an exhaustive approach to identifying the type of capability needed to address modeling and simulation for $\mathrm{SMH}$.

- The development of a model or execution of a simulation for SMH is not a product of this effort. Instead, the material presented in this report serves as a resource for identifying the critical SMH processes, interactions, and couplings that require modeling; a review of the current state of SMHrelated modeling and simulation capabilities; and a public call for addressing RD\&D gaps and challenges.

- The knowledge and modeling gaps identified herein are helpful for informing the needed processes of developing new applications, methods, and tools that will rely upon communal understanding and collaboration among industry stakeholders and research communities to address those additional needs.

- The current efforts to assess modeling and simulation capabilities pertain to the generation, fish passage, water passage, sediment passage, recreational passage, and foundation modules only. The remaining two modules as defined in the EDES - the interconnection and monitoring/control modules - are not included in this current effort.

The approach for assessing the modeling and simulation capabilities is depicted in Figure 2. The assessment is structured into three main areas - simulation use cases, modeling capability, and gaps and challenges. The simulation use cases are defined scenarios that can effectively be addressed with the use of a model or group of models. These scenarios are constructed based on input from stakeholder concerns and priorities and leverage the functional requirements, relationships, and constraints from the EDES (Witt et al. 2017). The use cases, discussed in greater detail in Section 3, are established to address the decision, design, and trade-off optimization issues relevant to SMH. These serve as the basis upon which a formal simulation, or execution of models for a particular defined case, can be constructed.

Examination of the use cases reveals a need for the modeling of similar processes, depicted in the modeling capability area in yellow in Figure 2. These eight processes serve as the basis upon which the modeling capability assessment is focused. In Section 4, the current state-of-the-art technologies for modeling of these processes, as well as interaction and coupling of processes are presented in the context of the modeling concepts presented in Section 2. The context of interaction and coupling may involve the behaviors of different phenomena for single categorical processes or across different processes. Whereas the capabilities may exist for modeling different physical processes individually, a need to model the interaction of two or more different processes may be more challenging and may require a state-of-the art approach for the coupling of models and methodologies.

The assessment of modeling capabilities is aimed at identifying the knowledge and modeling gaps. "Knowledge gaps" refers to a lack of understanding of some particular phenomena associated with a categorical process, or process interaction and coupling that is relevant to SMH. Likewise, "modeling gaps" refers to a current inability to model, or the lack of a model for, a particular process relevant to $\mathrm{SMH}$. These knowledge and modeling gaps inform and define the need for potential RD\&D activities to improve modeling not only for SMH, but also for broader academic and industrial uses where applicable. 


\section{Standard Modular Hydropower Simulation and Modeling Capability}

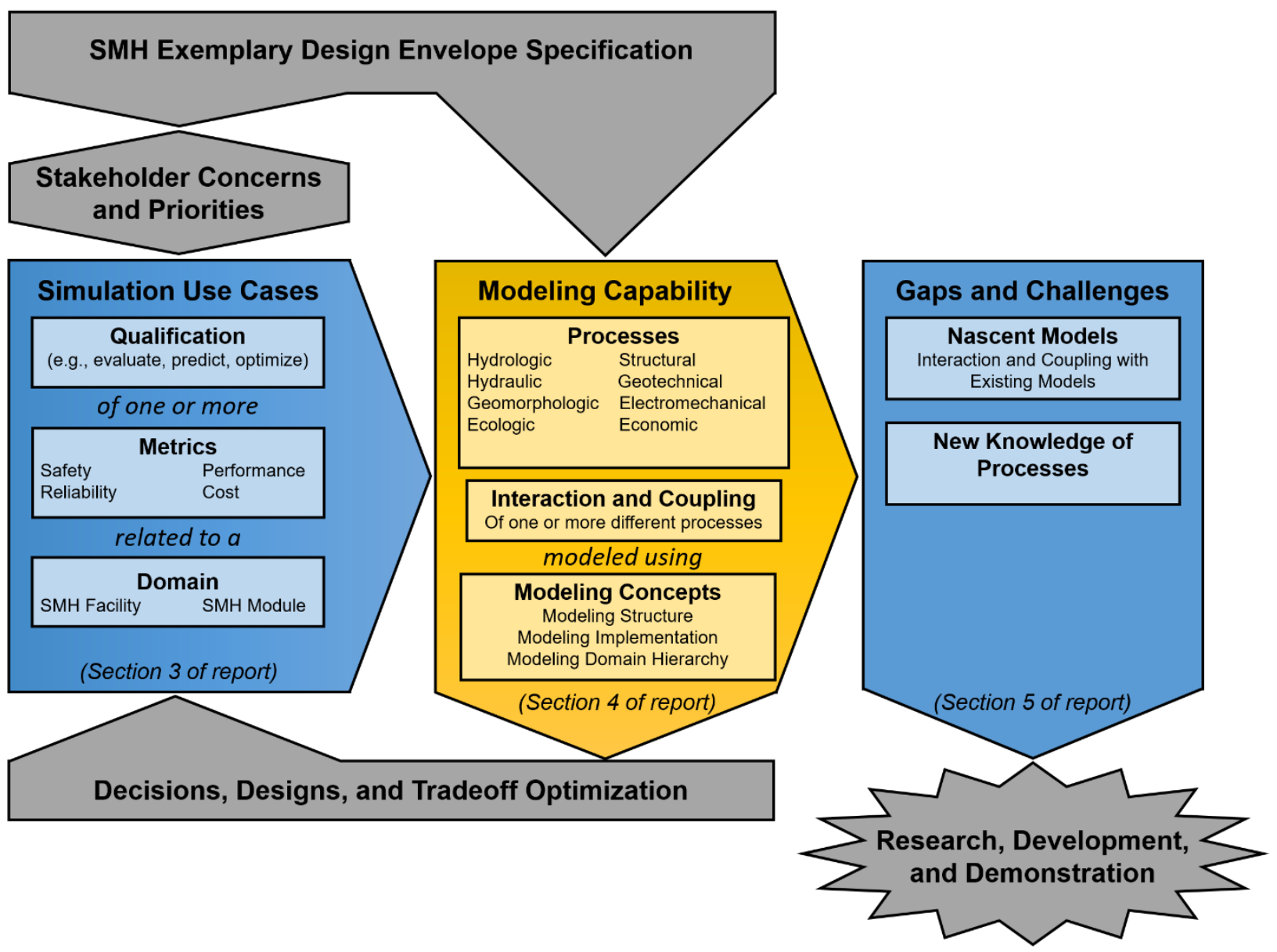

Figure 2. Schematic of the approach used to assess modeling and simulation capabilities. 



\section{MODELING CONCEPTS}

The process of modeling a system can take many forms, depending on the subject being modeled and the level of information and knowledge required to make decisions and identify conclusions about the system. Independent of the complexities of the system, model sophistication can range from simplified to very complex. For example, a conceptual model is a qualitative model that may be used to facilitate a high-level understanding of the general behavior, interlinkages, and couplings of a system. Even though conceptual models may be simple, they can be useful for identifying and categorizing main processes and establishing connected relationships among those processes - which can serve as an important step for the development of more complex models. More complex models may be more highly sophisticated with regard to the qualitative conceptual contexts or mathematical relationships among the processes that govern or describe the system.

This section presents the basic concepts of model structure, domain, and implementation for SMH modules and facilities. These concepts are used in Section 4 to identify model and simulation capabilities.

\subsection{MODELING STRUCTURE}

The development and use of models to perform simulations of a system first requires the identification of a model structure. "Model structure" is defined herein as the abstraction of the referent system into some form such that knowledge of the system can be gained from studying and investigating the behavior and outcome of the model. A model structure can take the form of a physical or virtual representation of a system: a physical model typically involves a tangible "mock-up" or reconstruction of a system at native or reduced physical scales used to study system phenomena and response. Its response is governed by the physical principles and processes occurring in the system.

Virtual representations of a system typically employ various techniques and approaches for studying systems, ranging from conceptual models to mathematical models. These models' responses are based on either simplified constructs resulting from observed or known behavior, or more elaborate mathematical constructs used for explicitly defining the underlying theoretical processes and mechanistic interactions of a system.

This report is concerned with virtual modeling and, more precisely, formal virtual models that consist of a modeling language, a definitive syntax, and the necessary semantics to support the context of the problem. Virtual models are often created because physical models are expensive and time consuming, dangerous, or impossible or may produce undesirable scale effects.

Models produce outputs governed by the interactions among inputs and the underlying principles and relationships used to define system operation and behavior. Two aspects of model structure necessary for understanding the various behaviors and processes present in the design and operation of SMH are identified as those governed by theory (i.e. mechanistic) and observation (i.e., empirical).

\subsubsection{Theoretical}

Theoretical modeling can be used to gain a new understanding of a complex system or to predict the behavior of a system based on mathematical representations of the actions and conditions of the system. Theoretical models require some fundamental knowledge and/or information related to particular phenomena involved in a system's governing behavior. They represent individual or coupled processes of the underlying system, such as physics, chemistry, biology, earth science, meteorology, psychology, sociology, and/or economics. 
Theoretical models incorporate mathematical representations of important system processes. They vary in complexity from steady state, one-dimensional (1D) models to complex, three-dimensional (3D), timevarying multiphysics problems. Consequently, some mathematical models can be solved analytically with simple desktop software, whereas others may require high-performance computers that employ complex mathematical solvers. In either case, the identification and execution of an approximation or numerical approach for applying the mathematical model must be clearly defined, along with appropriate assumptions, initial conditions, boundary conditions, and constraints imposed on the modeled system. Model outputs require proper calibration and validation to ensure the mathematical abstraction of the physical system is providing meaningful results. Results are interpreted; compared against real-world behavior and understanding; and then prepared for discussion, visualization, decision-making, or use in other models.

Theoretical models are critical tools for the development, demonstration, and advancement of SMH technologies. To bridge the gap between conventional and advanced hydropower technologies, a deep understanding of the physical processes that occur in a stream must be coupled with modeling capabilities that inform how state-of-the-art, sustainable hydropower systems must interface with the natural stream environment. Examples of theoretical modeling for SMH may involve ecological fish behavior and mechanistic modeling, sediment transport modeling, fluid mechanics and turbulence modeling, hydraulic modeling, hydrologic process modeling, geomorphologic modeling, economic modeling, structural and material modeling, and electromechanical modeling.

\subsubsection{Empirical}

Empirical modeling, like theoretical modeling, can be used to gain an understanding of a system or to predict its behavior; but it is based on observation and experimentation. Empirical modeling entails the development of, or utilization of data from, a well-prescribed plan or experiment to identify, measure, and understand a particular aspect of a physical system. Ideally, efforts to isolate, control, and perhaps vary particular aspects of a system are helpful in mapping dependent behaviors or processes in the system. Based on this mapping, correlative relationships can be developed and used as a means of predicting particular processes and behaviors of the system. Examples of empirical modeling for SMH may involve quantifying aspects of fish behavior and movement for particular ranges of flow or assessing rates of scour for various sediment bedload distributions and flows.

\subsection{MODELING IMPLEMENTATION: SCALES OF IMPORTANCE}

A virtual model representing the interactions between a hydropower system or hydropower modules and the surrounding environment must contemplate the spatial and temporal scales of importance, informed by the spatiotemporal extent over which the processes and behaviors occur. Equally important is an estimate of how accurately the processes and behaviors must be represented to provide meaningful and actionable model outputs. This section discusses the importance of the physical scale encompassed by a model, time scales represented in the model, and impact of these scales on model fidelity.

To frame this discussion, a nested hierarchy of SMH is shown in Figure 3. It is divided into five different levels - watershed, stream, site, facility, and module. The watershed is the most encompassing level within which the other four reference levels reside. This implies that processes occurring at each level are relevant to and affect processes at the next level. For modeling and simulation, this hierarchical structure facilitates defining the potential division of various spatial and temporal considerations that can be very important for developing modeling and simulation structure and implementation. 


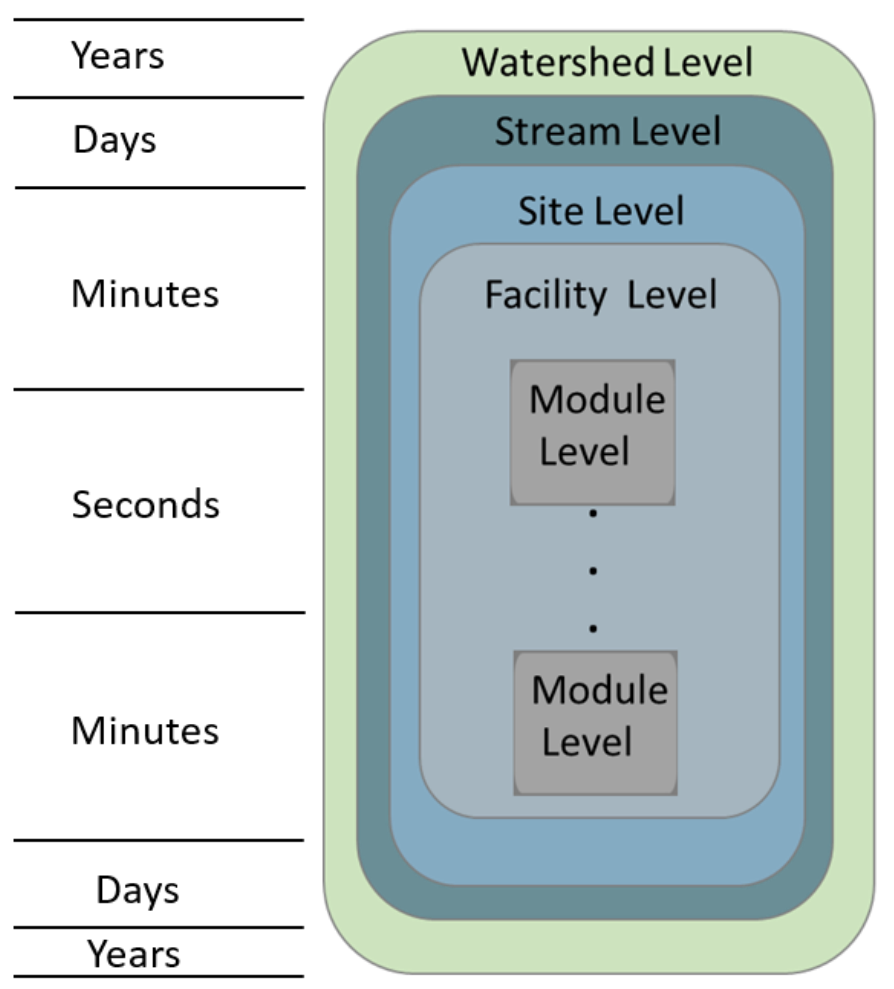

Figure 3. Schematic of the spatial and temporal scales of the domain hierarchy used for SMH.

\subsubsection{Spatial Scale Considerations}

Physical system processes and behaviors can occur over various spatial scales for SMH, ranging from millimeters to kilometers. "Spatial scale," as used herein, refers to a measure of length or size associated with a physical process in terms of the space it occupies and within which it behaves, and the extent over which the process environment has some meaningful or contributory effect. At each scale, process dimensionality, with respect to consideration of the relative changes in and significance of process behaviors over each of the three dimensions, is extremely important for the selection and application of a model. For example, the use of a 3D model to obtain surface runoff flow hydrographs is not needed given that this can be obtained with a simplified 2D approach for overland flow and a 1D approach for longitudinal flow in streams and rivers.

In the reference system, processes behave in a continuous manner throughout its environment, unimpeded by discrete divisions of scales and boundaries imposed on a model. In a model, handling how processes behave at the spatial extents of the model domain is accomplished via the specification of boundary conditions. Well-defined boundary conditions should allow processes to behave much as they do in the reference system and should limit or control any errors that are uncharacteristic of the behavior reference system.

For the SMH domain hierarchy defined in Figure 3, the watershed and stream levels serve as the sections of the domain where broader processes and information inform the more refined processes and information at the facility and module level. The facility level serves as a representation of the collection of modules holistically. The site level is the transition between the natural, undisturbed stream domain and the engineered development of SMH in the undisturbed stream. It also serves as the most appropriate and feasible location for model refinement and changes in dimensionality. 
The watershed level is where many of the processes and much of the information, such as rainfall to runoff flow, sediment, and other water quality source and transport mechanisms are important. Here, processes occur over large spatial scales. In contrast, processes occurring at the module level — such as turbulence, fish response to changes in flow, and turbine generation-occur over much smaller spatial scales but possess higher spatial variability.

\subsubsection{Temporal Scale Considerations}

Physical system processes and behaviors can occur over various temporal scales for SMH, ranging from seconds to years. "Temporal scale" herein refers to a measure of time associated with a process, in terms of the range over which it occurs, changes, and the extent over which the process environment has some meaningful or contributory effect. Processes that exhibit a significant change with respect to time are termed "unsteady," and those with no significant changes over time are referred to as "steady." Proper selection and application of a model with respect to the steadiness or unsteadiness of a process is very important. For example, the use of a steady turbine-flow model formulation to capture blade vibration is not appropriate, given that shedding of coherent flow structures in the wake flow of a turbine blade is a process for which the changes over time are significant enough to cause blade vibration. It requires an unsteady formulation.

Real time step specification is the increment over which a model formulation is advanced in time to obtain a single instance or a "snapshot" of the process condition, based on governing equations for behavior. It should be defined at a small enough time step to capture and satisfactorily resolve the relevant and desired changes in the modeled process. Pseudo-time steps are iterations used in the numerical solution process for arriving at a converged solution for an instance of a real-time step. Both time step types may affect the model stability or the ability of the model to appropriately and correctly obtain a numerical solution for approximate process formulations. The number of real time steps defines the length of real time being modeled.

Much as boundary conditions are defined for the spatial extent of a model, initial conditions are defined as starting solutions for a model run. These are generally specified based either on observed information or on assumptions that are based on familiarity with the system.

With respect to the SMH domain hierarchy defined in Figure 3, watershed- and stream-level processes are typically modeled over longer time scales than facility- and module-level processes.

\subsubsection{Scale Impact on Model Fidelity}

"Model fidelity" refers to the degree to which the model produces the same outcomes as the tangible reference system being modeled (Bailey and Kemple 1992) or to the accuracy of a model (DoDD 1995). The fidelity depends on the accuracy with which the underlying processes and data were formulated, the spatial and temporal resolution specification of the model and data, and the adequacy of calibration and validation.

It is important to assess model fidelity with respect to the performance expectations according to which it is structured and implemented. That is, if a model is defined to capture only larger-scale changes in a process, its fidelity for that application is not compromised because it does not resolve finer-scale processes it is not designed to capture. Therefore, it is important to understand and define what level of accuracy is expected from the reference system so that the model can be properly developed for that level.

The capability to capture varying levels of processes and behaviors depends on the accuracy, or correctness, of the theoretical and empirical structures governing them. The response of a system can be defined as a prescribed or observed dependence of some variable in the system. The dependence can be 
first-order (i.e., directly proportional); or it can be of a higher order (i.e., nonlinear, as is the case with second-order and higher relationships).

The degree to which a model performs accurately also depends on its resolution. Decomposing continuous process behaviors into discrete representations in both space and time requires an appropriately defined resolution — or spatial and temporal discretization, or divisions of space and timeat which the model formulation is applied. Effective considerations for spatial scales and dimensionality in model implementation dictate the domain size and resolution of the model and can significantly affect the design and run times for models and simulations.

Effective considerations for the resolution of temporal scales and time steps in model implementation can significantly affect the design and run times for models and simulation and experiments.

Depending on the level of accuracy required at each of the levels defined in the SMH hierarchy in Figure 3 , different models with varying degrees of fidelity and dimensionality may be required. Also, depending on the need for and use of a model or simulation to address an SMH issue, it may be necessary to use different models at different levels - or a series of models or nested models spanning several different levels. For example, determining the effect of flow variability on the reliability of a foundation design in preventing scour may require a different model at various levels. First, a 1D hydrologic model at the watershed level may be used to predict runoff magnitudes and timing for local tributary streams. A 1D open-channel hydraulic routing model at the stream level may be used to predict river flow magnitude and timing. Modeling of flow using a 1D model may transition to using a computational fluid dynamics (CFD) model with refined dimensionality, such as a 2D or even 3D model with increased spatial resolution; so that flow patterns can be resolved as the flow approaches the facility level. A 3D CFD model with increased spatial resolution will be required at the facility level to properly predict flow structures and shear stresses responsible for causing scour 



\section{SMH SIMULATION USE CASES}

In Witt et al. (2017), various objectives and requirements are identified for SMH generation, passage, and foundation modules and help form an EDES for SMH technology designs. In conjunction with those designs, this report serves to identify the simulation and modeling capabilities needed to predict whether proposed designs meet the desired objectives and requirements. At the heart of both the EDES and this simulation and modeling capability plan are concerns and priorities gleaned from stakeholder perspectives on small hydropower development. After formulating the SMH concept through the development of a Multi-Year Research Plan (Smith et al. 2017) and the EDES (Witt et al. 2017), ORNL has begun a stakeholder engagement process in which various hydropower technology developers, suppliers, and project developers have provided feedback on selected discussion questions related to SMH. Although the discussions have mostly focused on design-driven opportunities, challenges and concerns, important simulation and modeling needs were identified that reinforce the EDES objectives and constraints.

The SMH concept explores a new paradigm of small hydropower development that addresses functionality explicitly using a modular design approach and proffers cost reductions through standardization. The placement of SMH modules in a stream imparts various effects that are informed by and impact the natural stream environment. These effects are generally understood by hydropower stakeholders and the science community, although traditional small hydropower designs often do not conduct holistic assessments of the relevant active stream functions.

At a fundamental level, each stakeholder seeking to apply a model faces design decisions that may result in trade-offs affecting (1) safety, (2) performance, (3) reliability, and/or (4) cost. To simulate these metrics for a desired end goal, a simulation use case is identified:

Simulation use case: a scenario in which the application of a model or series of models through simulation can inform decision-making.

For SMH technologies, these simulation use cases may be used to evaluate, predict, or optimize the safety, performance, reliability, and/or cost of the SMH facility, individual SMH modules, or a combination of modules. A graphical representation of a simulation use case structure is provided in Figure 4.

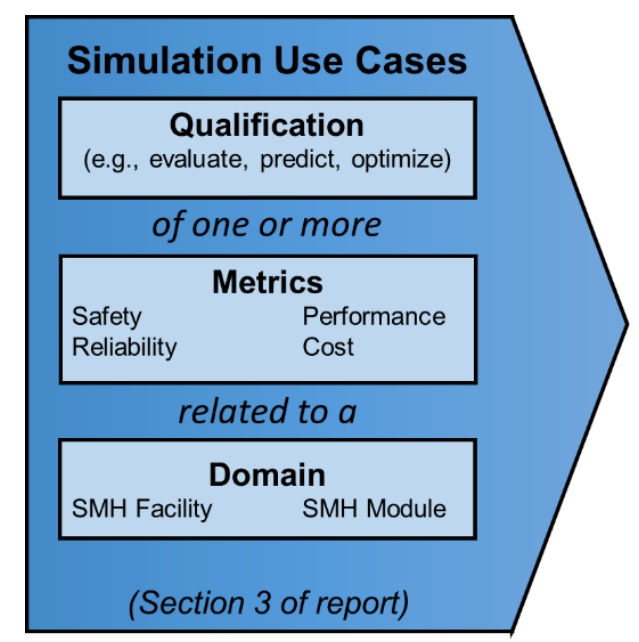

Figure 4. Simulation use case structure. 
Section 3.1 of this report introduces a series of simulation use cases that are developed based on stakeholder concerns and priorities and the EDES objectives and constraints. Use cases are organized for facility-level application and module-level application (see Section 2.3) and are not intended to be comprehensive; instead, the use cases presented herein reflect the most important scenarios currently envisioned for which RD\&D efforts and technology acceleration may yield the greatest impact.

Since SMH-related simulations are primarily intended to inform and refine the facility/module design and layout, simulation use cases are identified herein at the facility- and module-levels. Conditions and processes that occur upstream and downstream of a facility are integral to facility-level simulations. Module-level use cases are further categorized into the six functional modules identified in the EDES (Witt et al. 2017). Since current EDES research efforts have not yet developed specifications for additional modules (e.g., interconnection module and monitoring and control module), use cases related to electrical interconnection, monitoring, and controls are not explicitly identified in this report.

Throughout Section 3, example simulation use cases are identified for the SMH facility level and each of the SMH module levels: generation, fish passage, sediment passage, recreation passage, water passage, and foundation modules. ${ }^{6}$ At a high level, each simulation use case requires modeling one or more processes, and the tables presented in Section 3 identify the categories of processes that may need to be modeled to fully simulate each use case. These processes are separated into eight categories as follows:

- Hydrologic processes: Involved with the transport and properties of water throughout the water cycle, including both water quantity and quality characteristics.

- Hydraulic processes: Involved with the effects of moving water, including the transfer of energy and flow effects in pipes, open channels, or other water conveyances.

- Geomorphologic processes: Involved with the formation, alteration, and configuration of landforms, including bathymetry and sediment, and their relationships with underlying structures (American Heritage 2005).

- Ecologic processes: Involved with the functions of a stream and the behavior of, transformation of, and interaction between living organisms and the stream environment.

- Structural processes: Involved with the resistance and response of man-made structures to applied and loading forces.

- Geotechnical processes: Involved with the behavior of subsurface rock and soil properties, including response to physical and chemical forces.

- Electromechanical processes: Involved with the conversion of mechanical energy to electrical energy or vice versa.

- Economic processes: Involved with the production and sale of goods and services (NASA 1996).

Additional information on the SMH-related modeling capabilities needed to model these processes is provided in Section 4.

\subsection{FACILITY-LEVEL USE CASES}

Use cases for the SMH facility level are contained in Table 1.These are generally associated with processes occurring at locations upstream and/or downstream of a facility as well as at the facility itself. The processes may be affected by the presence of the facility as a whole, irrespective of individual module identities. For each use case, a description is provided, along with the respective processes involved with the modeling of a particular use case.

\footnotetext{
${ }^{6}$ For more information on SMH modules, see Witt et al. (2017) and Smith et al. (2017).
} 
Table 1. Example SMH facility-level simulation use cases

\begin{tabular}{|c|c|c|c|c|c|c|c|c|c|}
\hline \multirow[b]{2}{*}{ Use case ID } & \multirow[b]{2}{*}{ Use case description } & \multicolumn{8}{|c|}{$\begin{array}{c}\text { Process categories involved in use case } \\
\text { modeling }\end{array}$} \\
\hline & & 尊 & 弟 & $\begin{array}{l}0 \\
\frac{0}{0} \\
\frac{0}{0} \\
\frac{\partial}{2} \\
0 \\
0 \\
0 \\
0 \\
0\end{array}$ & $\frac{0}{80}$ & है: & 范 & 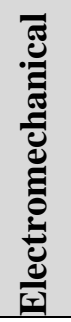 & : \\
\hline FAC-1 & $\begin{array}{l}\text { Optimize module design, facility } \\
\text { layout, and module flow control } \\
\text { configurations to maximize energy } \\
\text { generation }\end{array}$ & & $\mathrm{X}$ & & & $\mathrm{X}$ & & $\mathrm{X}$ & \\
\hline FAC-2 & $\begin{array}{l}\text { Predict water distribution and flow } \\
\text { characteristics upstream and } \\
\text { downstream of a facility to ensure } \\
\text { public safety, reliable facility } \\
\text { operation, stream function, ecological } \\
\text { habitat, and stream aesthetics }\end{array}$ & $\mathrm{X}$ & $\mathrm{X}$ & $\mathrm{X}$ & $\mathrm{X}$ & $\mathrm{X}$ & $\mathrm{X}$ & $\mathrm{X}$ & \\
\hline FAC-3 & $\begin{array}{l}\text { Predict water quality characteristics } \\
\text { upstream and downstream of a facility } \\
\text { to ensure public safety, reliable facility } \\
\text { operation, stream function, ecological } \\
\text { habitat, and stream aesthetics }\end{array}$ & $\mathrm{X}$ & $\mathrm{X}$ & $X$ & $\mathrm{X}$ & $\mathrm{X}$ & $\mathrm{X}$ & $\mathrm{X}$ & \\
\hline FAC-4 & $\begin{array}{l}\text { Predict fish movement upstream or } \\
\text { downstream of a facility to ensure } \\
\text { acceptable fish passage }\end{array}$ & & $\mathrm{X}$ & & $\mathrm{X}$ & & & & \\
\hline FAC-5 & $\begin{array}{l}\text { Predict in-stream sediment movement } \\
\text { and distribution upstream, downstream, } \\
\text { and adjacent to a facility to ensure } \\
\text { acceptable sediment passage }\end{array}$ & $\mathrm{X}$ & $\mathrm{X}$ & $\mathrm{X}$ & & & & & \\
\hline FAC-6 & $\begin{array}{l}\text { Predict small recreational craft } \\
\text { movement upstream or downstream of } \\
\text { a facility to ensure acceptable passage }\end{array}$ & & $\mathrm{X}$ & & $\mathrm{X}$ & & & & \\
\hline FAC-7 & $\begin{array}{l}\text { Predict erosion and scour of module } \\
\text { foundations to ensure structural } \\
\text { stability }\end{array}$ & & $\mathrm{X}$ & $\mathrm{X}$ & & $\mathrm{X}$ & $\mathrm{X}$ & & \\
\hline FAC-8 & $\begin{array}{l}\text { Predict intermodule load interactions to } \\
\text { ensure structural stability }\end{array}$ & & $\mathrm{X}$ & $\mathrm{X}$ & & $\mathrm{X}$ & $\mathrm{X}$ & & \\
\hline FAC-9 & $\begin{array}{l}\text { Predict the initial capital costs of } \\
\text { developing an SMH facility }\end{array}$ & & & & & $\mathrm{X}$ & $\mathrm{X}$ & $\mathrm{X}$ & $\mathrm{X}$ \\
\hline FAC-10 & $\begin{array}{l}\text { Predict the long-term feasibility and } \\
\text { trade-offs of developing an SMH } \\
\text { facility }\end{array}$ & & & & & $\mathrm{X}$ & $\mathrm{X}$ & $\mathrm{X}$ & $\mathrm{X}$ \\
\hline
\end{tabular}

\subsection{MODULE-LEVEL USE CASES}

Use cases for the module level are contained in Table 2 through Table 7 in Sections 3.2.1 through 3.2.6, respectively. They are associated with processes occurring at the module level and may involve some processes occurring at a sub-module level, such as those involving machinery and equipment. For each 
use case, a description is provided, along with the respective processes involved with the modeling of a particular use case.

\subsubsection{Generation Module Simulation Use Cases}

Use cases for the generation module are presented in Table 2. These pertain in general to the generation of hydroelectric power from flowing water under pressure. The main processes of interest are the hydraulic processes occurring in conjunction with the hydropower turbine system and the electromechanical processes occurring in conjunction with the generation of electricity. Aspects of structural processes are associated with the design and performance of the turbine blades with respect to material, strength, and dynamic processes associated with spinning machinery. The economics are used to evaluate trade-offs and benefits.

Table 2. Example SMH generation module simulation use cases

\begin{tabular}{|c|c|c|c|c|c|c|c|c|c|}
\hline \multirow[b]{2}{*}{ Use case ID } & \multirow[b]{2}{*}{ Use case description } & \multicolumn{8}{|c|}{$\begin{array}{c}\text { Process categories involved in use case } \\
\text { modeling }\end{array}$} \\
\hline & & 范 & 弟 & 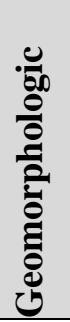 & $\frac{0}{80}$ & 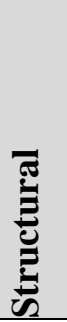 & ฮ્ટ & 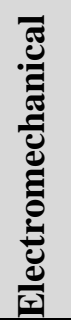 & 薃 \\
\hline GEN-1 & $\begin{array}{l}\text { Predict the hydraulic performance of } \\
\text { flow regimes that result from partial } \\
\text { impoundment of a river for generation } \\
\text { modules that generate hydroelectric } \\
\text { power from flowing water under } \\
\text { pressure }\end{array}$ & & $\mathrm{X}$ & & & & & $\mathrm{X}$ & \\
\hline GEN-2 & $\begin{array}{l}\text { Optimize generation module turbine } \\
\text { hydraulic efficiency and manufacturing } \\
\text { cost trade-offs with respect to turbine } \\
\text { blade material and design }\end{array}$ & & $\mathrm{X}$ & & & $\mathrm{X}$ & & $\mathrm{X}$ & $\mathrm{X}$ \\
\hline GEN-3 & $\begin{array}{l}\text { Optimize the physical safety and } \\
\text { performance characteristics of a } \\
\text { generation module that contains a } \\
\text { lightweight composite turbine runner }\end{array}$ & & $X$ & & & $X$ & & $X$ & $X$ \\
\hline GEN-4 & $\begin{array}{l}\text { Evaluate trade-offs between design, } \\
\text { installed cost, and hydraulic } \\
\text { performance for standardized } \\
\text { multigeneration module arrays }\end{array}$ & & $X$ & & & & & $\mathrm{X}$ & $\mathrm{X}$ \\
\hline GEN-5 & $\begin{array}{l}\text { Predict electrical and physical safety of } \\
\text { fully submerged generation module } \\
\text { under flood conditions }\end{array}$ & & $X$ & & & $X$ & & $\mathrm{X}$ & \\
\hline GEN-6 & $\begin{array}{l}\text { Evaluate trade-offs among design, } \\
\text { installed cost, and performance for } \\
\text { generation modules with permanent } \\
\text { magnet generators designed from non-- } \\
\text { rare earth materials }\end{array}$ & & & & & & & $X$ & $X$ \\
\hline GEN-7 & $\begin{array}{l}\text { Evaluate trade-offs between cost and } \\
\text { performance for generation modules } \\
\text { that achieve flow control with variable- } \\
\text { speed power electronics }\end{array}$ & & $X$ & & & & & $X$ & $X$ \\
\hline
\end{tabular}


Table 2. Example SMH generation module simulation use cases (continued)

\begin{tabular}{|c|c|c|c|c|c|c|c|c|c|}
\hline \multirow[b]{2}{*}{ Use case ID } & \multirow[b]{2}{*}{ Use case description } & \multicolumn{8}{|c|}{$\begin{array}{c}\text { Process categories involved in use case } \\
\text { modeling }\end{array}$} \\
\hline & & 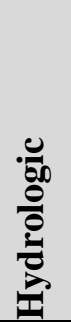 & 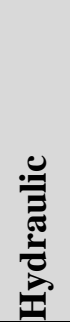 & 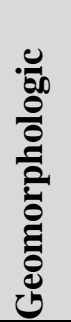 & 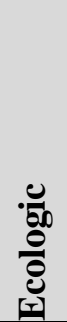 & 预 & 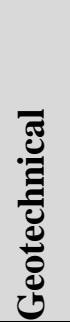 & 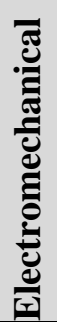 & 元 \\
\hline GEN-8 & $\begin{array}{l}\text { Evaluate trade-offs among turbine } \\
\text { blade shape, speed, and performance } \\
\text { for maximizing fish survival rates }\end{array}$ & & $\mathrm{X}$ & & $\mathrm{X}$ & $\mathrm{X}$ & & $\mathrm{X}$ & \\
\hline GEN-9 & $\begin{array}{l}\text { Optimize design and performance } \\
\text { trade-offs for aerating generation } \\
\text { modules }\end{array}$ & & $\mathrm{X}$ & & $\mathrm{X}$ & $\mathrm{X}$ & & $\mathrm{X}$ & \\
\hline GEN-10 & $\begin{array}{l}\text { Predict the performance of generation } \\
\text { modules under flow regimes that result } \\
\text { from partial impoundment of a river }\end{array}$ & & $\mathrm{X}$ & & & & & $\mathrm{X}$ & \\
\hline
\end{tabular}

\subsubsection{Fish Passage Module Simulation Use Cases}

Use cases for the fish passage module are presented in Table 3. These pertain in general to the unimpeded and safe passage (upstream and downstream) of fish through an SMH facility. The main processes of interest here are the hydraulic processes with respect to flow conditions in the context of ecologic aspects of fish behavior, mechanics, and so on. Aspects of structural processes are associated with the design and performance of structures like screens, turbine blades, and other pertinent physical structures affected by or responsible for attaining particular flow conditions associated with fish attraction and passage.

Table 3. Example SMH fish passage module simulation use cases

\begin{tabular}{|c|c|c|c|c|c|c|c|c|c|}
\hline \multirow[b]{2}{*}{ Use case ID } & \multirow[b]{2}{*}{ Use case description } & \multicolumn{8}{|c|}{$\begin{array}{c}\text { Process categories involved in use case } \\
\text { modeling }\end{array}$} \\
\hline & & 总 & 弟 & 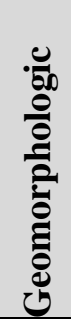 & $\frac{0}{80}$ & 莺 & 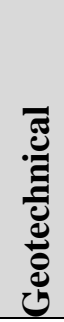 & 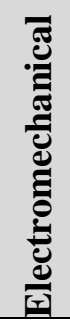 & : \\
\hline FISH-1 & $\begin{array}{l}\text { Predict pertinent fish passage module } \\
\text { flow conditions based on design } \\
\text { alternatives that ensure unimpeded and } \\
\text { safe fish passage upstream and } \\
\text { downstream of a SMH facility }\end{array}$ & & $\mathrm{X}$ & & $\mathrm{X}$ & $\mathrm{X}$ & & & \\
\hline FISH-2 & $\begin{array}{l}\text { Predict hydraulic performance for fish } \\
\text { and debris exclusion screens }\end{array}$ & & X & & $\mathrm{X}$ & $\mathrm{X}$ & & & \\
\hline FISH-3 & $\begin{array}{l}\text { Predict fish attraction for upstream } \\
\text { passage modules based on tailwater } \\
\text { hydraulics }\end{array}$ & & $\mathrm{X}$ & & $\mathrm{X}$ & $\mathrm{X}$ & & & \\
\hline
\end{tabular}


Table 3. Example SMH fish passage module simulation use cases (continued)

\begin{tabular}{|c|c|c|c|c|c|c|c|c|c|}
\hline \multirow[b]{2}{*}{ Use case ID } & \multirow[b]{2}{*}{ Use case description } & \multicolumn{8}{|c|}{$\begin{array}{c}\text { Process categories involved in use case } \\
\text { modeling }\end{array}$} \\
\hline & & 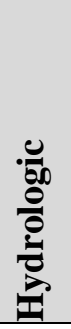 & 弟 & 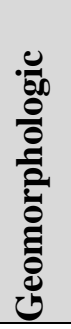 & 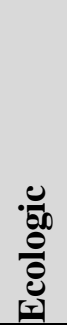 & 氖 & 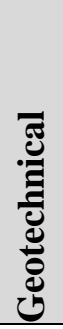 & 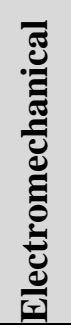 & 导 \\
\hline FISH-4 & $\begin{array}{l}\text { Predict fish attraction for downstream } \\
\text { passage modules based on headwater } \\
\text { hydraulics }\end{array}$ & & $\mathrm{X}$ & & $\mathrm{X}$ & $\mathrm{X}$ & & & \\
\hline FISH-5 & $\begin{array}{l}\text { Predict turbine fish passage } \\
\text { characteristics based on turbine } \\
\text { operational characteristics }\end{array}$ & & $\mathrm{X}$ & & $\mathrm{X}$ & $\mathrm{X}$ & & & \\
\hline FISH-6 & $\begin{array}{l}\text { Predict timing of fish arrival } \\
\text { frequencies and temporal dynamics for } \\
\text { upstream and downstream passage } \\
\text { modules }\end{array}$ & & $\mathrm{X}$ & & $\mathrm{X}$ & & & & \\
\hline
\end{tabular}

\subsubsection{Sediment Passage Module Simulation Use Cases}

Use cases for the sediment passage module are presented in Table 4. These pertain in general to the transportation of incoming sediment through an SMH facility. The main processes of interest here are the hydraulic processes with respect to flow conditions for sediment transport and the geomorphological processes associated with aggradation and degradation of sediment. Ecologic processes involving water quality issues associated with sediment-laden water are of interest with respect to the economics and design tied to the performance of the passage module. Structural processes are associated with the design and performance of structures affected by or responsible for managing particular flow conditions associated with sediment passage.

Table 4. Example SMH sediment passage module simulation use cases

\begin{tabular}{|c|c|c|c|c|c|c|c|c|c|}
\hline \multirow[b]{2}{*}{ Use case ID } & \multirow[b]{2}{*}{ Use case description } & \multicolumn{8}{|c|}{$\begin{array}{c}\text { Process categories involved in use case } \\
\text { modeling }\end{array}$} \\
\hline & & 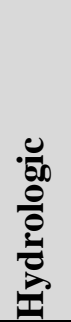 & 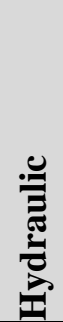 & 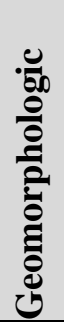 & $\begin{array}{l}\stackrel{0}{0} \\
\frac{0}{80} \\
\frac{0}{80}\end{array}$ & & 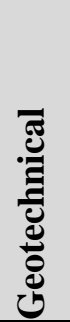 & 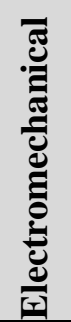 & 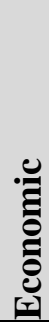 \\
\hline SED-1 & $\begin{array}{l}\text { Optimize upstream and downstream } \\
\text { sediment transport, deposition, and } \\
\text { accumulation to optimize sediment } \\
\text { passage module designs that allow the } \\
\text { transport of incoming sediment through } \\
\text { a SMH facility }\end{array}$ & & $\mathrm{X}$ & $\mathrm{X}$ & & $\mathrm{X}$ & & & \\
\hline
\end{tabular}


Table 4. Example SMH sediment passage module simulation use cases (continued)

\begin{tabular}{|c|c|c|c|c|c|c|c|c|c|}
\hline \multirow[b]{2}{*}{ Use case ID } & \multirow[b]{2}{*}{ Use case description } & \multicolumn{8}{|c|}{$\begin{array}{c}\text { Process categories involved in use case } \\
\text { modeling }\end{array}$} \\
\hline & & 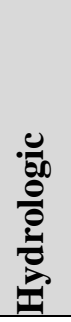 & 弟 & 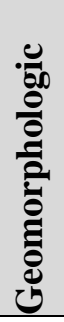 & $\underset{8}{8}$ & 氖 & 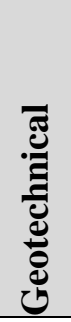 & 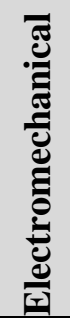 & 蒫 \\
\hline SED-2 & $\begin{array}{l}\text { Predict the performance of sediment } \\
\text { passage module designs while not } \\
\text { compromising the functions of other } \\
\text { modules }\end{array}$ & & $X$ & $X$ & & $X$ & & & \\
\hline SED-3 & $\begin{array}{l}\text { Evaluate trade-offs between cost and } \\
\text { performance of sediment module } \\
\text { installation }\end{array}$ & & $\mathrm{X}$ & $\mathrm{X}$ & $\mathrm{X}$ & $\mathrm{X}$ & & & $\mathrm{X}$ \\
\hline SED-4 & $\begin{array}{l}\text { Evaluate trade-offs between cost and } \\
\text { performance for sediment passage } \\
\text { modules manufactured with advanced } \\
\text { materials }\end{array}$ & & $\mathrm{X}$ & $\mathrm{X}$ & & $\mathrm{X}$ & & & $\mathrm{X}$ \\
\hline
\end{tabular}

\subsubsection{Recreation Passage Module Simulation Use Cases}

Use cases for the recreation passage module are presented in Table 5. These pertain in general to the passage of small recreational craft consistently and safely through an SMH facility. The main processes of interest here are the hydraulic processes with respect to flow conditions for supporting effective and safe recreational passage. Structural processes are associated with the design and performance of structures affected by or responsible for managing particular flow conditions associated with recreational passage. Economics are used in the determination of the trade-offs and benefits of the performance and design.

Table 5. Example SMH recreation passage module simulation use cases

\begin{tabular}{|c|c|c|c|c|c|c|c|c|c|}
\hline \multirow[b]{2}{*}{ Use case ID } & \multirow[b]{2}{*}{ Use case description } & \multicolumn{8}{|c|}{$\begin{array}{c}\text { Process categories involved in use case } \\
\text { modeling }\end{array}$} \\
\hline & & $\frac{.}{\frac{0}{00}}$ & 弟 & 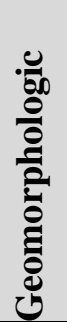 & $\frac{0}{30}$ & 离 & 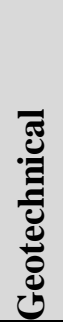 & 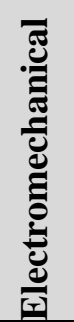 & : \\
\hline REC-1 & $\begin{array}{l}\text { Predict flow characteristics and safety } \\
\text { for recreation passage modules that } \\
\text { enable consistent and safe passage of } \\
\text { small recreational craft through a SMH } \\
\text { facility }\end{array}$ & & $\mathrm{X}$ & & $\mathrm{X}$ & & & & \\
\hline REC-2 & $\begin{array}{l}\text { Predict the need and cost for } \\
\text { recreational access based on predicted } \\
\text { recreational use }\end{array}$ & & $\mathrm{X}$ & & $\mathrm{X}$ & & & & $\mathrm{X}$ \\
\hline
\end{tabular}


Table 5. Example SMH recreation passage module simulation use cases (continued)

\begin{tabular}{|c|c|c|c|c|c|c|c|c|c|}
\hline \multirow[b]{2}{*}{ Use case ID } & \multirow[b]{2}{*}{ Use case description } & \multicolumn{8}{|c|}{$\begin{array}{c}\text { Process categories involved in use case } \\
\text { modeling }\end{array}$} \\
\hline & & 范 & 弟 & 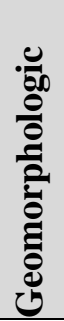 & $\frac{0}{80}$ & 苞 & 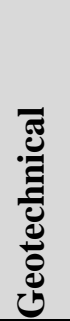 & 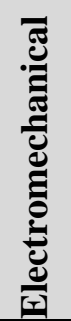 & 蒫 \\
\hline REC-3 & $\begin{array}{l}\text { Predict upstream hydraulics and } \\
\text { performance for exclusion devices that } \\
\text { prevent unsafe interactions between } \\
\text { recreational craft/people and modules }\end{array}$ & & $\mathrm{X}$ & & $\mathrm{X}$ & $\mathrm{X}$ & & & \\
\hline
\end{tabular}

\subsubsection{Water Passage Module Simulation Use Cases}

Use cases for the water passage module are presented in Table 6. These pertain in general to the conveyance of non-generating water through the SMH facility. The main processes of interest here are the hydraulic processes with respect to flow conditions for supporting effective water passage and control, if necessary. Ecologic processes are included to account for the effect that water passage hydraulics may have on the integrity of the environment. Structural processes are associated with the design and performance of structures affected by or responsible for managing particular flow conditions associated with water passage. Economics are used in the determination of the trade-offs and benefits of the performance and design.

Table 6. Example SMH water passage module simulation use cases

\begin{tabular}{|c|c|c|c|c|c|c|c|c|c|}
\hline \multirow[b]{2}{*}{ Use case ID } & \multirow[b]{2}{*}{ Use case description } & \multicolumn{8}{|c|}{$\begin{array}{c}\text { Process categories involved in use case } \\
\text { modeling }\end{array}$} \\
\hline & & 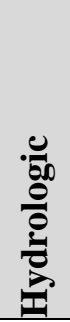 & 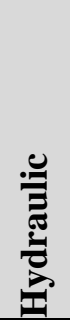 & 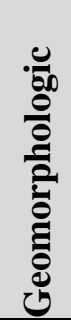 & $\frac{0}{8}$ & 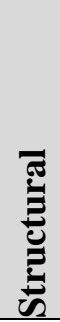 & 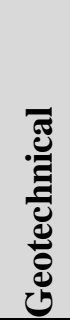 & 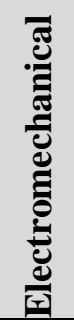 & $\stackrel{\circlearrowright}{•}$ \\
\hline WAT-1 & $\begin{array}{l}\text { Predict feasible water passage module } \\
\text { sizing based on optimal allocation of } \\
\text { flow between generation and other } \\
\text { (environmental) passage modules }\end{array}$ & & $\mathrm{X}$ & & & $\mathrm{X}$ & & & \\
\hline WAT-2 & $\begin{array}{l}\text { Evaluate dynamic head control } \\
\text { capabilities for an advanced water } \\
\text { passage module at an SMH facility }\end{array}$ & & $\mathrm{X}$ & & & $\mathrm{X}$ & & & \\
\hline WAT-3 & $\begin{array}{l}\text { Optimize cost and stability trade-offs } \\
\text { for additively manufactured (3D- } \\
\text { printed) water passage modules }\end{array}$ & & $X$ & & & $\mathrm{X}$ & $\mathrm{X}$ & & $\mathrm{X}$ \\
\hline WAT-4 & $\begin{array}{l}\text { Optimize stability of multiple water } \\
\text { passage modules assembled in parallel }\end{array}$ & & $\mathrm{X}$ & & & $X$ & $\mathrm{X}$ & & \\
\hline
\end{tabular}


Table 6. Example SMH water passage module simulation use cases (continued)

\begin{tabular}{|c|c|c|c|c|c|c|c|c|c|}
\hline \multirow[b]{2}{*}{ Use case ID } & \multirow[b]{2}{*}{ Use case description } & \multicolumn{8}{|c|}{$\begin{array}{c}\text { Process categories involved in use case } \\
\text { modeling }\end{array}$} \\
\hline & & 窇 & 弟 & 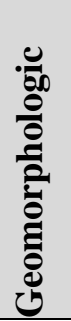 & $\frac{0}{80}$ & 苞 & 异: & 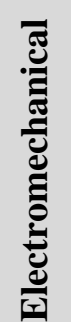 & : \\
\hline WAT-5 & $\begin{array}{l}\text { Optimize tailwater hydraulic } \\
\text { performance for generation and } \\
\text { upstream fish passage based on the size } \\
\text { and placement of water passage } \\
\text { modules }\end{array}$ & & $\mathrm{X}$ & & $\mathrm{X}$ & $\mathrm{X}$ & & & \\
\hline WAT-6 & $\begin{array}{l}\text { Predict water quality improvement } \\
\text { potential and aerating characteristics of } \\
\text { water passage module under various } \\
\text { flow regimes }\end{array}$ & & $\mathrm{X}$ & & $\mathrm{X}$ & $\mathrm{X}$ & & & \\
\hline
\end{tabular}

\subsubsection{Foundation Module Use Cases}

Use cases for the foundation module are presented in Table 7. These pertain in general to the performance of foundation modules functioning as structural components that anchor passage and generation modules to the streambed and banks (i.e., ensure placement of the facility within the site). The main processes of interest here are the hydraulic processes with respect to the determination of loading conditions on the facility and modules. The structural and geotechnical processes involve the performance and design of the module structure and its linkage with the ground with respect to the ability to resist loading conditions and prevent failure. Ecologic processes are included to account for the effect that foundation design may have on disruption to the environment. Economics are used in the determination of the trade-offs and benefits of the performance and design.

Table 7. Example SMH foundation module simulation use cases

\begin{tabular}{|c|c|c|c|c|c|c|c|c|c|}
\hline \multirow[b]{2}{*}{ Use case ID } & \multirow[b]{2}{*}{ Use case description } & \multicolumn{8}{|c|}{$\begin{array}{l}\text { Process categories involved in use case } \\
\text { modeling }\end{array}$} \\
\hline & & 参 & 兽 & 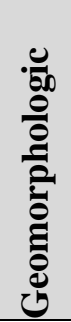 & $\frac{0}{8}$ & 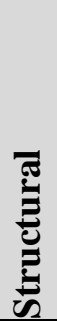 & 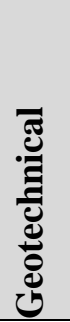 & 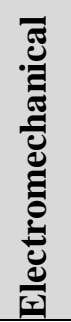 & 元 \\
\hline FOUND-1 & $\begin{array}{l}\text { Evaluate trade-offs among structural } \\
\text { design, cost, and performance for } \\
\text { foundation modules used to anchor } \\
\text { modules to the stream environment }\end{array}$ & & $\mathrm{X}$ & & & $\mathrm{X}$ & $\mathrm{X}$ & & $\mathrm{X}$ \\
\hline FOUND-2 & $\begin{array}{l}\text { Evaluate trade-offs among structural } \\
\text { design, cost, and performance for } \\
\text { foundation modules used to connect } \\
\text { multiple modules }\end{array}$ & & $\mathrm{X}$ & & & $\mathrm{X}$ & $\mathrm{X}$ & & $\mathrm{X}$ \\
\hline
\end{tabular}


Table 7. Example SMH foundation module simulation use cases (continued)

\begin{tabular}{|c|c|c|c|c|c|c|c|c|c|}
\hline \multirow[b]{2}{*}{ Use case ID } & \multirow[b]{2}{*}{ Use case description } & \multicolumn{8}{|c|}{$\begin{array}{c}\text { Process categories involved in use case } \\
\text { modeling }\end{array}$} \\
\hline & & 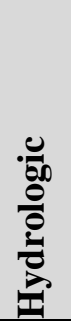 & 兽 & 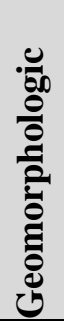 & $\frac{0}{80}$ & שֶ & 元 & 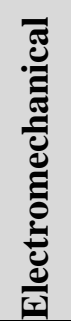 & : \\
\hline FOUND-3 & $\begin{array}{l}\text { Predict foundation module failure } \\
\text { modes to ensure public safety during } \\
\text { extreme events (e.g., floods and } \\
\text { earthquakes) and under normal } \\
\text { operation }\end{array}$ & & $\mathrm{X}$ & $\mathrm{X}$ & $\mathrm{X}$ & $\mathrm{X}$ & $\mathrm{X}$ & & \\
\hline FOUND-4 & $\begin{array}{l}\text { Predict the impacts of bed scour, } \\
\text { deposition, abrasion, and debris on the } \\
\text { structural performance and reliability } \\
\text { of foundation modules }\end{array}$ & & $\mathrm{X}$ & $\mathrm{X}$ & & $\mathrm{X}$ & & & \\
\hline FOUND-6 & $\begin{array}{l}\text { Predict the environmental impact of } \\
\text { foundation module designs on benthic } \\
\text { habitats and flow conditions }\end{array}$ & & $\mathrm{X}$ & $\mathrm{X}$ & $\mathrm{X}$ & $\mathrm{X}$ & & & \\
\hline FOUND-7 & $\begin{array}{l}\text { Evaluate design, cost, and performance } \\
\text { trade-offs between scalability and } \\
\text { foundation module design }\end{array}$ & & $\mathrm{X}$ & $X$ & & $\mathrm{X}$ & $\mathrm{X}$ & & $\mathrm{X}$ \\
\hline
\end{tabular}




\section{SMH MODELING NEEDS AND CAPABILITY}

The simulation use cases defined in Section 3 provide the framework needed to identify and categorize the modeling needs for SMH design and analysis. Section 4 presents the modeling needs and capabilities. The modeling needs are discussed with respect to the modeling structure and implementation needed to properly model the processes. Available modeling capabilities, software, and tools are also presented.

The identification of the processes specific to a use case, usually associated with a particular module, reveals common modeling needs. These common modeling needs define the capability required for modeling the processes. Modeling needs may be multifaceted and may influence multiple levels of an SMH system. These may encompass variability in spatial and temporal scales at any SMH hierarchical level (Figure 3). In addition, interactions among processes may occur that require specific modeling capabilities or coupling of two or more capabilities.

This section is organized by the eight processes identified in Section 3: hydrologic, hydraulic, geomorphologic, ecologic, structural, geotechnical, electromechanical, and economic. For each process, subcategories relevant to the understanding of the main processes are presented. These are followed by a discussion of the interaction and coupling of one or more of the eight processes presented. The modeling needs and capabilities are discussed in each section with the goal of identifying modeling gaps and challenges for SMH-related simulations.

\subsection{HYDROLOGIC PROCESSES}

Fundamental information for the various types of SMH modeling and analysis with respect to the hydrologic processes is the water quantity and the water quality.

\subsubsection{Water Quantity Modeling}

Streamflow time series data used to develop and calibrate flow models should ideally be measured at stream-reaches near targeted locations daily (or even subdaily) and should have over 30 years of data records to reasonably capture the interannual and interdecadal hydrologic variability (i.e., natural oscillation between wet and dry years; see Tootle and Piechota [2006] for further discussion). The streamflow time series can be used to derive a flow-duration curve to estimate a certain quantile of flow for capacity planning (e.g., $30 \%$ streamflow exceedance percentile), to evaluate the potential impacts of both flood and drought events, to serve as initial and boundary conditions for hydraulic simulations, or to inform biological and ecological evaluation.

Unfortunately, site-specific long-term, high-quality direct streamflow measurements are usually unavailable. Although there are more than 23,000 streamflow gauge stations in the US Geological Survey (USGS) National Water Information System, many of them have been discontinued or do not have continuous records. Considering the total number of stream-reaches across the nation (e.g., $\sim 3$ million National Hydrography Dataset flowlines), it is not surprising that most of the national stream-reaches have not been monitored. This is a critical issue for future SMH development, as many of the potential sites are in smaller tributaries and are likely ungauged. Therefore, for SMH development, a major focus of hydrologic simulation and analysis will be to synthesize reasonable and credible streamflow time series at multiple potential sites. The methods can be as simple as statistical analyses (e.g., interpolation and regression) using historic measurements from neighboring gauge stations and flow approximation using unit runoff, or as complicated as process-based rainfall-runoff modeling. The choice will be governed by the sufficiency of existing flow measurements, the stage of development (e.g., initial siting or final engineering design), and the desired accuracy. Other external issues, such as land use and land cover change (i.e., affecting impervious areas and direct runoff), changes in natural streamflow variability 
(caused by long-term climate change), and flow regulation from upstream dams, may further complicate the required efforts for hydrologic modeling and analysis.

When sufficient neighboring gauge records are available, statistical methods can be fairly useful in estimating site-specific conditions. In particular, with the advance of hydrogeography data sets in the recent decade (e.g., USGS National Hydrography Dataset), engineers can obtain detailed watershed characteristics such as slope and drainage area fairly easily. If the neighboring gauge stations are in the same watershed and have drainage areas similar to those of the targeted sites, an adjustment (e.g., rescaling or area-weighted average) based on watershed characteristics can usually provide satisfactory results. However, because of the data insufficiency described earlier, this is not always possible.

When gauge stations are insufficient or totally unavailable, a full hydrologic rainfall-runoff model will be needed. Commonly used models include variable infiltration capacity (VIC) ${ }^{7}$ models (Liang et al. 1994), the Hydrologic Engineering Center Hydrologic Modeling System (HEC-HMS ${ }^{8}$; Feldman 2000), the Sacramento Soil Moisture Accounting model (SAC-SMA; Peck 1976), and the Hydrological Simulation Program-Fortran (HSPF; Dinicola 1990). Compared with streamflow observations, these enable better daily or subdaily rainfall observations across the country. For instance, there are multiple publicly accessible precipitation data sets such as the Oregon State University PRISM (Daly et al. 2008) or the ORNL Daymet (Thornton et al. 1997) that can be used to drive hydrologic models. Other required hydrologic model parameters, such as soil characteristics, vegetation, and land use types, can also be obtained from several publicly available data sources (see Oubeidillah et al. 2014 for an example of conterminous US hydrologic simulation). With the support of modern high-performance computing, these hydrologic models can be set up to a required accuracy in a more efficient manner and can potentially provide general streamflow estimates for all ungauged locations. The existing, precalibrated conterminous US hydrologic models (e.g., conterminous US variable infiltration capacity [CONUS-VIC] by Naz et al. 2016 and Oubeidillah et al. 2014) can be used as foundations to reduce the required efforts.

Regardless of the modeling and analysis route selected, a flexible and user-friendly data service system is needed. For a targeted watershed streamflow simulation, data assimilation and validation can be performed in advance. The high-resolution historic streamflow time-series (as well as the flow-duration curves and other flow percentiles) can then be precalculated for each stream-reach for further analysis. These calculations will help SMH developers compare water availability across multiple sites more efficiently. The improved flow estimates can also increase the accuracy of other SMH components (e.g., hydraulics, biological, and ecological processes) in an integrated manner.

\subsubsection{Water Quality Modeling}

\section{Sediment Quantity Modeling}

Sediment delivery from the watershed to the stream involves a variety of transport processes that occur over a wide range of timescales. The rate of eroded sediment transport to streams, the sediment yield, is the primary focus of this section. Yield occurs as a result of interrill (rainfall-driven) erosion, rill/gully (runoff-driven) erosion, and runoff processes (Akosy and Kavvas 2005). The former erodes sediment and moves it to the latter two processes, by which primary overland transport and continued erosion occurs (Foster and Meyer 1975; Bennett 1974). Rainfall-detached sediment moving overland via these processes typically moves at capacity; so when the flow subsides (i.e., during the falling limb of the hydrograph), the sediment quickly deposits. This, combined with deposition in small pools, decreases with slope gradient or vegetation interception and reduces the amount of eroded sediment that transports to a stream (Morris and Fan 1998). As a result, most of the total eroded sediment, or sediment loss, is not translated

\footnotetext{
${ }^{7}$ http://www.hydro.washington.edu/Lettenmaier/Models/VIC/index-old.shtml

${ }^{8} \mathrm{http} / / / \mathrm{www} \cdot h$ ec.usace.army.mil/software/hec-hms/
} 
into the sediment yield. The latter is generally estimated by multiplying the former by an empirically derived delivery ratio.

The watershed variables that affect the erosion of sediment and transport to a streamway include soil type, soil erodibility, moisture content, slope, and slope changes, as well as vegetation. The hydrologic variables include storm length, rainfall volume, and rainfall intensity (Bennett 1974). The watershed variables determine the effort required to detach a sediment particle and transport it within the watershed. If the particle is intercepted en route to a stream, the hydrologic variables control the driving forces applied to move that sediment particle. Modeling of the hydrological sediment processes involves mimicking these variables and their interaction mathematically over different spatial and temporal scales. Once sediment reaches a stream, hydraulic modeling (Section 4.2) is used to describe sediment transport. Hydrologic routing determines the movement of sediment from the watershed to a river, and hydraulic routing determines the movement of sediment and water in a stream with given inputs. Sediment is delivered from upland areas and combines with stream bank and bed eroded material in small-order streams, via which it is transported to larger-order streams that have flows that make run-of-the-river hydropower feasible (Papanicolaou and Abban 2016).

Watershed-scale models can be generally categorized as empirical, mechanistic, and conceptual and may model hydrologic routing, stream routing, or both. Empirical models are developed using data from specific watersheds and are most accurate for similar watersheds with unchanging land uses. Conceptual models divide the watershed into a series of internal storages and connecting flow paths. Physical models are the most detailed and computationally intensive, solving applicable governing equations (i.e., mass and momentum) across the watershed topography (Merritt et al. 2003).

Models may be further categorized as lumped or distributed. The former apply homogeneous characteristics to the entire watershed, and the latter divide the watershed into areas of different characteristics. An appropriate model must be chosen to account for the physical properties of the watershed, desired outputs, and computational capacity. For a comprehensive list of available watershed scale models by type, use, and assumptions, the reader is referred to the work of Aksoy and Kavvas (2005) and Merritt et al. (2003).

\section{Dissolved Oxygen Modeling}

Dissolved oxygen (DO) is integral to the health of the stream ecosystem. Impoundments, such as those caused by hydroelectric plants, can either reduce or increase DO, depending on the location and stream obstruction. Nutrients in slow-moving, upstream waters can cause deoxygenation through microbial metabolism. Increased turbulence of water flowing through turbines and outlet works may increase DO and the presence of bubbles. The height of the water column (hydrostatic pressure) and temperature also affect the amount of stream DO based on solubility principles. DO can vary over diurnal to seasonal timescales and with changes in SMH operation (Loperfido et al. 2010; Morris and Fan 1998).

DO fluctuations can occur spatially from the module to the stream scale and from hourly to seasonal timescales. These are driven by a myriad of different processes. Module and site increases in DO occur as a result of increased turbulence at outfalls and in generation module turbines. Likewise, diurnal and seasonal temperature changes can affect DO concentrations at the stream scale as a result of the temperature effect on oxygen saturation. Seasonal changes in DO can also occur in stagnant upstream reaches, which are deep enough to stratify. This can occur at the site scale and can encompass the spatial extent of the backwater, depending on nutrient loading and temperature profile. The release of cold, anoxic, upstream water into warm, oxygenated, downstream reaches may have negative consequences for downstream biota not accustomed to such conditions (Cushman 1985). 
There are several different types of models that can be used to model DO. These include 1D limnologic models such as the General Lake Model (GLM) that can model water quality in general (e.g., temperature, DO, nutrients). Streamflow models up to 3D may be used to model oxygen transfer as turbulent flows pass through outlet structures (Gulliver et al. 1998). Higher-dimension models are often limited in their use, given computational constraints and domain size.

\section{Water Temperature Modeling}

Temperature is a water quality attribute linked with DO and is also essential to ecosystem health. Water in impoundments that is sufficiently deep may stratify during summer months. That is, the top water layer may be warmed (epilimnion) and thus become less dense than the colder water below (hypolimnion), which causes the two not to mix (Morris and Fan 1998). Stratification is one factor driving deoxygenation in deeper waters during summer months. Depending on the outlet location and season, water that is either warmer or colder, relative to the more natural conditions preceding impoundment, may be released downstream of the hydroelectric plant. Temperature fluctuations severely affect benthic organisms and fish, which are all cold-blooded, so natural (i.e., pre-impoundment) temperature profiles must be maintained.

Temperature changes occur on spatial scales that extend from the facility to the site scale, and depend on the impoundment geometry, depth, and planform spatial extent. That is, impoundment surface area, depth, and extent upstream all affect stratification effects. The generation module or water passage module intakes, with regard to typical stratification depths, also determine the temperature of water transferred downstream.

Temporal changes occur from diurnal to seasonal time scales. This is an important issue, especially considering the transmission of impounded water downstream and the effect it has on benthic species. Cold, anoxic water transmitted from the hypolimnion during summer months to a warm downstream reach may have serious impacts on native fish species (Cushman 1985). That is, upstream effects are manifested by temperature stratification, whereas downstream effects are manifested by pulses of unnaturally warm or cold water within the stream reach.

Stream models such as Hydrologic Engineering Center-River Analysis System (HEC-RAS ${ }^{9}$ ) and the Delft ${ }^{10}$ packages can model temperature. Given the possible spatial extent of temperature changes in the upstream and downstream directions, 1D models may be the most appropriate for modeling at the site scale and greater.

\subsection{HYDRAULIC PROCESSES}

Hydraulic processes are those behaviors concerned with the movement of fluids through a pipe or open channel, typically for an engineering application. The theoretical basis for hydraulics is fluid mechanics, which entails both static and dynamic considerations for the forces exerted as a result of fluids at rest and fluids in motion, respectively. The applications for modeling fluid mechanics include the use of analytical and numerical formulations. These approaches can range from the use of simplifying assumptions of flow dimensionality, which yield simple models, to the treatment of fluid as a continuum with comprehensive treatments of spatial and temporal variability, which requires 3D numerical models.

The behavior of fluid flow is governed by the conservation of mass, momentum, and energy, collectively formulated as the Navier-Stokes equations (NSE) as a series of unsteady, nonlinear, second-order, partial differential equations. Owing to the complexity of this formulation, the equations have no exact

\footnotetext{
${ }^{9}$ http://www.hec.usace.army.mil/software/hec-ras/

${ }^{10} \mathrm{http}: / / w w w . d e l f t s o f t w a r e . c o m . a u /$
} 
mathematical solution except in a few cases (Munsun et al. 1994). These cases pertain to simplifications of complex terms of the NSE for flows - for example, for steady laminar flow between parallel plates or in circular tubes - which lead to exact analytical solutions. For most cases, an exact analytical solution does not exist; and so approximate solutions to the differential NSE are obtained using numerical techniques. In such cases, CFD modeling is used, which requires the use of a computer to implement numerical methods to obtain a solution. CFD is generally used to resolve very fine flow details, which requires treating the fluid domain as a continuum of discrete elements at which solutions for the movement of fluid are obtained.

NSE simplifications based on assumptions of reduced dimensionality and reduced flow complexity generate formulations that can either be solved analytically with an exact solution, or approximated with simplified derivations that require fewer computational resources than fully $3 \mathrm{D}$ CFD applications. These simplifications generally involve assumptions pertaining to relatively smaller flow gradients and convective mechanisms along particular directions compared with a primarily dominant direction. These simplifications result in 1D and 2D applications for either pressurized or free surface flows.

One-dimensional applications are used for systems with variability along only one direction - such as unsteady flow routing along a stream reach in which flow gradients along the transverse directions are much smaller than the gradients along the longitudinal direction, and can therefore be ignored. They result in a 1D longitudinal model for which averaging over the cross-section is conducted (Martin and McCutcheon 1998). Typical 1D open-channel hydraulic flows can be classified as steady and uniform or unsteady and spatially varied (Chow 1959). Whereas the magnitudes of these flows may vary with time, and their free surface profiles can vary from location to location, depending on channel shape, the longitudinal flow is the dominant flow direction; thus transverse flow details are negligible.

Similarly, for some simple 2D flow cases, such as shallow water flow, the vertical velocities are relatively negligible compared with those along the longitudinal and transverse directions; thus they can be ignored, greatly simplifying the formulation. Such a model represents a depth-averaged formulation in which vertical velocity distributions are assumed to be uniform and the pressure distributions are assumed to be hydrostatic (e.g., River2 $\mathrm{D}^{11}$ ). This type of model resolves differences along the width and length of a water body (Martin and McCutcheon 1998). It is useful for modeling and predicting water surface elevations, as in floodplain mapping, and generalized 2D flow in bodies of water like lakes, estuaries, or shallow streams where changes in processes along the depth are negligible. Similarly, width-averaged models are used for cases in which the relatively more significant processes occur along the depth and longitudinal directions, such as long, narrow, deep water bodies (Martin and McCutcheon 1998).

Fully 3D flows that require resolving very fine details of multidimensional flow call for CFD models, which use numerical methods to approximate solutions to the NSE for a discretized spatial domain. These models can be used to model free-surface and pressurized flow for steady and unsteady cases of laminar and turbulent flows.

The gamut of hydraulic model implementations and complexity are presented in the following subsets of hydraulic processes:

- Open Channel Free Surface Modeling

- CFD Modeling

- Turbulence Modeling

\footnotetext{
${ }^{11}$ www.river2d.ualberta.ca/Downloads/documentation/River2D.pdf
} 
- Closed Conduit Modeling

- Hydropower Modeling

\subsubsection{Open-Channel Free-Surface Modeling}

Several use cases require open-channel free-surface modeling from the watershed to the module level to address the modeling of flow behavior, flow timing, and water surface profile determination.

At the watershed and stream levels, flow routing is required to assess flow magnitude and determine timing to support the assessment of flow variability at the facility and module levels. Since only the flow along the streamwise or longitudinal direction is necessary at the watershed and stream levels, the modeling need is for a 1D analytical approach for routing flow. The model needs to be capable of incorporating stream geometry and specifications of stream section connectivity, and of accounting for flow resistances associated with flow blockages and wall friction effects. The spatial resolution of the model would depend on the variability of the changes in the cross-sectional area of the stream geometry. Typically, spatial resolutions on the order of tens of meters are appropriate.

Currently, hydraulic modeling model capabilities like the Army Corps of Engineer's HEC-RAS ${ }^{12}$ and MIKE $11,{ }^{13}$ the Environmental Protection Agency's Storm Water Management Model (SWMM), ${ }^{14}$ and some others are available for assessing 1D hydraulic flow. These are applicable for the demands for modeling 1D hydraulic flow cases for SMH.

At the site level, multidimensional flow considerations and behaviors become important, as facility approach flows contain more spatial variability because of stream geometries and the presence of the SMH facility itself. Flow information such as flow magnitude and water surface elevations from upstream is expected to inform boundary conditions at the site level, as the modeling structure and implementation are expected to change to account for the need for higher-fidelity modeling applications. Spatial resolution of coherent flow structures, multidimensional flows, and more detailed interactions with the environment — such as the stream itself and the instream effects of the presence of the SMH facilitybecome more important to resolve and model accurately. The approach for modeling these types of hydraulic conditions transitions from requiring coarse modeling to more refined treatments like the use of CFD modeling.

CFD modeling capabilities are available in the form of academic, commercial, and open source software packages. Commercial software is available as specialty, computer-aided design (CAD)-integrated, or comprehensive packages. Specialty packages target markets such as automotive, internal combustion, aerospace, marine, electronics, and turbomachinery applications. CAD-integrated packages like SolidWorks ${ }^{15}$ and AutoDesk Inventor ${ }^{16}$ offer simplified applications for steady state, single-phase, nonreacting flow problems. Comprehensive CFD packages like ANSYS Fluent, ${ }^{17}$ ANSYS CFX, ${ }^{18}$ Star$\mathrm{CCM}+,{ }^{19}$ and $\mathrm{COMSOL}^{20}$ offer capabilities to model a diverse range of complex physics, including fluid flow, heat transfer, multiphase flows, turbulent flows, reacting flows, acoustics, and fluid-structure interactions. ANSYS CFX is recognized for its robust capabilities for modeling multiphysics applications

\footnotetext{
${ }^{12} \mathrm{http}: / / w w w . h e c . u s a c e . a r m y . m i l / s o f t w a r e / h e c-r a s /$

${ }^{13} \mathrm{https} / / /$ www.mikepoweredbydhi.com/products/mike-11

${ }^{14} \mathrm{https} / / / \mathrm{www} . e p a . g o v /$ water-research/storm-water-management-model-swmm

$15 \mathrm{http}: / / \mathrm{www}$. solidworks.com/

${ }^{16} \mathrm{http}: / / \mathrm{www}$. autodesk.com/products/inventor/overview

${ }^{17} \mathrm{http} / / /$ www.ansys.com/Products/Fluids/ANSYS-Fluent

${ }^{18} \mathrm{http}: / /$ www.ansys.com/Products/Fluids/ANSYS-CFX

${ }^{19} \mathrm{http} / / / \mathrm{mdx}$.plm.automation.siemens.com/star-ccm-plus

${ }^{20} \mathrm{https}: / / \mathrm{www} . \mathrm{comsol} . \mathrm{com} /$ products
} 
associated with rotating machinery like hydraulic turbines. CFX contains tools for enabling turbo-specific meshing and blade design. All these packages offer comprehensive capabilities to model multiphysics problems with meshing and post-processing capabilities.

Open source softwares like OpenFOAM ${ }^{21}$ are made available free of charge, permitting users to study, contribute to, change, and improve the software. OpenFOAM offers CFD solver capabilities similar to those in commercial software, except that, unlike those, it does not include a GUI (graphical user interface) that makes it easier to use and interface with the software.

A greater depth of discussion of CFD modeling is presented in the next section.

\subsubsection{CFD Modeling}

In the past three decades, with advancements in computing technology, increasingly sophisticated CFD models of complex systems in engineering have been developed. As the design of various SMH systems continues to evolve, it is anticipated that simulation and modeling will play an important role. It is also anticipated that, in light of recent advancements in additive and advanced manufacturing techniques, the design of many engineering systems, and particularly SMH systems, will greatly benefit from the use of multifidelity models that can widen the design space. This development will enable the investigation of novel unconventional designs and fine-tuning of existing conventional designs. This will have a direct impact on improving the effectiveness, reliability, and efficiency of these new systems. The following paragraphs review some of the potential analysis/design techniques that can be used in the design process.

First-principles-based methods: These techniques offer benefits in the preliminary design stage, as they allow the designer to consider the generation module as a black box. At this stage, the overall performance of the system, determined in terms of integral quantities of interest as related to functional relationships, can be rapidly investigated to define design requirements. The analysis of fluid flow can be simplified by the use of first-principles-based methods, which consider 1D, 2D, or both, forms of the governing equations. As an example, the draft tubes (if they are to be used in the system) can be modeled as 1D channels in multiple planes, and the performance of the turbine can be determined by a simplified momentum equation resulting in an actuator disc model. These analyses can be performed relatively quickly.

Moderate-fidelity steady techniques: Once the design requirements and limitations are identified using first-principles-based analyses, the next step is to analyze potential designs (e.g., generator module, foundation module) using CFD simulation tools. Because of the high computational cost of high-fidelity solutions, one could adopt a roadmap with increased fidelity in each stage of the design/analysis process. In light of that, it is expected that 3D steady CFD simulation tools that model Reynolds-Averaged NavierStokes (RANS) equations would be used extensively. Since there would be many different options for modeling "turbulent viscosity," some guidelines need to be established as to which turbulence model (e.g., k- $\varepsilon, \mathrm{k}-\omega, \mathrm{SST}, \mathrm{RNG}$ ) would be the most appropriate for use in different components/modules of the overall system. For rotating parts of the system, one could simply use a relative coordinate system that incorporates the rotational effects through additional centrifugal and Coriolis acceleration source terms in the governing equations. With current computing technology, RANS-based flow solvers should provide a relatively accurate (at least in the global sense) picture of the system. Note that these analyses offer insight into only the hydrodynamic performance. For higher-fidelity solutions, one may need to consider a multiphysics coupled approach. At this stage, the steady (global) performance of the generator module can be determined with relative accuracy using 3D RANS simulations.

\footnotetext{
${ }^{21}$ http://www.openfoam.com/
} 
Moderate-fidelity unsteady techniques: As mentioned earlier, for some parts of the SMH system, the hydraulics (and performance) can be modeled accurately using 3D steady RANS equations. As an example, the draft tube could be expected to have a relatively steady flowfield that could be modeled using RANS equations. However, improved flow physics should be considered for highly unsteady turbulent flow fields that are observed in the runners (turbines) and stators (or the inlet guide vanes).

Today, most unsteady analyses for turbomachines are based on unsteady time-accurate methods, which model RANS equations in an unsteady fashion (Richman and Fleeter 2000; Denton 1990; Chen and Whitfield 1993; Chen et al. 1994; Volmar et al. 2000; Chaluvadi et al. 2001). Unsteady flow calculations in turbomachinery using direct time simulation techniques are commonly employed. Generally, research and commercial codes use the "dual time-stepping" approach in which, at each physical time, the solution is obtained using inner iterations to drive the residual to convergence. With this approach, many possible flow physics/flow regions can be investigated in a time-accurate manner. As an example, one can model interactions of an inlet guide vane wake with a downstream rotor (runner) in a straightforward fashion. However, this approach may be expensive in a design stage because

- Multiple blade passages (if not all) may need to be considered.

- The simulation must be carried out for a long time to capture any periodic response.

- For each period, very small physical timesteps must be taken to ensure solution

- If a dual-timestepping approach is used, a number of pseudo timesteps must be performed to drive the residual to machine accuracy for each physical timestep.

Other moderate-fidelity unsteady approaches can be useful in the analysis of the flowfield. One such technique that is being more widely used is the harmonic balance method (HB, also known as the timespectral/time-collocation/parallel in-time method). At its core, the HB method takes advantage of the fact that many flows of interest in SMH generation modules are periodic in time. For a given number of blades (in addition to blade, hub, and tip geometry), and the rotational speed, one can determine the dominant frequencies in the flow field a priori (excluding frequencies that are present because of, for example, natural shedding or buffeting) and model the flow field as a Fourier representation in time (and space, owing to spatial periodicity). Following this approach, the computational requirements can be reduced significantly (compared with dual-timestepping time-accurate approaches) by reducing the computational domain to a single blade passage in each row and by solving the unsteady time-periodic problem as a coupled set of "steady" problems. As mentioned earlier, the use of HB techniques in the turbomachinery community has increased during the past decade. HB applications to hydrodynamic problems have recently been reported in the literature (Hall et al. 2002; He and Wing 1998; Campobasso and Baba-Ahmadi 2012; Ekici and Hall 2007; Ekici et al. 2010; Luder and Block-Jacobi 2013), and there are a number of research and commercial codes that have adopted this approach. It is expected that, in the conceptual analysis and design of new SMH generation modules, both time-accurate and HB-based RANS methods will be used extensively.

High-fidelity unsteady techniques: Although most companies/research laboratories will probably use unsteady RANS (URANS) solvers for analysis and design purposes, parts of the system may require even higher-fidelity techniques, including hybrid RANS methods such as detached-eddy simulation (DES) or large-eddy simulation (LES) that are useful in modeling small-scale unsteadiness and turbulence in the flow field. Because of the requirement that larger-scale eddies be modeled (which can be done using a very fine computational grid), the mesh requirement for LES and DES approaches may be significantly higher than for the RANS approach. Therefore, the designer would have to make a judicial choice of which regions would benefit from increased-fidelity solution. More discussion regarding the choice of turbulence modeling requirements is provided later in this document. 
Reduced-order models: Another family of modeling approaches that can potentially be adopted in the design stage is reduced-order modeling (also commonly referred to as ROM). In general terms, ROM (Lucia et al. 2004) is used

... to transform the original high-order system of governing equations to a system of much lower order, whereby only the most important or dominant parts of the system dynamics are preserved. A projection-based model reduction method compresses the system's state information by projecting the state behavior onto a lower dimensional subspace and rewrites the governing equations in a compressed representation. (Djeddi et al. 2017)

Order reduction is achieved by decomposing the problem (the flow field, in this case) into a set of modes. Generally speaking, proper orthogonal decomposition (POD) is used to form these modes into orthogonal basis vectors based on system observations. Data analysis using POD is often conducted to extract "mode shapes," or basis functions, from experimental data or detailed simulations of high-dimensional systems for subsequent use in Galerkin projections that yield low-dimensional dynamical models. The ROM/POD approach has been applied to various problems in the literature to obtain approximate, low-dimensional descriptions such as those needed for turbulent fluid flows and structural vibrations, for example (Holmes et al. 1998). In the framework of SMH generation module design, this approach can be very useful to speed up the design cycle. As an example, the high computational times required for parametric studies for optimum performance can be reduced by obtaining "snapshots" based on converged moderate- to high-dimensional RANS simulations for a design parameter at a number of values (e.g., varying mass flow rate). The system response for other values of the design parameter can be projected using a linear combination of the snapshots. The weighting coefficients for each snapshot are determined using model order reduction.

\subsubsection{Turbulence Modeling}

\section{LES vs. RANS}

As explained in Section 4.2.2, LES is a mathematical model used in CFD to simulate turbulence. LES, in some sense, is similar to direct numerical simulation (DNS), which simply models the governing NSEs at very small time and length scales to resolve small-scale turbulence. Unlike DNS, LES uses low-pass filtering to ignore the smallest length scales, significantly reducing computational time compared with DNS. Currently, the use of DNS codes to model engineering systems is still not attainable, and the use of LES has only started being reported in the literature. Because of the increased computational cost, LES simulations require the use of supercomputers to ensure accuracy. This requirement may put pressure on small as well as large SMH manufacturing companies. Therefore, generating a roadmap (through basic research) that outlines which approach is most suitable for different parts of the SMH system will be invaluable to the community.

Because of the computational cost of LES, RANS is often used because simulations can be run on personal or small computer clusters with appreciable accuracy. Simply put, RANS separates the timeaveraged and fluctuating quantities of the governing fluid equations to provide accurate mean solutions. The fluctuating part of the NSE is approximated using constitutive models of turbulence such as the SST, k- $\omega$, k- $\varepsilon$, and Spalart-Allmaras (more commonly used for aerodynamic applications) turbulence models (Bensow and Liefvandahl 2008; Kang et al., 2012; and Tian et al. 2016). 


\section{Laminar-Turbulence Transition}

A potential problem in accurate modeling of turbine blade performance is the prediction of laminarturbulence transition. The transition is difficult to model with RANS solvers because of their treatment of turbulence. A recent study that investigated several commonly used turbulence models found that "none of them properly capture the transition effect" (Cheng et al. 2009). Some models have shown the potential to predict turbulence transition, but only for a class of flow problems. However, all models studied predicted the pressure distribution accurately. Whether the transition effect needs to be properly modeled will depend on what structural and hydropower parameters need to be obtained (Suzen and Huang 2005; Sanders et al. 2009; Yershov and Yakovlev 2016; Biswas 2006).

\subsubsection{Closed Conduit Modeling}

A generation module may contain a conduit that conveys water from the intake to the turbine. Contrary to open channel flow, closed conduit flow does not have a free surface open to the atmosphere. Rather, the flow exerts continuous pressure on the inner perimeter of the conduit. Closed conduit flow models are primarily used in hydropower design to determine the flow profile and friction head losses present during conveyance. The primary source of head loss in conduits is wall friction losses along straight segments and at directional changes, such as bifurcations, bends, expansions, and contractions. Head losses due to wall friction are proportional to the square of the velocity through the conduit, and they are generally modeled using basic steady state calculations that include an estimate of conduit surface roughness, simplified velocity profiles, and coefficients that correspond to the geometry and type of directional change encountered.

Owing to the small, modular nature of SMH designs, a long conduit is not expected, and the need for independent closed conduit modeling is minimal. An array of generation modules, however, may have several intakes with short conduits that lead to small, separate turbines. Advanced CFD modeling of a generation module array may need to account for the forebay, intake, and conduit flow regimes to optimize flow profiles and discharge to the turbine. The modeling of closed conduits has always been particularly difficult because of the laminar-turbulence transition. Recently, hybrid turbulence models, particularly SST k- $\omega$, with RANS, have proven more effective at modeling conduit flows, as they can properly handle the transition (Zhang and Kleinstreuer 2003).

\subsubsection{Hydropower Modeling}

When using a turbine to convert hydraulic energy into mechanical energy, one of the most important parameters to measure is the output power. Output power is directly related to the torque imposed on the blades by the shearing of fluid. The force that the fluid imparts on the blade can be calculated by integrating the pressure forces at the surface of the blade and assuming that viscous forces are negligible at the blade surface. One research group at the University of Minnesota applied this method to a real-life hydrokinetic turbine and found that they were able "to predict with reasonable accuracy the torque and power generated ...." (Kang et al. 2012). The modeling was done with LES, so a high-resolution mesh was used. However, the researchers state that they obtained results with "grids that are far too coarse to resolve the details of the flow in the immediate vicinity of solid walls." This is promising for RANS models that are unable to resolve the same level of detail.

\subsection{GEOMORPHOLOGIC PROCESSES}

Geomorphological changes in river systems are driven by the imbalance between the sediment transport capacity and the sediment supply from upstream and the adjacent watersheds (Witt et al. 2017; Lane 1955). This imbalance causes river aggradation or degradation, when the sediment transport capacity is 
smaller or larger than the sediment supply, respectively. The interaction of the aggradation or degradation with the existing river morphology and boundary conditions at different spatial and temporal scales triggers further geomorphological processes that change the river system geomorphology to restore equilibrium conditions at the river. These geomorphological processes are examined in detail in the following sections:

- River Metamorphosis Modeling,

- Incision

- Bed Gradient Changes

- Channel Widening and Narrowing

- Textural Changes and Bedform Development

- Scour Modeling

Hydropower facilities are known to act as flow conveyance and sediment supply barriers (Brandt 2000; Schmidt and Wilcock 2008; Wild et al. 2016) and, as such, to cause imbalances between sediment transport capacity and supply. As a result, hydropower facilities cause river geomorphic changes on a range of spatial and temporal scales to the rivers in which they are placed (Magilligan et al. 2013). In the context of geomorphologic processes, the simulation and modeling capability aims to predict these geomorphological changes and assess the impacts that placement of SMH facilities would generate by employing a suite of morphodynamic modeling packages (Papanicolaou et al. 2008; Coulthard and van der Wiel 2013).

The main principle behind most river morphodynamic models is to estimate the imbalance between sediment transport capacity and sediment supply in every grid cell of a discretized domain and use this imbalance to predict erosion, deposition, or textural changes (Papanicolaou et al. 2004; Papanicolaou et al. 2008; Coulthard and van der Wiel 2013). These predictions are then used to adjust the morphology of the modeled domain accordingly, by varying channel bed elevation, channel slope, and bed sediment composition, as well as channel planview and cross-sectional geometry. The sediment transport capacity in most morphodynamic models is estimated as a function of the flow parameters through the use of one or multiple sediment transport formulae (Garcia 2008). These formulae are usually semi-empirical in nature and can be either deterministic or probabilistic, depending on their treatment of the sediment transport process. The sediment supply is typically assessed through a continuity equation for sediment mass transport, such as the Exner equation. The more sophisticated models may also account for lateral contributions from the adjacent watersheds, although modeling of the lateral contributions remains an open research challenge, as is discussed in Section 5 (Papanicolaou and Abban 2016).

The key processes that result from the interaction of aggradation and degradation with river geomorphology and boundary conditions include the following (Figure 5): (1) river metamorphosis, (2) incision, (3) channel gradient change, (4) widening or narrowing, (5) textural changes and bedform development, and (6) scour. Each one of these processes is briefly examined in the following subsections, along with typical modeling strategies, requirements, and caveats. It is noted, however, that multiples of these processes may occur concurrently at the same scale and interact with one another and with other hydraulic and geotechnical processes (Skalak et al. 2017). These interactions are discussed in detail in Section 4.9. 


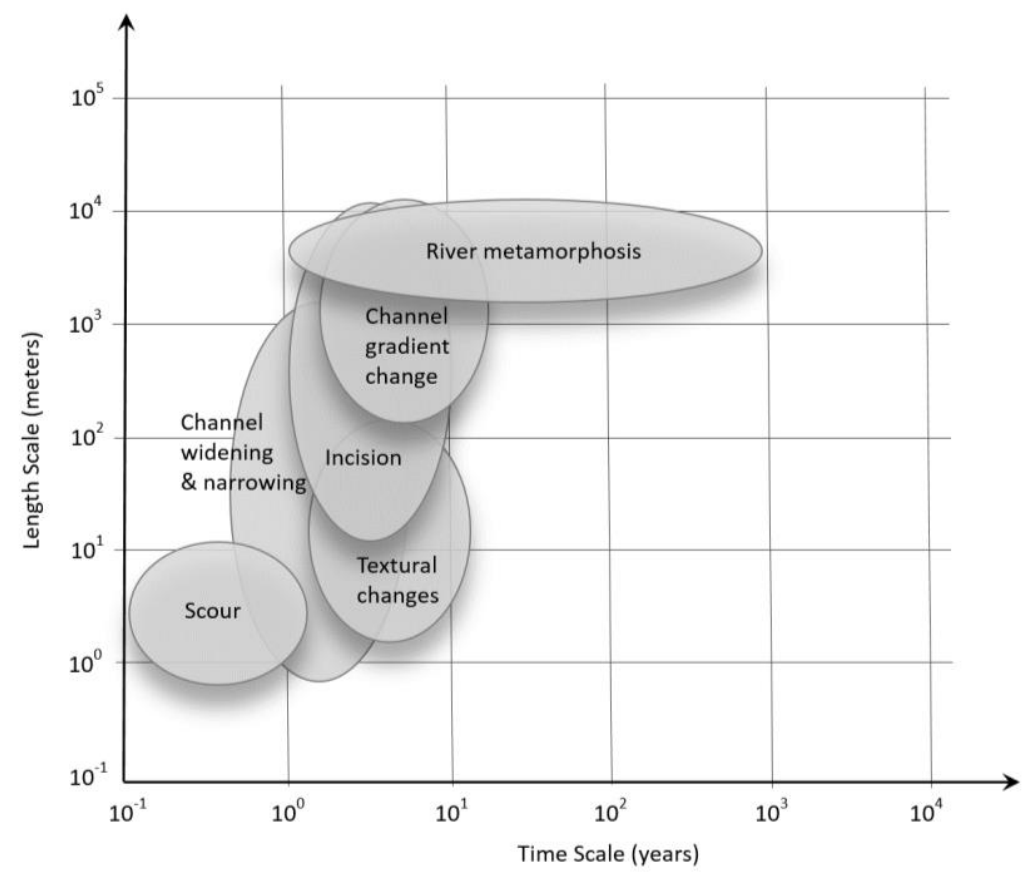

Figure 5. Characteristic spatial and time scales of key river geomorphic processes (after Knighton 1998).

\subsubsection{River Metamorphosis Modeling}

River metamorphosis is the change in river planform geometry due to sediment aggradation and degradation over larger spatiotemporal scales (Schumm 1977; Bridge 2003; Ashmore 2013; Hooke 2013). Such large-scale river planform geometry changes are river meandering and/or braiding. River meandering is triggered especially in rivers with erosion-prone banks, which allow lateral migration of the stream and the formation of alternating bars (Bridge 2003; Hooke 2013). River braiding often follows meandering, when high-transport-capacity flows erode the alternating bars caused by meandering, or following the deposition of large amounts of material within the river floodplain (Bridge 2003; Ashmore 2013).

Changes in the planform river geometry, such as meandering and braiding, occur at larger spatial and temporal scales, which in the SMH context would correspond to the river scale. Typical spatial domains for modeling meandering include between $10^{3}$ and $10^{4}$ meters. Typical temporal scales of such large-scale processes are on the order of several years to thousands of years. The modeling spatial resolution must include transitions in river 3D topography and roughness and the temporal resolution.

Because meandering and braiding are processes acting in the planform of a river, they require coupling $2 \mathrm{D}$ or $3 \mathrm{D}$ hydraulic models to properly simulate the flow hydraulics in these settings, and $2 \mathrm{D}$ sediment transport models to account for the streamwise and lateral transport of sediment. Of paramount importance to correctly accounting for the model hydraulics is that the hydraulic model must account for secondary flows (secondary currents), which are a key flow feature at the meander bends (Odgaard 1989; Papanicolaou et al. 2007). Furthermore, the models must account for variable river cross-sectional and planform geometry, including the variable curvature encountered in meandering reaches, as well as variable bed roughness. The models must allow for erodible river beds with multiple fractions of bed material, as well as erodible river banks with different material properties and erodibility from those of the river bed material. Because modeling these planform river changes requires higher-order dimension 
models and larger spatiotemporal scales, modeling of these large-scale processes may become computationally expensive.

Models that can be used for simulating river planform changes are the model of Sun et al. (2001), a suite of linear models that have been introduced in the past (Parker 1976; Ikeda 1987), and the International River Interface Cooperative (iRIC) ${ }^{22}$ software package co-developed by the USGS. Another model that can be used for modeling meandering is DELFT3D ${ }^{23}$ (Rinaldi et al. 2008; Matsubara and Howard 2014).

\subsubsection{Incision Modeling}

Incision occurs in stream reaches where the stream bank conditions preclude lateral expansion of the channel, and the sediment transport capacity greatly exceeds the sediment supply (Williams and Wolman 1984; Grams et al. 2007; Schmidt and Wilcock 2008). Boundary conditions precluding lateral stream expansion include bedrock channels and channels with non-erodible banks. Incision may take place over a wide range of spatial scales ranging over the reach scale, i.e., $\sim 10^{1}$ meters up to $\sim 10^{4} \mathrm{~m}$ (Schmidt and Wilcock 2008), and on the order of a few years in terms of time scales. Within the SMH scale framework, incision is a process acting on the river and site scales.

To model incision, morphodynamic models must treat the bed as an erodible, movable boundary that will allow accounting for the bed elevation changes that result from the incision action. Furthermore, the morphodynamic models must allow specification of the cross-sectional geometry of the stream and banks, as well as the bank boundary conditions. Because incision is a predominantly 1D process, 1D hydraulic models may be used for predicting the transport capacity. The spatial resolution of the model should be sufficiently fine to account for changes in the cross-sectional geometry, bed material, and bank material and boundary conditions. Models that can be used for modeling incision are 3ST1D (Papanicolaou et al. 2004), the USGS iRIC, and the FAST2D/3D and DELFT2D/3D. ${ }^{24}$

\subsubsection{Bed Gradient Modeling}

Channel bed gradient changes, and most commonly increases or channel steepening, are the outcome of increases in sediment transport capacity, which is often triggered by increased sediment supply from the upstream (Schumm 1977; Bridge 2003). Channel steepening is typically observed following sediment releases from hydropower facilities. Modeling is required to predict the final slope in a river reach following steepening, as it affects the flow hydraulics in that reach.

Channel steepening occurs on the site and river scales spanning between the orders of $10^{2} \mathrm{~m}$ and $10^{4} \mathrm{~m}$. Its temporal scales also vary from a fraction of a year to several years. The model spatial resolution must be sufficiently fine to allow representation of variations in the river cross-sectional geometry and textural differentiation of the river bed material.

Modeling of channel gradient changes requires that the models incorporate depictions of the planform and longitudinal river geometry. The models should also feature erodible beds and allow for the deposition of incoming sediment to replicate the changes in elevation that lead to channel steepening. Also, depending on the planform geometry of the river, 1D models may be acceptable in relatively straight reaches, whereas at curved river reaches, the use of at least 2D models must be considered.

\footnotetext{
22 http://i-ric.org/

${ }^{23} \mathrm{https}: / /$ oss.deltares.nl/web/delft3d

${ }^{24} \mathrm{http}: / /$ www.delftsoftware.com.au/products.html
} 
Models that can be used for modeling channel steepening are 3ST1D, iRIC, ${ }^{25}$ FAST2D/3D, and DELFT2D/3D. ${ }^{26}$

\subsubsection{Channel Widening and Narrowing Modeling}

Changes in the river channel width, including widening and narrowing, are frequently encountered in rivers where hydropower facilities are installed (Brandt 2000; Grant et al. 2003). Channel widening is usually the outcome of increased transport capacity in reaches with limited sediment supply and banks made up of erosion-prone material that allows lateral expansion of the river. Channel narrowing has been observed in reaches with lower transport capacity relative to the incoming sediment supply, which results in deposition of the incoming material that narrows the channel.

Changes in the river width may occur over a range of spatial scales spanning $10^{1} \mathrm{~m}$ to $10^{4} \mathrm{~m}$, and they correspond to the site and river scales of the SMH framework. The time scales of these changes range from a fraction of a year to several years. The spatial resolution of the models to be used must be such that variations in the cross-sectional geometry in bed and bank erodibility are represented in the model. The temporal resolution of the model must be relatively high, e.g., on the order of days. Modeling of changes in the river width requires that the model incorporate the capability to handle variable crosssectional characteristics and river planform geometry. Furthermore, the models must allow changes in the geometry of the river cross-sections modeled, especially in the lateral direction, and thus must feature erodible beds and banks. The models must also be capable of delineating textural variability for the bed and banks to allow for their variable erodibility.

Models that can be used for modeling widening and narrowing are CONCEPTS, the model of Eke (2014) and of Wu and Wang (2007).

\subsubsection{Modeling of Textural Changes and Bedform Development}

One of the most common geomorphologic effects resulting from the placement of hydropower facilities is changes in the grain size distribution of the river bed surface and organization of the river bed surface material in bedforms. Bed surface textural changes may lead to either coarsening (also known as armoring) or fining of the grain size distribution (Bridge 2003; Grant 2003). The prediction of such textural changes is important, as they affect the channel roughness and the flow conveyance required for hydraulic modeling and may promote other geomorphologic changes, such as river meandering and braiding (as discussed in Section 4.9).

Coarsening of the river bed surface occurs when the transport capacity is sufficient to selectively entrain a subset of the grain sizes available at the river bed surface (Brandt 2000; Grant 2003). In contrast, fining typically is an outcome of the deposition of incoming finer material during high-supply events at low transport capacities.

Textural changes and bedform development typically occur over smaller spatial scales, i.e., on the order of 1 through $10^{2} \mathrm{~m}$, which correspond to the site level. Their temporal scales are on the order of from one year to several years, depending on the existing grain size distribution. Modeling textural changes in the bed surface requires that the model spatial resolution be sufficiently fine to account for the presence of textural patches in the bed. This requirement may necessitate spatial resolutions below the $1 \mathrm{~m}$ scale. Temporal resolutions must be as low as 1 day, as coarsening and fining may occur on shorter time scales.

\footnotetext{
${ }^{25} \mathrm{http}: / / \mathrm{i}$-ric.org/

${ }^{26} \mathrm{http}: / /$ www.delftsoftware.com.au/products.html
} 
To account for textural changes and the development of bedforms, morphodynamic models must consider erodible beds with variable bed topography and must have the capability to account for multiple grain size fractions for the bed material. These models also need to account for the cross-sectional and planform geometry of the stream. A key requirement for modeling textural changes is that the model formulations incorporate the capability for selective entrainment of the available bed surface sizes and selective deposition of a subset of the supplied sediment sizes. Models that can account for textural changes are 3ST1D, iRIC, ${ }^{27}$ SRH2D,${ }^{28}$ CCHE3D. ${ }^{29}$

\subsubsection{Scour Modeling}

Scour is localized erosion caused by local alteration of the flow field following its interaction with hydraulic structures, such as the various SMH facility modules (Lagasse 1995; Melville and Coleman 2000). The prediction of scour around SMH facility modules is of paramount importance for the stability of these modules, as scour can compromise the stability of the foundation module and thus the stability of the SMH facility. A key feature of scour is that it is a localized phenomenon that is intimately related to the turbulent flow structures that develop from the interaction of the flow with hydraulic structures (Ettema et al. 2010).

Because of its localized character, scour occurs at the smaller facility and module scales of the SMH framework. This, in turn, suggests that the modeling domain for scour is comparable to the size of the SMH module, around which scour is modeled. In addition, the time scales required for scour to develop are rather short, on the order of days. However, because of the intimate relationship of scour with the turbulent flow structures, modeling of scour may require quite fine resolutions that are comparable to the spatial and temporal scales of the turbulence structures generating the scour. Along the same lines, because of the 3D nature of the turbulent flow field in the vicinity of the structures, modeling of scour should be performed in $3 \mathrm{D}$ with $3 \mathrm{D}$ flow data. The models need to incorporate the 3D geometry of the domain around the hydraulic structures. Furthermore, modeling of scour must consider erodible beds, by accommodating the lowering of the bed surface elevation under the scour action. Scour modeling must also account for the different types of bed sediment materials (e.g., gravel or sand), as processes specific to each type may additionally affect scour. For instance, in gravel streams, gravel particle interlocking and/or armoring may reduce the predicted scour depth. Models that can be used for modeling scour are FLUENT $^{30}$ and FLOW3D. ${ }^{31}$

\subsection{ECOLOGIC PROCESSES}

Ecologic processes include a wide range of human and animal uses of and interactions with the natural resources of the river. Modeling and simulation needs to address various ecologic processes that are likely to occur at all levels of organization, from watersheds to modules. In many cases, the same model may address issues at more than one level.

Identified herein are several ecologic challenges that might be faced during the design and operation of SMH projects for which a variety of modeling approaches could provide insight and solutions. They are the following:

\footnotetext{
${ }^{27} \mathrm{http}: / /$ i-ric.org/

${ }^{28} \mathrm{https} / / /$ www.usbr.gov/tsc/techreferences/computer\%20software/models/srh2d/index.html

${ }^{29} \mathrm{https}: / /$ www.ncche.olemiss.edu/cche3d

${ }^{30} \mathrm{http} / / /$ www.ansys.com/Products/Fluids/ANSYS-Fluent

${ }^{31} \mathrm{https}: / / \mathrm{www}$. flow3d.com/
} 
- Fish Behavior and Response Modeling

- Fish Physiology and Biomechanics Modeling

- Benthic Habitat Modeling

- Cumulative Effects/Population-Level Response Modeling

- Recreational Modeling

\subsubsection{Fish Behavior and Response Modeling}

In the context presented here, fish behavior refers to such characteristics as general habitat preference and use, movement patterns, migration timing, and response to facility features and flow patterns.

To address fish passage needs requires accurate estimation of the timing of fish movements and migrations upstream and downstream of a facility. For some migratory species, models exist that predict time of occurrence based on river conditions (e.g., temperature and flow); but for many species, empirical data are still need to construct such models.

Altered flow at the stream level caused by other water users or natural phenomena (e.g., flood, drought) in the basin can affect natural resource use at the facility and can produce cumulative environmental effects that the facility by itself might not cause. Assessing river-wide flow alteration is important and necessary not just for environmental resources protection but also for accurate assessment of generation capacity. Models that use publicly available stream flow data to assess natural and unnatural flow variation and alteration at a wide range of temporal scales (hourly to yearly) are widely available to address this challenge.

To safely pass fish around or through an SMH project in either an upstream or downstream direction, it will be necessary to design passage modules based on the behavior of resident and migratory fish in the river and on the local hydraulics. Behavioral aspects include understanding when fish will approach the facility and how they will respond at entrances to upstream and downstream passage devices. Getting fish to find fish ladder entrances has always been a challenge because of the complex flow fields around most hydropower facilities. There are a variety of hydraulic models that can be brought to bear to evaluate fish ladder designs for upstream passage so as to achieve velocity and flow field criteria that will result in appropriate attraction. Similarly, hydraulic models can also be used to assess the hydraulic conditions around collection and exclusion devices for downstream passage (Nestler et al. 2005).

\subsubsection{Fish Physiology and Biomechanics Modeling}

Being able to understand and model the relationships among fish physiology and biomechanics and various characteristics of the environment around an SMH facility will be important in solving many of the ecological challenges faced at an SMH site. For example, to safely pass fish around an SMH project, it will be necessary to design passage modules based on swimming performance criteria (as well as the behavioral criteria mentioned above) of resident and migratory fish in the river.

Ladder designs for upstream passage incorporate features that produce resting pools, pour-overs, and eddies, which are based on various fish performance features such as swimming endurance, burst swimming speed, and jumping ability. There are a variety of hydraulic models that can be brought to bear to evaluate ladder designs to achieve velocity and flow field criteria based on select species' swimming performances (Rajaratnam et al., 1986; Katopidis, 1992).

Similarly, hydraulic models can also be used to assess the hydraulic conditions around collection and exclusion devices for downstream passage. Hydraulic conditions at fish screens must be such that fish are not impinged on screens but moved past them to a directed bypass route. 
For some species and some turbine types, various turbine features (such as turbine speed and blade shape) could be modified to reduce the risk of turbine injury to the point that passage through the turbine for downstream-moving fish could become the preferred route. Modeling tool sets that combine CFD models of internal turbine conditions with fish injury risk models are available to turbine manufacturers to produce more turbines that reduce the risk of fish injury (Richmond and Romero-Gomez 2014; Richmond et al. 2014).

Healthy fish populations are directly dependent on various aspects of water quality, in particular temperature and DO. A variety of models are available that can predict fish responses (e.g., physiological stress, growth, and mortality) to water quality issues such as elevated temperature and low DO (Van Winkle et al. 1997; Bevelhimer and Bennett 2000; Bevelhimer 2002).

\subsubsection{Benthic Habitat Modeling}

Changes to the stream bottom as a result of construction and modified hydraulic forces can affect available fish habitat, food resources, and spawning habitat. Stream fish typically have species-specific spawning requirements, which often include sediment type and hyporheic flows. The hydrodynamics and the sediment transport around the facility will involve the design, functionality, and location of all modules. Addressing these challenges will likely require a combination of site-specific 3D hydrodynamic models, sediment transport models, and models of fish response.

In addition to near-facility concerns, maintaining natural sediment transport is important to preserve natural steam ecological functions downstream. Models that can predict the amount and quality of bedload transport at the stream scale are available and should be considered in designing both a sediment passage module and the overall facility. These solutions will span sediment transport dynamics from the module to the watershed. See Section 4.3 for a description of example sediment transport models.

\subsubsection{Cumulative Effects/Population-Level Response Modeling}

Large-scale ecological impacts - such as changes in populations, community structure, habitat fragmentation, genetic diversity, and biodiversity - are cumulative functions of many of the issues discussed above, as well as of activities that occur throughout the watershed. There are a plethora of fish population models that could be used to assess the effects of these various stressors on local populations in addition to the effects of fragmentation that can occur when populations are geographically separated by instream structures (Hallam et al. 2000; Jager et al. 2000; Jager et al. 2013). Models that address population-level effects on highly migratory species, and changes in community structure and biodiversity, are more complex and not as readily available for application.

\subsubsection{Recreational Modeling}

Streams of the size most suited for SMH development are also popular sources of recreation, such as fishing, leisurely canoeing, and whitewater boating with rafts and kayaks. Maintaining these resource services by designing facilities and modules that allow for safe boat passage or portage will require knowing the type and amount of recreational resource use. Models that can predict the amount of small recreational craft movement upstream or downstream of a facility, and the need for and cost of recreational access, would be useful. It is unlikely that such specific models currently exist, but there are statistical models that have been developed to make similar resource use predictions and plentiful existing data that can be used for model development (Flug and Montgomery 1988).

If boat passage is deemed necessary at a site, then additional information will be needed to facilitate module design, such as the stream flow characteristics necessary to enable consistent and safe passage through a SMH facility or provide a desirable boating experience. It might also be necessary to be able to 
predict the upstream hydraulics that are related to the performance of exclusion devices intended to prevent unsafe interactions between boaters and modules. Existing 1D, 2D, and 3D hydrodynamic models can be used to characterize river currents upstream and downstream of the project, assess how these flows might be affected by facility structures, and assess how the flows could be manipulated to provide safe passage for recreational watercraft.

\subsection{STRUCTURAL PROCESSES}

Structural processes are the physical behaviors that determine the formation, arrangement, and relationships of a physical body or system. Structural analysis aims to predict the behavior of a physical structure when subjected to a force. The theoretical bases for structural analysis are the fields of applied mechanics, applied mathematics, and materials science. Determining the deformations, internal forces, stresses, and stability of a structure is crucial to prevent the failure of a design. Reasons for modeling the structural response of a design for a given geometry, loading conditions, and material properties include maximizing service life and safety, minimizing weight and cost, and selecting materials and manufacturing methods.

The response of a structure when subjected to load is governed by Newton's laws of motion. A structure could experience several forms of structural loads. A dead load is a static force that varies slowly enough that inertial forces based on Newton's first law can be ignored (Nayfeh and Pai 2008). A dead load can be in the form of compression or tension on a body and includes the weight of the structure. Live loads are dynamic forces that vary quickly, such as impacts, vibrations, or momentum. Environmental loads can act on a structure as a result of fluids, wind, seismic activity, and other types of natural occurrences. Understanding the loads a structure could encounter over its service life is crucial in the modeling process to ensure that a design does not exceed mechanical failure criteria for buckling, corrosion, creep, fatigue, fouling, fracture, yielding, and other modes of failure.

Structural processes influencing SMH facilities are found at the module and facility level. These processes can be modeled by the following:

- Structural Dynamics and Fracture Mechanics Modeling

- Finite Element Modeling (FEM)

- Topographical Optimization Modeling

- Probabilistic Durability Modeling.

\subsubsection{Structural Dynamics and Fracture Mechanics Modeling}

For structural response considerations of SMHs, important areas that need extensive modeling and simulation are structural dynamics and fracture mechanics. In light of advancements in additive and advanced manufacturing techniques, we anticipate the use of new and existing state-of-the-art materials in SMH turbines. As an example, composite materials are good candidates for use because of their excellent structural characteristics and their ability to withstand corrosion. Therefore, we anticipate extensive use of composites in SMH runners and turbines. In the wind turbine industry, turbine blades typically are made of braided fibers or, in some cases, are filament wound. They use combinations of carbon and Kevlar, which helps to avoid catastrophic failure.

To ensure that the structural properties of composite turbines meet loading requirements, an extensive set of simulations is needed using finite element analysis (FEA) or FEM (as discussed in Section 4.5.2). Data related to material properties, tension, compression, interlaminar shear, impact (low and high speed), and environmental durability available from the testing and validation pillar of the SMH Program will be 
crucial in validating numerical simulations. Simulations could provide insight into the optimization of ply thickness, number of layers, and ply orientation for the composite material used.

In addition, a coupled approach must be taken to model the hydroelastic response of the generation module with respect to the interaction of the turbine blade structure and the hydraulics of the turbine. This interaction is discussed in greater detail in Section 4.9.

\subsubsection{Finite Element Modeling}

FEM, also known as FEA, has become the most accepted analysis method in the design of complex structures. Structures are inherently continuous in nature and are 3D. Determining an analytical solution for continuous structure is nearly impossible because of complexities in geometry, boundary conditions, and material properties (Friswell and Mottershead 2013). FEM allows for an approximate solution by modeling a structure as a finite number of elements and nodes with a solvable number of degrees of freedom. The analytical and computational solutions are found by means of matrix algebra, solving partial differential equations.

The geometry of a structure is discretized into a mesh of finite elements of certain shape and sizes. The elements all have respective shapes and properties to accurately represent the mass and stiffness effects of the continuous structure. The physical behavior of each element must represent the response of the structural system in both a local and global sense; therefore, it may include properties of density, stiffness, shear modulus, thickness, and other material characteristics. The mesh can contain elements of multiple geometries. In modeling 1D structures such as trusses, cables, or beams, the elements used in FEM tend to be straight or curved $1 \mathrm{D}$ elements with representative axial, bending, or torsional stiffness and tend to contain two nodes (Oñate 2009). The elements used for modeling a 2D structure like a plate or shell can have a variety of shapes, such as flat or curved triangles or quadrilaterals, with nodes usually placed at the corners. FEM for 3D solids typically uses tetrahedrals and hexahedrals with nodes at the vertices. The discretization process is an essential part of the preprocessing step, and multiple discretion strategies exist as procedures to generate the element meshes.

Many use cases require FEM. It will be essential in the design of each module, module interaction with other modules, module interaction with the environment, and facility layout as whole.

At the site level, FEM can provide insight into the structural response of the entire facility when it is acted on by external forces. This insight can be instrumental in designing the site layout to ensure a safe, costeffective, and long-lasting operational facility. Building codes for hydropower facilities often require a large factor of safety for extreme environmental forces such as floods and seismic events. These requirements can be met with the implementation of FEM to assess the structural response of a facility under such rare extreme conditions. The earthquake engineering software packages for Diana FEA ${ }^{32}$ and OpenSees ${ }^{33}$ are available to meet this modeling demand.

The modules that collectively make up the facility will need to be interconnected with adjacent modules, and each must be connected with the foundation module. The connections between modules can be designed and modeled with FEM to ensure the modules will not become disconnected by shear, tension, or compression forces that are likely to occur from fluid flow, foundation settling, sediment buildup, and debris impacts. Several FEM software packages have modules dedicated to part-to-part connections that would be applicable in designing the module connections.

\footnotetext{
32 https://dianafea.com/

${ }^{33} \mathrm{http}: / /$ opensees.berkeley.edu/
} 
At the module level, FEM will be used in multiple ways. Each type of module will need analysis to ensure it will not fail under operation in normal or extreme conditions. Without compromising the high safety factors, module design can be altered to reduce cost by optimizing weight and material selection. Several FEM software developers, such as ANSYS Structural, ${ }^{34}$ offer strength, vibration, and motion analysis for composite materials. Several sophisticated FEM software programs are currently available, including such popular programs as Autodesk Simulation,,${ }^{35}$ ANSYS,${ }^{36}$ ADINA,${ }^{37}$ COMSOL,${ }^{38}$ Nastran, ${ }^{39}$ and CosmosWorks. ${ }^{40}$

\subsubsection{Topology Optimization Modeling}

Topology optimization modeling (TOM) optimizes the material layout in a design space, given a set of loads and design constraints, to maximize the system performance. TOM is a mathematical optimization problem that can be computed by some FEM programs, typically in manufacturing, and is used in early product development to design lighter, stiffer structures (Fancello and Pereria 2003).

Since the shapes and materials of SMH modules are unknown, the TOM design space might be the shape of the module itself or just a single component. Optimization of shapes pertains to several use cases on the module level. TOM can minimize the amounts of material needed for parts without compromising their mechanical functionality. Additive manufacturing processes have made it possible to produce some TOM-optimized parts that were too difficult to manufacture using traditional processes. Another possible SMH application of TOM is the design of module shapes to minimize scour and erosion.

Available FEM softwares that include TOM are MSC.Nastran,,${ }^{41}$ Genesis,${ }^{42}$ OptiStruct, ${ }^{43}$ ANSYS,${ }^{44}$ and TOSCA (Choi 2016).

\subsubsection{Probabilistic Durability Modeling}

Several use cases require models of the probability of failure at the facility and module level to ensure a design is safe and remains cost-effective well into its service life. Probabilistic analysis of the durability of a structure approximates the expected service life, maintenance needs, and overall reliability of a structure or component. Probabilistic durability modeling analyzes the temporal behavior of a structure when it is acted on by expected loading conditions and determines the probability of failure. The range of structural behavior modeling includes stress analysis, dynamics, deformation control, creep and relaxation, fracture, and fatigue and structural stability. Probabilistic analysis can use the Monte Carlo simulation technique, which relies on repeated random sampling and load cases to obtain a probability distribution of an array of outcomes. Reliability can be determined from the calculation of the probabilities of failure at various times, and hence the lifetime of a structure can be easily estimated. This estimation can be utilized to suggest inspection time frames for the structure to help prevent unexpected failures (Marek and Pustka 2007).

\footnotetext{
${ }^{34} \mathrm{http}: / / \mathrm{www} \cdot$ ansys.com/Solutions/Solutions-by-Application/Structures

${ }^{35} \mathrm{http}: / / \mathrm{www}$.autodesk.com/solutions/finite-element-analysis

${ }^{36} \mathrm{http}: / / \mathrm{www} \cdot$ ansys.com/

${ }^{37}$ http://www.adina.com/

${ }^{38} \mathrm{https}: / / \mathrm{www} . c 0 m s o l . c o m /$

${ }^{39} \mathrm{http}: / / \mathrm{www} . \mathrm{mscsoftware} . \mathrm{com} /$ product/msc-nastran

${ }^{40} \mathrm{http}: / / \mathrm{www} \cdot$ aertia.com/en/productos.asp?pid=319

${ }^{41} \mathrm{http}: / / \mathrm{www} . \mathrm{mscsoftware} . c 0 \mathrm{~m} /$ product/msc-nastran

$42 \mathrm{http}: / / \mathrm{www} . v$ rand.com/genesis.html

${ }^{43} \mathrm{http} / / /$ www.altairhyperworks.com/product/OptiStruct

${ }^{44}$ http://www.ansys.com/
} 
ANSYS nCode DesignLife ${ }^{45}$ is an FEM software that is used for durability and fatigue testing.

\subsection{GEOTECHNICAL PROCESSES}

Conventional hydropower plants are designed for long useful lives of 50-100 years. Over that time, the structure is required to remain in equilibrium with the subsurface to ensure overall public safety and the reliability of the services enabled by the structure. Equilibrium in this sense is not static; rather, it can be considered a measure of external global stability against a statistically determined range of probable environmental forces. To assess stability - defined herein as the bearing capacity of a structure and its resistance to sliding, rotation, flotation, and overturning - an engineer requires knowledge of (1) the engineering properties of the materials used to construct the structure and (2) the behavior of earthen materials under the external forces imposed upon the structure. This section is primarily concerned with the latter issue, outlining the processes that undermine the stability of a structure and how they are characterized through field investigations, empirical knowledge, and modeling. The standardization aspect of SMH will focus the discussion on a "typical" potential project - a small or medium-size hydraulic structure with no significant geological challenges.

This section contains the following subcategories:

- Characterizing Subsurface Conditions

- Stability Modeling

- Seepage Modeling

- Sediment Consolidation and Fluidization Modeling

\subsubsection{Characterizing Subsurface Conditions}

\section{Subsurface Exploration}

Hydropower facilities are designed to transmit all imposed loads into the ground. Consequently, the geologic and geotechnical conditions at a potential hydropower site are two of the most important factors that determine the overall safety of the structure (FERC 2017). Preliminary subsurface exploration can be carried out through desktop studies of state or local geologic maps, existing soil surveys, USGS topographic quadrangle maps, aerial photographs, well records, and technical publications pertinent to the area of development (DNR 2001). The most common and practical method of characterizing the subsurface of a specific site is through a site reconnaissance and field investigation that (1) classifies the general geologic setting of the area and condition of the foundation soils and rocks and (2) provides a general first impression of the engineering and geological aspects of the proposed site and the extent to which further study, exploration, and testing are necessary. The field investigation may entail subsurface exploration via test borings, test pits, and rock corings. Laboratory testing may be carried out to determine direct shear, unconfined and triaxial compression, sliding friction, modulus of elasticity, tensile strength, natural and dry density, moisture content, consolidation, grain-size analysis, and permeability of the earth materials at a site (FERC 2017). The efficacy of all subsequent geotechnical analyses relies on the accuracy of subsurface material characterization as determined by preliminary desktop, field, and laboratory studies.

\section{Bearing Capacity}

To provide stability in supporting a structure, the subsurface must have the capacity to bear the forces imposed upon it. As defined by the Army Corps of Engineers (USACE 2005), the allowable bearing

\footnotetext{
${ }^{45} \mathrm{http}: / / \mathrm{www}$.ansys.com/Products/Structures/ANSYS-nCode-DesignLife
} 
capacity is "the maximum pressure that can be permitted on a foundation soil or rock mass giving consideration to all pertinent factors, with adequate safety against rupture of the soil or rock mass." Principal factors that influence soil bearing capacities are type and strength of soil, foundation width and depth, soil weight in the shear zone, and surcharge (USACE 1992). The shear strength of soil is a complex function of numerous independent parameters, including mineralogy, particle size, shape and gradation, cementation, degree of consolidation, state of stress, anisotropy, and drainage conditions (USACE 2005). For small, low-hazard dams, laboratory tests of bagged subsurface samples may be used to obtain assumed shear strength and permeability parameters (DNR 2001). For rock, bearing capacity is influenced by joint spacing with respect to foundation width, joint orientation, joint condition (open or closed), rock type, and rock mass condition (intact, jointed, layered, or fractured). The shear strength of rock foundations is generally controlled by natural planes of discontinuity rather than intact rock strength. The final design of a structure founded on rock is generally not limited by bearing capacitydeformation/settlement, sliding stability, and overturning are the most influential considerations (USACE 1994).

The soil parameters required for a bearing capacity analysis include the shear strength, depth to groundwater of the pore water pressure profile, and distribution of total vertical overburden pressure with depth. Shear strength is a function of the undrained shear strength for cohesive soils, the effective angle of internal friction for cohesionless soils, and the effective cohesion and angle of internal friction for mixed soils (USACE 1992). The rock parameters needed for a bearing capacity analysis include the deformation modulus and compressive and shear strength of the rock mass. Rock shear strength is characterized by cohesion and internal friction, parameters that are quantified through direct testing (USACE 1995).

The strength parameters and bearing capacity of rock and soil are analyzed mainly through a combination of analytical methods, field load tests, laboratory testing, and traditional bearing capacity equations. These values will be furnished to a structural engineer, who must provide values for the size and shape of the structure and the character of the loading expected to occur to the structural engineer. Both geotechnical and structural properties must be analyzed together to ensure the structure does not exceed the bearing capacity of the soil or rock foundation.

\section{Deformation and Settlement}

Rock or soil may consolidate, settle, and deform when structures are placed upon them. The magnitude and rate of settlement is a function of the consolidation characteristics of the earth material, the characteristics of the structure, and the loading conditions imposed upon it. The deformation and settlement potential for small structures is generally determined through a combination of field investigations and 1D settlement analysis (DNR 2001), which may require iteration following more detailed stability analyses.

\subsubsection{Stability Analyses}

The objective of a stability analysis is to ensure the horizontal, vertical, and rotational equilibrium of the structure is maintained under various loading conditions. Stability is attained primarily by ensuring the bearing capacity of the subsurface is not exceeded, and by designing to an adequate factor of safety against sliding, overturning, and flotation along critical potential failure planes and along the subsurfacestructure interface. A safety factor is generally defined as the ratio of resisting forces (gravity forces and soil/rock shear strength) to driving forces (gravity forces, hydrodynamic forces, shear stresses, uplift) along the potential failure surface under various loading conditions. Important concepts related to stability and the resisting forces of the subsurface include loading conditions, sliding, overturning, flotation, and seepage. 


\section{Loading Conditions}

An instream hydraulic structure is designed to resist both normal and extreme individual loads and load combinations during construction and normal operation. The basic loading conditions generally used in concrete gravity dam design and analysis are classified as normal (normal operation), unusual (construction loads, flood discharge during normal operation, earthquake during normal operation) or extreme (earthquake during construction, maximum credible earthquake during normal operation, probable maximum flood during normal operation) (USACE 1995). Loading conditions in both cases consist of the combined lateral, vertical, and uplift forces that are likely to occur. Estimation of the magnitude of these forces requires coordination across many disciplines and, in many cases, the use of models or analytical methods to predict probable maximum floods and earthquake stresses.

\section{Sliding}

Stability against sliding is obtained by ensuring the maximum resisting shear $\left(T_{F}\right)$ is greater than the applied shear $(T)$, by some factor of safety $(F S)$ along the slip plane between the structure and the subsurface. This ratio is expressed mathematically as

$$
F S_{\text {sliding }}=\frac{T_{F}}{T}=\frac{(N \tan \varphi+c L)}{T},
$$

where $N$ is the resultant of forces normal to the assumed sliding plane, $\varphi$ is the angle of internal friction, $c$ is the cohesion intercept, and $L$ is the length of base in compression for a unit strip of dam (USACE 1995). The minimum $F S$ against sliding may range from 1.1 to 2.0, depending on the loading condition and the phase of development (construction or normal operation) (Gulliver and Arndt 1991). A common practice to compute the sliding factor of safety is to use the $2 \mathrm{D}$ multiple wedge analysis and analyze the forces required to bring the structural wedge and the driving and resisting wedges into a state of horizontal equilibrium (USACE 1995). This calculation is depicted in Figure 6 for a conventional dam structure.

Sliding analysis is relatively well understood for conventional dam structures, and a variety of modeling tools are available to automate calculations and determine stability requirements for new structures, including commercial packages such as PLAXIS and ANSYS and Army Corps of Engineers programs including SOILSTRUCT, CSLIDE, and 3DSAD (USACE 2005). Two-dimensional models are used as a first step to investigate a structure; whereas 3D models are reserved for cases in which the ability of a structure to meet a factor of safety against sliding is deemed marginal, or when structural complexity negates the assumptions made in 2D modeling. FEA is routinely carried out in 2D and 3D models. 


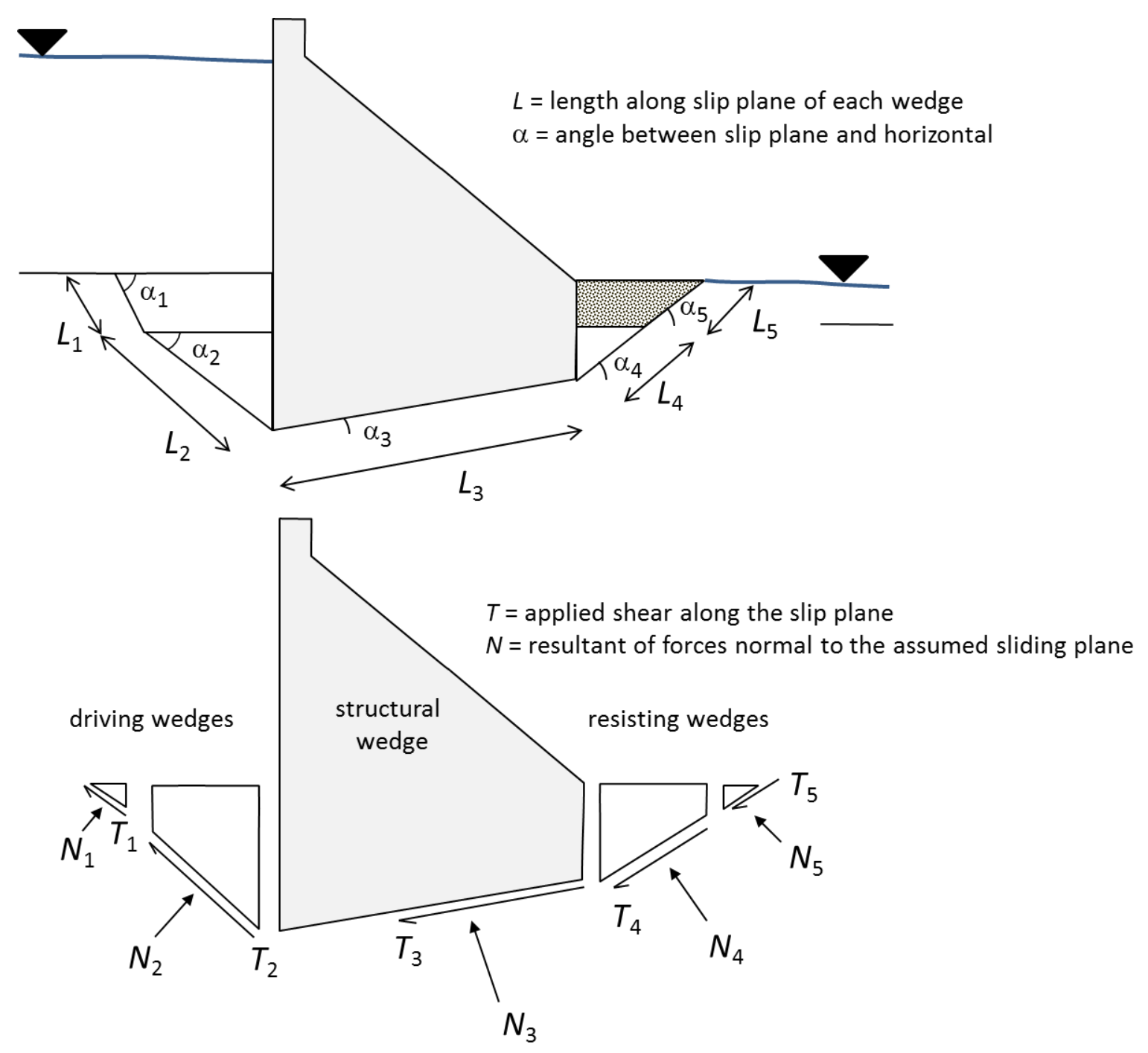

Figure 6. Geometry of structure-foundation system, showing driving, structural, and resisting wedges (adapted from USACE 1995).

\section{Overturning}

The requirement to maintain rotational equilibrium (i.e., stability against overturning) is achieved by constraining the permissible location of the resultant forces with respect to the potential failure plane. The sum of horizontal and vertical forces (resultant force) along a horizontal plane at the base of the dam must intersect the plane in the middle third to maintain compressive stresses in the structure (Figure 7). The risk of overturning increases significantly when the resultant falls outside the middle third of the base; thus, all potential loading conditions must be assessed in an overturning analysis.

For concrete gravity dams, the weight of the structure is designed to cause a moment that opposes the overturning moment, which is generally governed by hydrostatic pressure on the upstream side of the dam. Overturning failures can result from insufficient weight or weight distribution in the structure cross section, tensile cracking or erosion of the structure foundation, excessive uplift pressures, or high hydrostatic pressures. 


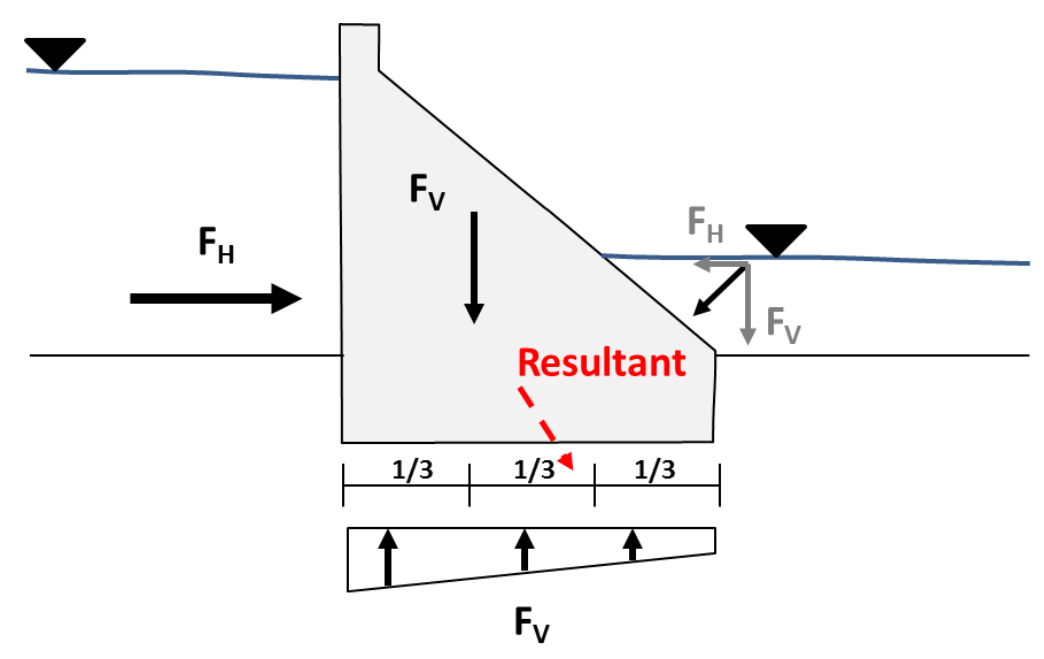

Figure 7. Resultant of a concrete gravity dam.

\section{Flotation}

Stability against flotation is achieved by ensuring that the vertical loads that can cause instability are balanced by the weight of materials that resist flotation. The factor of safety for flotation is expressed as

$$
F S_{\text {flotation }}=\frac{W_{S}+W_{C}+S}{U-W_{G}},
$$

where $W_{S}$ is the weight of the structure, fixed equipment, and soil above the top surface of the structure; $W_{C}$ is the weight of water within the structure; $S$ is surcharge loads; $U$ is uplift forces acting on the base of the structure; and $W_{G}$ is the weight of the water above the top surface of the structure (Figure 8)

(USACE 2005). Values for $F S_{\text {flotation }}$ range from 1.1 (extreme loading conditions) to 1.5 (normal loading conditions).

The geotechnical relevance of flotation stability lies in the estimation of uplift pressure, the upward water pressure in the pores of the rock or soil along the base of the structure that varies with time and the permeability of the material (USACE 1995). Uplift pressures are a function of the flow path under a structure, and they can have a significant impact on sliding stability, overturning, and flotation. Potential uplift pressure distributions should be determined from a seepage analysis (USACE 2005). Because of the small impoundments and low heads of SMH-type facilities, significant seepage and large uplift pressures are not expected, so flotation may not be a significant risk factor. However, conventional flotation stability analyses using conservative assumptions should still be carried out and would be most appropriate using hand methods or basic automated computer programs. 


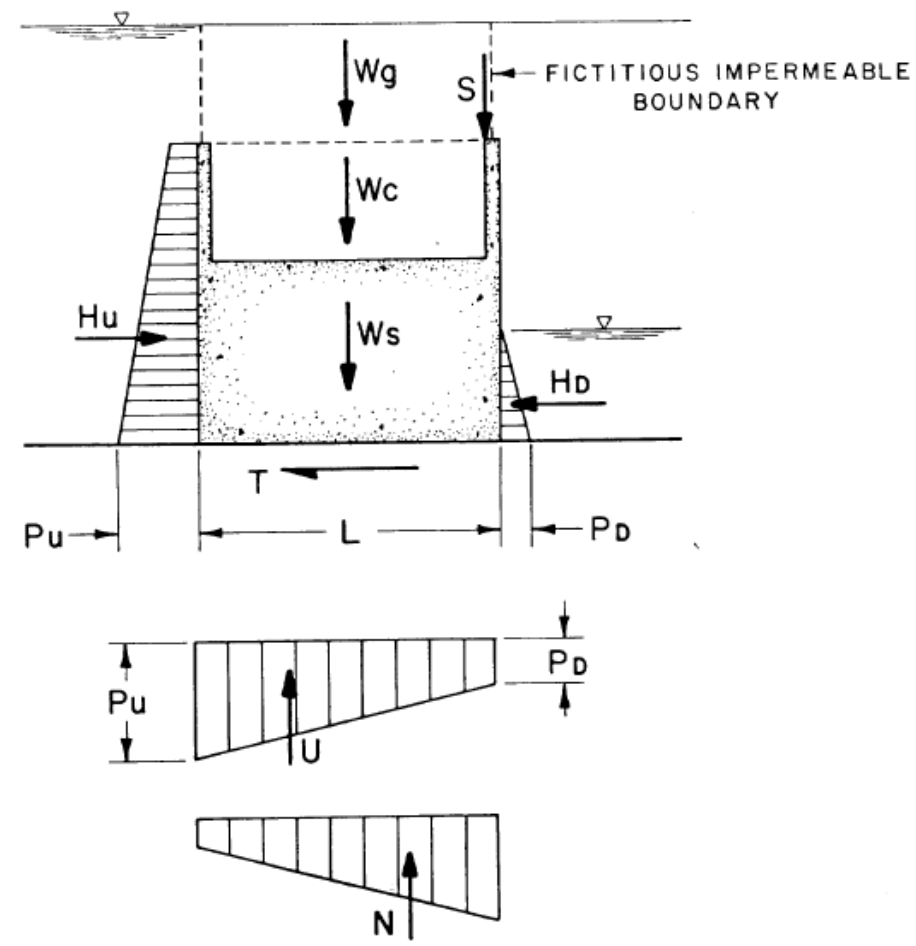

Figure 8. Generic geometry and loading conditions of a concrete gravity dam (USACE 1987). Additional terms in this illustration include lateral hydrostatic forces $\left(H_{U}, H_{D}\right)$, uplift pressure heads $\left(P_{U}, P_{D}\right)$, and the tangential component of the base reaction to horizontal loads $(\mathrm{T})$.

\section{Bank Mass Failure}

Mass failure of the river banks is often caused by two main mechanisms, slide failure and cantilever failure (Rinaldi and Darby 2008; Sutarto et al. 2014; Rinaldi et al. 2008). Slide failures relate to the movement of large masses of the bank across a flat plane, and cantilever failure is the rotational movement of a bank mass around a point of rotation. Assessment of bank mass failure from these two mechanisms involves the balance between the bank destabilizing forces, which are predominantly the weight of the bank soil and pore water pressure, and the stabilizing force, which is the bank soil shear strength. Bank mass failure is often accelerated by groundwater flow, which may increase the pore water pressure and thereby reduce the cohesive force of the soil. Another catalyst for bank mass failure is fluvial bank erosion, which over time may cause undercutting of the banks that in turn undermines bank stability, ultimately causing mass bank failure.

Bank mass failure occurs in the stream reach scale, which would roughly correspond to the site scale of the SMH framework. The spatial resolution for a bank mass failure model should be such that it can account for any variability in the bank soil properties and changes in the pore water pressure field. Bank mass failure is an episodic process occurring on the time scale of days. However, the occurrence of other catalytic processes that lead to bank mass failure, such as bank fluvial erosion and groundwater pore pressure fluctuations, may occur over larger time scales (e.g., months to a year), which a model would need to account for). The model temporal resolution would also need to account for these catalytic processes, which might require even hourly time steps. 
Models that can be used for modeling bank mass failure include CONCEPTS (Langendoen et al. 2001), SLOPE/W (Geoslope International 2001), and BSTEM. ${ }^{46}$

\subsubsection{Seepage Modeling}

Water ponded above a rock or soil foundation will seep through pores in the earth under a hydraulic gradient and travel under a structure. Seepage can undermine a structure by reducing the bearing capacity and shear resistance of the subsurface and by increasing uplift pressures and erosion. Seepage reduction techniques may be expensive and complex; therefore, site selection should seek to avoid locations with the potential for excessive seepage.

A seepage analysis relies on permeability data obtained from field and laboratory tests. Following subsurface characterization to determine soil/rock properties and boundary conditions, analytical models are used to determine critical seepage areas and pathways, including areas of excess pore pressure and high gradients (DNR 2001). Seepage analysis techniques used to determine uplift pressures and flow lines vary from basic analytical models that employ basic mathematical models and analytical methods in 1D and two dimensions (e.g., flow nets, line-of-creep method, method of fragments) to more complex finite element or finite difference methods in 3D. A description of various seepage methods and models is found in USACE (1993).

\subsubsection{Sediment Consolidation and Fluidization Modeling}

Reduction of transport capacity can cause settling of wash and suspended load, which consolidates under the action of its own weight, thereby increasing the porewater pressure that in turn initiates upward movement of water (Font et al. 1992; Vesilind and Jones 1993; Diplas and Papanicolaou 1997; Li and Mehta 1998). This upward water movement can balance the soil submerged weight and thereby cause the soil to lose its bearing capacity (Das 1997), which may in turn cause existing SMH structures to settle or make the soil unsuitable for placement of new SMH structures. Furthermore, in highly cohesive sediments, the upward movement of water causes the formation of pipes; these significantly increase the hydraulic conductivity of the sediment bed and may entrain chemicals and gases into the sediment bed surface, where they are released into the water column (Vesilind and Jones 1993; Tsakiris and Papanicolaou 2016). Pipe dynamics remain unknown to date; this knowledge gap is discussed in more detail in Section 5.

Self-weight consolidation and the resulting fluidization are processes that predominantly take place at the site scale of the SMH framework, specifically at areas where suspended material tends to settle out of suspension. Modeling self-weight consolidation requires relatively fine spatial resolutions, often on the order of $1 \mathrm{~mm}$ (Diplas and Papanicolaou 1997). Depending on the sediment bed properties, the consolidation phenomenon may last for several months; and its modeling requires time steps on the order of seconds.

Self-weight consolidation occurs predominantly in the vertical direction, so it is primarily a 1D process. It is possible, however, that the upward water movement requires a $2 \mathrm{D}$ model.

There are few numerical models for self-weight consolidation. The models of Diplas and Papanicolaou (1997) and Gibson et al. (1981) are two representative models. Moreover, as discussed in Section 5 of this report, very few models for fluidization and piping in such settings exist, making this process a key challenge for $\mathrm{SMH}$.

\footnotetext{
${ }^{46}$ www.ars.usda.gov
} 
Geotechnical processes for SMH refer to those loading conditions and responses of the SMH structure, particularly for the foundation module, that are important. These geotechnical processes occur at the facility and module level and

The geotechnical characteristics of a site determine the extent of modeling and analysis needed to ensure the stability of a hydropower facility. Any stability model will require, as inputs and boundary conditions, specific parameters obtained from a rigorous field or laboratory investigation, and close coordination with a geotechnical specialist. Stability analysis methods for gravity dam structures are well documented, ${ }^{47}$ and generally rely on the gravity method, which assumes the dam is a 2D rigid block interacting with the subsurface (FERC 2017). To the extent that SMH foundations are analogous to conventional concrete dam structures, these methods may be suitable. Advanced finite element methods are generally used for irregularly shaped structures; they permit explicit modeling and analysis of the interactions between the structure and the subsurface. It is likely these methods will be relied upon to assess disruptive SMH foundations that consist of smaller footprints, minimal design, and modular assembly and that rely on forces other than weight (i.e., they do not consist of a large concrete mass) to ensure global force and moment equilibrium are satisfied.

The SMH approach hypothesizes that increased standardization of design can result in the modular assembly of foundation elements at low cost and low impact. With that in mind, and in the context of the discussion in this section, the basic geotechnical modeling needs for SMH are as follows:

- Models to assess the stability of reduced-weight (non-concrete) structures on a limited class of different soil/rock types

- Models to classify soil or rock types that are most favorable for modular foundations

- Models to assess the stability of piling mechanisms that support generation and passage modules

- Models that take into account the dynamic operation of multiple movable gates

\subsection{ELECTROMECHANICAL PROCESSES}

Electromechanical processes are those associated with the conversion of mechanical power to electrical power. In the context of SMH, mechanical power is provided to the generator shaft as the turbine converts hydraulic power from water flowing through the generation module. For the purposes of demarcating modeling boundaries, we consider the electromechanical process to begin with the flow of mechanical power into the generator shaft and end with the flow of electrical power out of the generation module.

The generator is the central element of the electromechanical energy conversion process. Optimizing the cost and reliability of the generator requires modeling electromagnetic, thermal, and mechanical performance. In real systems, these three processes occur on different time scales and are coupled with varying degrees of rigidity. In addition, power electronics and digital controls are used in variable-speed generator applications, and they require a distinct modeling regime that includes a distinct set of simulation tools. The amount of coupling in this type of multiphysics modeling approach can refer to how often the information is passed between modeling domains. For example, since thermal systems have a much larger time constant than electromagnetic systems, many iterations or time-steps of the electromagnetic model can be solved before results are fed to the thermal model. Coupling can also refer to how closely the models correlate. For example, electric motors and generators can be modeled with varying degrees of accuracy, ranging from simple analytical expressions to detailed electromagnetic FEA implemented in a 2D or 3D simulation space. Similarly, thermal models can be represented with varying levels of accuracy, from lumped analysis techniques to full spatial models in 2D or 3D simulation space. The electromagnetic and thermal models would be considered highly coupled if the thermal and

\footnotetext{
${ }^{47}$ An extensive list of geotechnical modeling programs is found at http://www.ggsd.com/
} 
electromagnetic models directly passed results (e.g., spatial loss distribution from electromagnetics model to thermal model) associated with the $2 \mathrm{D}$ or 3D simulation space. The degree to which models of distinct processes in the electromechanical power conversion system are coupled depends on the goals of a particular simulation. In this section, the following modeling areas for electromechanical processes are discussed:

- Electromagnetic Field Modeling

- Electromagnetic Loss Modeling

- Mechanical Modeling

- Thermal Modeling

- Power Electronics Modeling

\subsubsection{Electromagnetic Field Modeling}

The electromagnetic processes provide fundamental limitations on generator performance. Given a range of operating speeds and a power rating, magnetic limitations guarantee generators will fall in a predictable range of sizes. The electromagnetics also determine a large portion of the system losses and can create or excite vibrational modes and non-ideal radial forces on the rotor. For these reasons, a model of the electromechanical energy conversion process usually begins with an electromagnetic model of the generator. The data resulting from the electromagnetic model are used as inputs to the other models. Occasionally, data produced from thermal and mechanical models may feed back into the electromagnetic model in an iterative fashion to more accurately determine performance ratings and material properties that depend on temperature and mechanical stress. Rarely will other models be fully coupled to the electromagnetic model, and then only to investigate very specific phenomena.

A fundamental understanding of generator operation can be gained through the use of magnetic circuits. Magnetic circuits model magnetic fields using bulk values of magnetic flux, magnetomotive force, and reluctance of the magnetic path. It is common to employ this approach for initial generator sizing. However, because of the inherent nonlinearity of magnetic materials and the strong dependence of generator performance on the spatial distribution of the magnetic fields, these modeling tools are usually insufficient for detailed generator design. More detailed modeling techniques are necessary for the development of generators with high performance and efficiency.

More generally, the physics of magnetism are governed by Maxwell's equations. Utility-level power conversion occurs at relatively low frequencies. As a result, various low-frequency approximations of Maxwell's equations are typically employed for generator modeling. In the context of Maxwell's equations, "low-frequency" means frequencies small enough that electromagnetic wave propagation can be safely ignored. For the evaluation of magnetic fields and flux densities in the generator core produced by static or low-frequency time-varying current/voltage waveforms, the magnetostatic approximation is employed. In particular, only Ampere's law and Gauss's law for magnetism are necessary to model static magnetic fields. For this approximation to be valid, the time scale of interest must be long enough that the diffusion of magnetic fields throughout the modeled domain can be assumed to occur instantaneously.

Because of the complex nature of computational domains involved with generator modeling and simulation, Maxwell's equations for magnetostatics are usually solved using finite elements. Twodimensional models using a cross-section of the generator are typical for initial design and optimization of the magnetic core and windings. More computationally expensive 3D models can be used for design refinement, taking into account end effects and additional leakage-flux. With care, magnetostatic models can give realistic estimates of generator power output capability. Some examples of commercial packages 
for magnetic FEA are ANSYS Maxwell, ${ }^{48}$ JSOL Corporation's JMAG,${ }^{49} \mathrm{COMSOL}^{50}$ Infolytica MagNet, ${ }^{51}$ and MagneForce. ${ }^{52}$

\subsubsection{Electromagnetic Loss Modeling}

Magnetostatic modeling can provide crude estimates of generator efficiency based on the winding losses, assuming the real effects of magnetic diffusion are small. However, this is not often the case. The losses in generator windings due to magnetic diffusion are more commonly understood as two separate phenomena, colloquially known as the "skin-effect" and "proximity-effect." The skin-effect is the tendency for the electrical currents to stay near the surfaces of conductors at high frequencies. The proximity-effect is the tendency of the electrical currents in adjacent conductors to redistribute in a nonuniform manner. In media with no forced electrical currents, such as silicon steel laminations, currents induced by a time-varying magnetic field are called "eddy currents." The severity of the eddy-current effect in ferromagnetic cores is the reason most generator stator and rotor cores are constructed from thin silicon steel laminations, ranging from 0.1 to $0.65 \mathrm{~mm}$ in thickness. Electrical steel also usually includes approximately $3 \%$ silicon content to reduce its electrical conductivity. Eddy currents also occur in permanent magnets, causing heating that degrades performance and increases the risk of demagnetization.

Faraday's law must be considered in modeling generators if the losses due to diffusion are significant. Together with Ampere's and Gauss's law for magnetism, this set of three equations gives the magnetoquasistatic approximation of Maxwell's equations. Similar 2D and 3D finite element models can be used to simulate the skin- and proximity-effect in electrical conductors if wire strands are modeled individually. This is more easily accomplished in two dimensions, which avoids the difficult 3D task of end turn modeling. Aside from finite-element models, analytical models exist to estimate the skin- and proximity-effects using the data produced by a set of magnetostatic simulations.

Eddy currents in the steel laminations are a 3D phenomenon. Because of the small thickness of the laminations compared with the total length of the generator, it is extremely computationally expensive to resolve this phenomenon with a full-fidelity model. Models of individual laminations or analytical equations may be used to attempt to estimate magnetic core eddy current losses.

In addition to eddy currents, magnetic hysteresis is another source of losses in ferromagnetic cores. Energy is required to change the magnetic state of a material, and because of grain boundaries, differing grain/lattice orientations, and defects in the crystal lattice, some energy is lost in the process. This lost energy results in the characteristic multivalued magnetic field/flux behavior of ferromagnetic materials observed on the macroscopic level.

Because of the difficulties inherent in the determination of magnetic core losses, simple models of eddy current and hysteresis losses based on measured data are commonplace. Steel manufacturers generally provided a limited set of loss data for their steel, usually at $50 / 60 \mathrm{~Hz}$ and a few flux density levels. For generators operating over wide speed ranges and varying load levels, this data may prove insufficient. Some commercially available software packages provide more detailed loss data for some materials, but it is often necessary for generator designers to take their own loss measurements. Steel samples in the form of either an Epstein frame or ring-core are characterized at various flux levels and frequencies. Magnetostatic finite-element simulation data can then be used in conjunction with the steel test data to estimate the magnetic core losses in the generator. The Epstein frame and ring-core tests may be

\footnotetext{
${ }^{48} \mathrm{http}: / /$ www.ansys.com/Products/Electronics/ANSYS-Maxwell

${ }^{49}$ https://www.jmag-international.com/

${ }^{50} \mathrm{https}: / / \mathrm{www} . \mathrm{comsol} . \mathrm{com} /$

${ }^{51} \mathrm{http}: / / \mathrm{www}$. infolytica.com/en/products/magnet/

$52 \mathrm{http} / / /$ www.magneforcess.com/
} 
considered models in the sense that the losses are determined for a simple system for which they are easily measured, and then extrapolated to a more complex system based on additional modeling data. The estimation of generator losses using empirical data and equations with finite-element simulation results is simply referred as "loss post-processing." It can be employed with varying degrees of accuracy, depending on the time allocated to fine-tuning the loss models.

\subsubsection{Mechanical Modeling}

Several distinct processes occur within the generator that fall in the mechanical domain. Centrifugal stress caused by rotation of the rotor is a key design constraint. Power-dense generator designs will tend to operate at speeds near the limit of mechanical reliability, as dictated by the mechanical strength and fatigue properties of the rotor steel. Vibration caused by electromagnetic forces can cause noise and reliability concerns and can propagate through coupled systems, causing issues elsewhere. Strong radial forces occurring as result of the electromagnetic interaction between the stator and rotor can be caused or amplified by manufacturing imperfections (rotor eccentricity, misalignment), which increase the bearing load and losses and decrease bearing life.

Stress and vibration phenomena in generators can be modeled using the equations of linear elasticity and their dynamic extensions. These equations are valid for small strain conditions. Since metals begin to yield at around $0.02 \%$ strain, the assumption of linear elastics is sufficient for the study of vibration and loading stress below failure. Fatigue caused by variations in mechanical load can cause a structural failure even when the material is operated below its yield strength. As a result, critical structural elements in the rotor are designed to operate well below yield stress (50\% or less) in the worst-case scenario.

For a baseline stress analysis of key structural elements, simple models can be developed using macroscopic forces and cross-sectional areas. These models assume uniform force distributions and are usually accurate enough for initial sizing and the rejection of obviously unfit designs. Real stress is distributed unevenly in generator rotors. In particular, stress tends to concentrate in corner regions where thin, highly loaded features transition to larger, lightly loaded features. Higher stress exists in these locations than would be predicted by simple bulk force analysis. Localized stress concentrations exceeding the yield strength of the material lead to the nucleation of local failures, which eventually propagate into a catastrophic global failure. Final designs should always be checked for such phenomena. Models for this behavior can be constructed using analytical equations, but FEA often provides a simpler and more reliable method of simulating non-uniform stress distributions. Vibrational analysis also can be performed using finite-element models.

Generator mechanical processes also contribute to the total losses of the power conversion processes. Losses due to the rotation of the rotor through a viscous fluid (air), called "windage," are one source of losses. Windage loss can be successfully modeled using analytical and empirical equations, whereas detailed analysis may require a CFD model. Bearing losses can cause a considerable decrease in efficiency and reliability if not properly addressed. Bearing manufactures typically provide methods of estimating bearing friction and losses, given loading information, which can be determined from electromagnetic and mechanical models.

\subsubsection{Thermal Modeling}

Modeling of losses in the electromechanical power conversion process is necessary for determining the overall generator efficiency. Losses also increase the operating temperature of the generator. High temperatures degrade the lifetimes of electrical insulation and bearings, reduce the performance of permanent magnets, increase winding resistance, impact magnetic and mechanical properties of lamination steel, and further decrease generator efficiency. Reliability concerns due to thermal issues reduce the overall performance of the generator below what would be dictated by the electromagnetic and 
mechanical constraints alone. It is common for generators to have both continuous and peak power ratings. The continuous rating is a power at which the generator can operate indefinitely without violating thermal constraints for a designed system lifetime. The peak rating is a level of power that can be converted by the generator for a short amount of time without drastically reducing the reliability of the generator. Therefore, it is necessary to study both steady-state and transient thermal processes. Thermal processes in the generator are governed primarily by heat conduction within and between the steel core, windings, bearings, and housing, and heat convection (natural and forced) from the end-turns, housing, and through/across the airgap between the generator stator and rotor.

Thermal circuits are a low-fidelity approach to modeling heat transfer within and away from the generator. In this method, all thermal conduction and convection processes are modeled using equivalent thermal resistances and capacitances. The accuracy of this approach depends critically on the size of the circuit and the ability to reliably translate material properties, geometric information, and empirical/analytical convection equations into lumped parameter elements.

Finite-element models in two and three dimensions can be used to model heat transfer using the heat equation. The simplest approach is to model all heat transfer processes using conduction. Combinations of empirical, analytic, and experimental methods are used to determine appropriate boundary conditions (heat transfer coefficients) and equivalent material properties (thermal conductivity, heat capacity) for fictitious materials representing convective processes. Otherwise, modeling of the thermal processes involves coupling heat conduction models to CFD models of the convective processes, requiring aspects of turbulence and transport modeling.

\subsubsection{Power Electronics Modeling}

Power electronics converters are used with variable-speed generators to convert alternating current (AC) power from the generator to AC power at the utility level (e.g., $60 \mathrm{~Hz})$. They typically achieve higher peak efficiencies than the generator alone, but they may have low efficiency in certain regions of the operational range. Therefore, modeling the power electronic losses is important for determining the overall system efficiency. A large portion of the space allocated to any power electronics system is dedicated to the cooling system; thus, the cooling system is a determining factor in the size and cost of the modules.

Given a voltage and current rating of the generator, power electronics modules and discrete devices/dies can be selected based on manufacturer data in conjunction with the design of a cooling system. This process may be iterative, especially if a custom module is being designed and packaged. For design and analysis of the cooling system, most of the methods described in the section on thermal modeling for generators apply. Manufacturer data on switching losses and on-state voltage and resistance can be used to construct empirical power electronic loss models based on expected generator output current/voltage waveforms.

More accurate power electronic loss estimates can be constructed through the use of nonlinear device models in an equivalent electrical circuit. Capturing parasitic inductances and capacitances in these equivalent circuits is important for accurately modeling switching losses and stray impedances of the converter. Nonlinearities and frequency dependencies in the generator inductance and resistance will also play a role in determining the overall switching behavior.

In actively controlled generators, it is desirable to keep the power electronics switching losses as low as possible. This usually means selecting the switching frequency to be as low as possible. When the switching frequency is very high compared with the fundamental electrical frequency of the generator, the behavior observed in the generator is very close to ideal. As the switching frequency is decreased, non- 
ideal effects of the inverter become more pronounced in the generator current waveforms. Predicting and achieving peak performance at low frequencies requires modeling the interaction between these two systems.

A directly coupled approach to modeling these interactions is to treat the generator as a generic nonlinear element in the electric circuit. A magnetostatic or magneto-quasistatic FEA simulation of the generator is performed whenever the circuit requires an evaluation of the generator voltage/current relationship. This can be quite computationally expensive given the small switching periods that must be resolved.

A different approach involves model order reduction from the magnetic finite-element models. A suitable set of finite-element simulations are performed before the circuit simulation. Appropriate bulk-parameter states are identified to construct a nonlinear circuit element model of the generator from the data. For example, results from electromagnetic FEA simulations can be used to define a nonlinear lookup table of flux linkage or inductances/impedances as functions of current and relative rotor position, for use in a modeling environment in which the power electronics converter and generator are simulated together without running an FEA simulation each time-step. Although this method lacks some of the fidelity of a directly coupled approach, it can dramatically reduce the computational time.

\subsection{ECONOMIC PROCESSES}

Economic processes are "activities, actions, and operations that involve the production and sale of goods and services" (NASA 1996). In a hydropower context, economic processes can be quite diverse and require a wide range of modeling capabilities. At the heart of all economic processes is the influence of human behavior across various systems. Human behavior drives all aspects of the economy; and for hydropower, socioeconomic drivers influence how raw materials and services are valued and what value is placed on renewable electricity sources.

Economic processes influencing SMH and other small hydropower development are a byproduct of project design characteristics, power system arrangements, and regional and market conditions. At a base level, economic processes can be simulated using both cost modeling and financial modeling. Before ground is broken on a small hydropower project, a full life-cycle cost-benefit analysis should be conducted to adequately simulate long-term project feasibility. To conduct such an analysis and offer useful insight, sufficiently complex cost and financial modeling is needed. This section is subcategorized into Cost Modeling (Section 4.8.1) and Financial Modeling (Section 4.8.2).

\subsubsection{Cost Modeling}

Cost modeling typically involves the use of mathematical or parametric techniques to estimate the cost of a product or process. In a hydropower context, cost modeling is further refined herein into project development cost modeling and operations and maintenance $(\mathrm{O} \& \mathrm{M})$ cost modeling.

\section{Project Development Cost Modeling}

Project development cost modeling involves the costing of various project development features based on the physical, regulatory, and financial costs incurred during project development. These pre-operational costs are also referred to as initial capital costs (ICC) and are classified in O'Connor (2015a) into three subcategories: generating plant costs, balance-of-station costs, and financial costs.

For most traditional small hydropower development, project development costs (roughly 75\%; O'Connor et al. 2015b) stem from civil works and electromechanical equipment requirements. Traditional hydropower project development requires a significant amount of civil works to support water 
conveyance, energy extraction and control (usually within a powerhouse), site preparation, and other essential project functions. More information on hydropower design and cost estimation and relevant literature is found in O'Connor et al. (2017).

Although various existing tools attempt to estimate overall project costs using parametric approaches (e.g., O'Connor et al. 2015b), more refined modeling can offer increased estimation accuracy. It is needed to model the specific cost components that drive small hydropower development. Recent and ongoing DOE-funded research led by ORNL has resulted in the development of an integrated design and economic assessment model (IDEA), which attempts to provide both design and cost estimation for hydropower and offers volumetric cost modeling where available (O'Connor et al. 2017). By following a volumetric costing approach, many of the site-specific considerations that drive hydropower ICC can be more explicitly modeled.

In addition to the design-driven capital costs required to construct a hydropower facility, many financial and soft costs must be incurred to move a facility from design to reality. Chief among these are the costs to finance and insure a project during construction and to obtain the necessary regulatory permits and licenses to begin construction and operation.

For SMH development, many design elements may differ from traditional hydropower applications and may make use of nontraditional materials or construction practices. Generation and passage modules using standard designs and manufacturing may offer reduced material and labor costs and could greatly reduce construction timelines and costs through offsite manufacturing and assembly. Foundation modules that reduce the need for structural assembly and make use of locally sourced materials also offer opportunities to decrease costs. Standard approaches to review plans, site permitting, environmental and safety certifications, and testing offer significant opportunity to reduce overall project development costs.

Much of the cost modeling involved in SMH project development will be driven by design-specific considerations and the associated installation and regulatory requirements. As standard designs, installation, and regulations are realized, such modeling will offer much value to project developers, investors, and other stakeholders.

\section{O\&M Cost Modeling}

In addition to the up-front ICC associated with developing a hydropower project, ongoing O\&M imparts ongoing costs for a project to help ensure the safe and reliable operation of a facility.

Unlike fossil energy sources, hydropower and other renewables incur no fuel cost and therefore have relatively low O\&M costs. A few onsite electric-driven services are needed to support facility operations, such as lighting, communications, active controls and maintenance (e.g., gate control and trash raking), and environmental management (e.g., DO infusers).

For long-term maintenance, hydropower facilities and components require periodic rehabilitation and replacement. Electromechanical equipment, for instance, may require annual or semi-annual maintenance and may require more intense rehabilitation or replacement over the course of a few decades. Controls and electrical equipment may also need to be replaced every decade or so, and other civil works (e.g., water conveyances and structures) may be rebuilt once or twice a century (Zhang et al. 2012).

In the event of extreme events (e.g., floods or earthquakes), structural damage may occur and require reconstructive maintenance. 
Understanding the O\&M requirements for SMH designs is critical to successful project planning, and the ability to reasonably model the O\&M costs offers improved assurance of successful facility development and operation.

\subsubsection{Financial Modeling}

Like cost modeling, financial modeling typically involves the use of mathematical or parametric techniques and is used to estimate how economic drivers influence prices, interest rates, markets, and so on. In a hydropower context, financial modeling is further refined herein into operational modeling, power system modeling, and electricity market modeling.

\section{Operational Modeling}

Hydropower plays an important role in providing renewable energy and does so as a part of the broad stream ecosystem. The presence and operation of a hydropower facility can influence water management in a number of ways. Bonnet et al. (2015) describe how hydropower-producing reservoirs offer multipurpose benefits through various end uses, including power generation, navigation, flood control, recreation, municipal water supply, and irrigation. Although SMH facilities are envisioned as run-of-river facilities without significant storage reservoirs, the quantity of water available for hydroelectric power generation is an important operational consideration that requires modeling. The amount of electricity generated is a complex function of flow availability and environmental flow requirements and must ensure non-generating flow requirements are met via non-generation module flow.

Being able to accurately model the operation of a SMH facility, particularly the electricity generated via generation modules, is critical to estimating potential project revenue.

\section{Power System and Electricity Market Modeling}

To understand a hydropower facility's role in the broader power system and electricity market, modeling may be required. Interconnection and transmission models help simulate the conditions in which hydroelectricity is used. The system's power mix and loading conditions help determine how reliably end-user needs are being met and whether a hydropower facility's energy production may serve baseload or peaking services. In some cases, the ancillary services (e.g., frequency regulation and operating reserves) and other benefits offered by hydropower are not "readily quantifiable or financially compensated in today's market framework" although "improved market structures and compensation mechanisms could more appropriately incentivize new and existing hydropower for the numerous services and benefits it provides" (DOE 2016).

As power demand increases, hydroelectric power production via run-of-river SMH facilities can offer a reliable source of increased capacity. Ultimately, the power system and electricity market conditions need to be understood before accurate electricity sale estimates can be provided. Models that simulate these conditions are important for widespread SMH development.

On a project or regional scale, understanding the electricity market structure — such as day-ahead, hourly, and subhourly pricing - is an important facet of revenue estimation. A power purchase agreement may also be put in place to set guidelines for anticipated power production and transfers.

Although hydropower financial modeling can be quite complex, many project developers rely upon estimated metrics to help inform the likelihood of feasibility. Models that simulate ICC, O\&M, and revenue can be used to estimate the benefits-cost-ratio, net present value, internal rate of return, levelized cost of energy, and other metrics (Zhang et al. 2013). 


\subsection{INTERACTION AND COUPLING}

Interactions and coupling of the processes discussed in Sections 4.1 through 4.8 can occur. To allow a more systematic examination of the interactions between the various processes and facilitate the assessment of their physical and modeled coupling, the interactions of the processes are distinguished as internal and external. The internal interactions are those within singular processes, e.g., hydraulic or geomorphologic, alone. In contrast, the interactions between singular processes and other singular processes, such as hydraulic and geotechnical, are referred to as external. This distinction between processes as internal and external interactions is made herein only to allow a more systematic examination.

\subsubsection{Internal Interaction and Coupling}

\section{Geomorphological Processes}

The internal interactions between geomorphological processes in Figure 9 are indicated with solid arrows that connect the geomorphological processes identified in Section 4.3. The direction of a solid arrow indicates the directionality of the interaction, with double arrows indicating a feedback interaction between the interacting processes. At the smaller spatiotemporal scales, textural changes can be influential for channel widening and narrowing and may contribute to channel metamorphosis at larger scales. Coarsening of the channel bed material, which can occur because of selective entrainment of the finer sediment and lack of sediment supply, could promote the erosion of the channel banks. Accelerated bank erosion can, in turn, lead to lateral migration and the development of channel meanders (Eke 2014). Fining of the river bed material is typically an outcome of deposition of the material transported in suspension. When this material aggrades near the banks of the river, it can lead to narrowing of the channel and ultimately to channel incision because the flow is concentrated in a narrow channel (Schmidt and Wilcock 2008). When deposition of the fine material occurs within the channel during lower-flow conditions, it can result in the formation of bars and islands, which ultimately contribute to braiding of the channel (Bridge 2003; Ashmore 2013).

Changes in the bed gradient are positively related to changes in the river transport capacity. By increasing the transport capacity, an increase in channel slope can lead to coarsening of the river bed through selective entrainment of the finer sediment, and thus to channel widening and meandering (Grant 2003; Schmidt and Wilcock 2008; Magilligan et al. 2013). On the contrary, a decrease in channel slope would generate a decrease in sediment transport capacity and hence the deposition of transported sediment, leading to fining of the bed material, narrowing, and even braiding. 


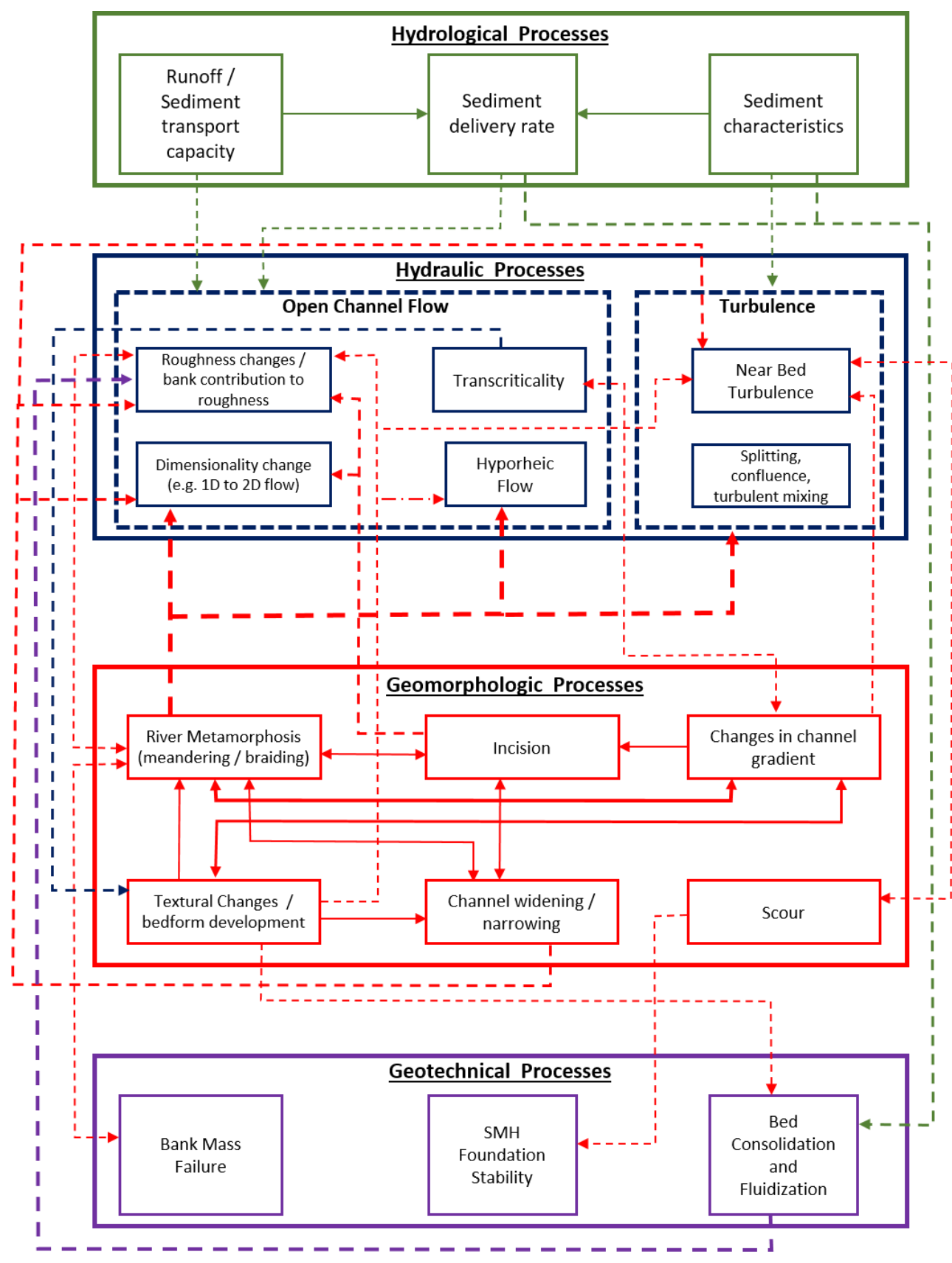

Figure 9. Interactions of the geomorphologic processes among themselves and with the hydraulic and geotechnical processes.

\subsubsection{External Interaction and Coupling}

\section{Geomorphological with Hydraulic Processes}

The majority of the external interactions of the geomorphological processes are with the hydraulic processes (Figure 9). The open channel flow, turbulence, and other hydraulic processes examined in Section 4.2 are the main drivers of sediment transport capacity and supply, the imbalance of which, in turn, triggers the geomorphologic processes examined in Section 4.5. However, this interaction is reciprocal - the geomorphologic processes also affect the hydraulic processes. At the smaller 
spatiotemporal scales, textural changes in the river bed surface (i.e., larger roughness elements or bedforms) alter the open channel flow hydraulics by altering the bed roughness through modifications in the skin friction and the addition of form roughness (Bridge 2003). Such textural changes are also known to affect the near-bed turbulence field, especially during coarsening and bedform formation. Under such conditions, the interaction of the flow with the protruding crests of the bed roughness elements and bedforms causes turbulent structures that alter the near the near-bed hydrodynamics (Detert et al. 2010; Hardy et al. 2010; Venditti 2013). Further river bed textural changes cause changes in the hyporheic flow patterns. For instance, bed coarsening and bedform development creates a complex subsurface pressure field that affects the transport of contaminants and intrusion of finer sediment (Papanicolaou et al. 2011).

Furthermore, changes in the river width, i.e. widening and narrowing, as well as incision and river metamorphosis, cause changes in the flow dimensionality (Nezu and Nakagawa 1993; Ferro 1999). Specifically, channel narrowing, incision, and meandering are processes that are known to introduce secondary flows and therefore make the flow $2 \mathrm{D}$.

Changes in bed channel gradient affect the flow regime and bed roughness. Channel steepening leads to supercritical flow regimes due to the increased flow velocity and reduced flow depth resulting from the increased bed slope. The change in the flow regime could in turn bring changes in the types of bedforms, as well as in the bed frictional characteristics (Recking et al. 2008). Typically, supercritical conditions are associated with increases of the friction factor (Millar 1999; Recking et al. 2008).

Successful prediction of the geomorphological changes at SMH facilities requires that the models employed by the simulation and modeling capability capture the feedback interactions between the geomorphological and hydraulic processes. Some key guidelines for modeling these interactions are given here, although detailed guidance is also available in more specialized literature. The models to be selected must have sufficient length scales to capture the flow dimensionality that causes these geomorphologic processes.

\section{Geomorphological with Geotechnical Processes}

The geomorphologic processes also have interactions with key geotechnical processes. For instance, the fluvial bank erosion that occurs during river meandering and channel widening is known to gradually undercut the toe of the river bank, promoting the probability of bank mass failures (Sutarto et al. 2014). Similarly, the occurrence of scouring around the SMH modules may expose the foundation module of the facility and compromise its stability. In addition, the settling and deposition of fine sediment when the sediment supply exceeds the transport capacity is known to cause consolidation of the sediment and subsequent fluidization.

\section{Fluid (Hydraulic)-Structural Processes-Hydroelasticity}

It is anticipated that one of the most substantial coupling constraints with regard to modeling SMH behavior will be the fluid-structure interaction (or hydroelastics) due to the wide methodological variability between solvers that model the fluid and the structure. Hydroelasticity considers the interaction of fluid dynamics forces, inertial forces, and elastic forces, and can be represented by a Collar triangle similar to one used in the field of aeroelasticity. Some interactions of interest in SMH generation modules can be classified as

1. Structural dynamics due to interaction of inertial and elastic forces

2. Static hydroelasticity due to interaction of hydrodynamic and elastic forces

3. Dynamic hydroelasticity due to the interaction of all three forces 
Traditionally, dynamic hydroelasticity (such as flutter) or static hydroelasticity (such as divergence) have not been significant concerns in hydropower applications because the runners (or turbines) are traditionally made of solid metal with relatively high stiffness.

In general, flutter is classified as a dynamic instability in which self-excited blade vibrations are amplified by hydrodynamic forces. A common way of modeling flutter involves modal analysis, which provides the dominant modes, shapes, and frequencies of vibration for a given design (and material used) and the solution of the hydrodynamic response due to these oscillations. A careful coupling of hydrodynamics and structural dynamics can provide insight into the nature of the damping provided by the fluid flow onto the structure. If the damping is negative, it indicates that the hydrodynamic force "feeds into" the vibrations of the blades, resulting in instability. If the hydrodynamic damping is positive, the result is dampening of the structural vibrations, indicating a stable state. This type of analysis is very common in aeroelasticity, and segregated solvers of structural dynamics and fluid flow are commonly used. The fact that segregated solvers for different physics can be used offers great flexibility to the designers. The fluid flow can be modeled using in-house research codes (offering special features that are customized particularly for SMH designs and applications), well-established open-source codes such as OpenFOAM ${ }^{53}$ and Stanford University's SU2 ${ }^{54}$ code, and commercial codes such as ANSYS-Fluent, ${ }^{55}$ Star-CCM $+{ }^{56}$, and others. Also available are a few codes, such as COMSOL Multiphysics,${ }^{57}$ that can model multiple physics in a fully coupled manner. In these codes, the structural dynamics can be coupled to CFD solutions in a monolithic fashion, via which the governing equations for both physics are discretized and solved at the same time and no interpolation/extrapolation (or lagging) is required in the coupling process. This approach may be helpful in some cases to eliminate the artificial energy - a potential source of numerical instability - generated by the segregated code coupling of the CFD and the computational structural dynamics solvers.

Another important phenomenon is wake/rotor interactions for generation modules that incorporate inlet guide vanes (IGVs). The wake of the IGV blades creates periodic forced excitations on the downstream rotor blades, and designers must ensure that the frequency of those excitations is away from the natural frequencies of the blades and does not have a catastrophic effect on the integrity of the rotor blades and the entire system. If unaccounted for, those forced excitations may cause undamped vibrations or may have long-term implications such as high cycle fatigue. In light of the possibilities for the use of new materials (e.g., composites) and additive and advanced manufacturing techniques, these hydroelastic problems (in addition to issues such as cavitation, surface degradation) should be considered.

\section{Electromechanical and Hydraulic Processes}

The electromechanical processes are mainly coupled to other systems through power flow and vibration. Any process that alters the power flow through the system is either directly or indirectly coupled to the generator. The degree to which power flow processes are coupled to the electromechanical processes depends roughly on physical proximity. Hydraulic processes at the watershed level affect the magnitude and timing of power flows over a relatively long time scale; they mostly serve to set limits on the range of boundary conditions (e.g., continuous power rating) that must be considered with respect to the electromechanical process models. Hydraulic processes occurring closer to the turbine blade have a more direct impact on the electromechanical processes. There may be a need, for example, to couple models of the turbine and the generator to determine how unsteady power flow and vibration produced by the turbine will impact the generator, particularly for smaller installations with relatively lower power ratings

\footnotetext{
${ }^{53} \mathrm{http}: / /$ www.openfoam.com/

${ }^{54} \mathrm{http}: / / \mathrm{su} 2$. stanford.edu/

$55 \mathrm{http}: / /$ www.ansys.com/Products/Fluids/ANSYS-Fluent

${ }^{56} \mathrm{http}: / / \mathrm{mdx}$.plm.automation.siemens.com/star-ccm-plus

${ }^{57}$ https://www.comsol.com/comsol-multiphysics
} 
and components with lower inertial masses. Coupled electromechanical modeling may also be needed to study acoustic noise, fatigue, and reliability, as the generator may excite vibration modes in the turbine and/or foundation module.

\section{Hydropower Operation and Ecological Response}

Much of the research exploring ecological responses to hydropower operations has been motivated by the restoration of environmental flows in highly regulated river systems (see, e.g., Poff and Zimmerman 2010). A regulated river alters the natural flow variability - magnitude, timing, duration, frequency, and rate-of-change - to varying degrees that have negative impacts on aquatic and riparian communities. In SMH type facilities that are hypothesized to operate as run-of-river with limited hydrologic alteration, water may be delivered downstream with the same variability as in the pre-development condition. The need to maintain natural flow variability will inform the sizing and operational strategies of passage modules and the types of generation modules suitable for a site. In theory, the full range of flows could be passed entirely by generation modules if they were capable of sustaining all stream functions at the site. Practically, a combination of passage and generation modules will be required.

The SMH facility itself may serve as a barrier to migrating and foraging species that navigate a river corridor and to sediment transport. In addition, ponding behind the facility may cause the inundation of riparian regions and a local habitat/flow regime shift from riverine to lacustrine. This shift may encourage invasive species or negatively impact the ecosystem functionality and habitat suitability. However, the degree to which the natural flow regime and ecology are altered may vary widely between designs and would be localized. Compared with conventional small hydropower designs (involving in-stream dams), SMH facilities should have significantly less impact on the surrounding environment. Facility design and complementary modeling must consider the likely responses of fish and other invertebrates to an instream barrier, as well as the movement of sediments that may form critical habitats in downstream reaches. 


\section{GAPS AND CHALLENGES}

Examination of the different processes described in Section 4 highlights some key knowledge gaps that need to be illuminated by further research if they are to be successfully implemented in a modeling effort. At the same time, some processes are well understood, but currently the tools are not available to systematically explore them within the context of hydropower projects; these are considered modeling gaps and challenges. Some of these key knowledge gaps and modeling gaps and challenges are presented in more detail in Sections 5.1 and 5.2.

To determine the necessary research path forward, Table 8 and Table 9 (Sections 5.1 and 5.2) are used to identify and rank the gaps and challenges, thereby informing the research priorities in Section 6. For each gap and challenge identified, the respective process or processes involved are noted. In addition, the impact that the gap or challenge has on informing decision making, design, and trade-off optimization activities for SMH is provided. The impact is noted as one or more of the metrics-safety, reliability, performance, and cost - used in developing "simulation use cases" in Section 3 and illustrated in Figure 2.

A qualitative assessment (low, medium, or high) is provided for each gap or challenge's anticipated significance of impact toward increasing SMH deployment. Those gaps or challenges ranked as "high" represent a more crucial barrier that is currently hindering or could possibly hinder successful development and deployment of SMH in the future. Logically, those ranked as "low" represent a less significant barrier to successful SMH deployment. Significant barriers to deployment are issues related to costs of equipment, materials, and installation methods for a standardized and modular paradigm. Time, as well as costs, related to environmental and biological regulatory studies also serve as significant barriers to deployment. These significant barriers hinder the incorporation and improvement of standardization with respect to design and application of modularity principles to the manufacturing and installation of SMH. In contrast, non-significant barriers to deployment are issues that do not have an immediate and substantial relationship to initial cost and installation, but may provide improved longterm performance and longevity of SMH installation and operation.

\subsection{Knowledge Gaps Summary}

"Knowledge gap" refers to the lack of understanding of the underlying physics of a known process, or a difficulty in identifying and quantifying relationships and behaviors associated with a process. Based on the review of processes and modeling capabilities in Sections 4.1 through 4.8 and process interactions in Section 4.9, knowledge gaps have been identified and tabulated in Table 8. A more detailed discussion of each of the identified knowledge gaps is provided in Appendix A.

Table 8. Summary of knowledge gaps

\begin{tabular}{|c|c|c|c|c|}
\hline Item & Knowledge gap & $\begin{array}{c}\text { Related categorical } \\
\text { process(es) }\end{array}$ & Impact to SMH & $\begin{array}{c}\text { Significance of } \\
\text { impact } \\
\text { (low, medium, or } \\
\text { high })\end{array}$ \\
\hline 1 & $\begin{array}{c}\text { Fish Behavior and Response-fish } \\
\text { motivation, behavior, and sensory } \\
\text { perception in hydraulic conditions }\end{array}$ & Ecological & Performance & High \\
\hline 2 & $\begin{array}{c}\text { Scour-scouring of } \\
\text { foundations/structures anchored to the } \\
\text { ground using both conventional and } \\
\text { unconventional techniques }\end{array}$ & $\begin{array}{c}\text { Geomorphologic/ } \\
\text { hydraulic }\end{array}$ & $\begin{array}{c}\text { Safety and } \\
\text { reliability }\end{array}$ & High \\
\hline
\end{tabular}




\begin{tabular}{|c|c|c|c|c|}
\hline 3 & $\begin{array}{c}\text { Non-traditional Material } \\
\text { Utilization-use of alternative (non- } \\
\text { concrete, non-steel) material for } \\
\text { modules, module interfacing, and } \\
\text { foundation anchoring }\end{array}$ & $\begin{array}{c}\text { Structural/hydraulic/ } \\
\text { geotechnical }\end{array}$ & $\begin{array}{c}\text { Performance/ } \\
\text { reliability/safety }\end{array}$ & High \\
\hline 4 & $\begin{array}{c}\text { Bank Erosion-In situ effects of } \\
\text { unsteady flow and meandering stream } \\
\text { effects on erosion }\end{array}$ & Geomorphologic & $\begin{array}{c}\text { Safety and } \\
\text { performance }\end{array}$ & Medium \\
\hline
\end{tabular}

\subsection{Modeling Gaps and Challenges Summary}

"Modeling gap" refers to the need for new or improved modeling methodologies and approaches for modeling a process or interaction of processes. "Modeling challenge" refers to the difficulty associated with the application and/or utilization of one or more models to the modeling of a process and/or interaction of processes. Process interactions generally require a methodology for using results from two different models, each of which may inform the other. Based on the review of processes and modeling capabilities in Sections 4.1 through 4.8 and process interactions in Section 4.9, the following modeling gaps and challenges have been identified with respect to the processes. They are listed in Table 9. A more detailed discussion of each of the identified modeling gaps and challenges is provided in Appendix A

Table 9. Summary of modeling gaps and challenges

\begin{tabular}{|c|c|c|c|c|}
\hline Item & Modeling gap/challenge & $\begin{array}{c}\text { Related categorical } \\
\text { process }(\mathrm{es})\end{array}$ & Impact to SMH & $\begin{array}{l}\text { Significance of } \\
\text { impact } \\
\text { (low, medium, } \\
\text { or high })\end{array}$ \\
\hline 1 & $\begin{array}{l}\text { Techno-Economic [Gap]-model } \\
\text { methodology to assess cost-benefit trade-offs } \\
\text { for various configurations and requirements for } \\
\text { modular facilities }\end{array}$ & All & Cost & High \\
\hline 2 & $\begin{array}{c}\text { Hydroelasticity of Composite Turbine } \\
\text { Blades [Gap]—assessing comprehensive } \\
\text { performance and integrity of composite } \\
\text { material blades }\end{array}$ & $\begin{array}{l}\text { Hydraulic/structural/ } \\
\text { economic }\end{array}$ & $\begin{array}{l}\text { Performance/cost } \\
\text { /reliability }\end{array}$ & High \\
\hline 3 & $\begin{array}{c}\text { Sediment Delivery from Watersheds } \\
\text { [Challenge] - high variability of watershed } \\
\text { characteristics and processes }\end{array}$ & $\begin{array}{l}\text { Geomorphologic/ } \\
\text { hydraulic }\end{array}$ & Performance & High \\
\hline 4 & $\begin{array}{c}\text { Fish Response Quantification to Hydraulic } \\
\text { Conditions [Gap]-laboratory modeling of } \\
\text { fish response to hydraulic conditions and } \\
\text { hydraulic modeling for appropriate flow } \\
\text { conditions }\end{array}$ & Ecological/hydraulic & Performance & High \\
\hline 5 & $\begin{array}{c}\text { Scour [Gap]-methodologies for predicting } \\
\text { scouring of foundations/structures in gravel } \\
\text { beds }\end{array}$ & $\begin{array}{l}\text { Geomorphologic/ } \\
\text { hydraulic }\end{array}$ & $\begin{array}{l}\text { Safety and } \\
\text { reliability }\end{array}$ & High \\
\hline 6 & $\begin{array}{c}\text { Stability of Non-concrete Structures } \\
\text { [Gap]-methodologies for assessing structures } \\
\text { made of alternative materials that do not use } \\
\text { weight and gravity as primary stabilizing } \\
\text { mechanisms }\end{array}$ & $\begin{array}{l}\text { Geomorphologic/ } \\
\text { structural }\end{array}$ & $\begin{array}{c}\text { Performance/ } \\
\text { safety/reliability }\end{array}$ & High \\
\hline
\end{tabular}


Table 9. Summary of modeling gaps and challenges (continued)

\begin{tabular}{|c|c|c|c|c|}
\hline Item & Modeling gap/challenge & $\begin{array}{c}\text { Related categorical } \\
\text { process(es) }\end{array}$ & Impact to SMH & $\begin{array}{l}\text { Significance of } \\
\text { impact } \\
\text { (low, medium, } \\
\text { or high })\end{array}$ \\
\hline 7 & $\begin{array}{l}\text { Streamflow Synthesization [Gap]- } \\
\text { hydrologic modeling for development of } \\
\text { streamflow estimates at ungauged streams }\end{array}$ & Hydrologic & $\begin{array}{l}\text { Cost and } \\
\text { performance }\end{array}$ & High \\
\hline 8 & $\begin{array}{l}\text { Upland Erosion and In-stream Hydraulic } \\
\text { and Morphodynamics [Challenge]- } \\
\text { coupling of process-independent models while } \\
\text { maintaining spatiotemporal scale consistency } \\
\text { and model interface congruency }\end{array}$ & $\begin{array}{l}\text { Geomorphologic / } \\
\text { hydraulic }\end{array}$ & Performance & Medium \\
\hline 9 & $\begin{array}{c}\text { Generator and Power Converter } \\
\text { [Challenge]—accurate modeling of losses, } \\
\text { magnetic-related manufacturing effects, and } \\
\text { thermal effects }\end{array}$ & Electromechanical & $\begin{array}{l}\text { Performance and } \\
\text { cost }\end{array}$ & Medium \\
\hline 10 & $\begin{array}{l}\text { Ensemble Averaging [Gap]—accounting for } \\
\text { the effects of processes occurring at different } \\
\text { spatiotemporal scales by ensemble averaging } \\
\text { (upscaling) the effects of processes occurring } \\
\text { on smaller scales }\end{array}$ & $\begin{array}{c}\text { Geomorphologic / } \\
\text { hydraulic }\end{array}$ & Performance & Low \\
\hline 11 & $\begin{array}{c}\text { Bank Erosion [Gap] —incorporating effects of } \\
\text { bank water pressure, weathering, and channel } \\
\text { geometry }\end{array}$ & $\begin{array}{c}\text { Geomorphologic / } \\
\text { hydraulic }\end{array}$ & $\begin{array}{l}\text { Safety and } \\
\text { reliability }\end{array}$ & Low \\
\hline
\end{tabular}




\section{RECOMMENDATIONS AND PRIORITIES}

Producing a successful SMH deployment will require the use of advanced simulation and modeling capabilities that effectively address the links and trade-offs between technical, environmental, and economic concerns. There are existing capabilities for modeling the basic processes outlined in this report. Knowledge and capabilities are currently lacking, however, for predicting, modeling, and simulating the coupled processes that an SMH facility will encounter. To achieve a better understanding of how standard modular designs can be deployed at many different sites, new simulation and modeling tools should be applied to model such processes across the facility, in different stream environments, and throughout the modular facility design life. Based on the summary of knowledge gaps and modeling gaps and challenges presented in Section 5, recommendations and priorities for research are presented in this section. Although the findings reveal several areas of research importance, those that currently serve as critical barriers to the design and deployment of SMH are included as recommendations.

The recommendations for research are presented as a list of priorities. Priorities are assessed based on the requisite dependence on the nature of the findings. For example, a modeling effort to assess technology and cost benefits and trade-offs based on the performance of manufactured components would first require the capability to assess the performance of a component before engaging the capability to assess a cost benefit and trade-off optimization. Based on the findings outlined in this report and the high-level priorities listed in Table 8 and Table 9, the following items for simulation and modeling capability research are recommended:

Table 10. Summary of recommended simulation and modeling capability research priorities

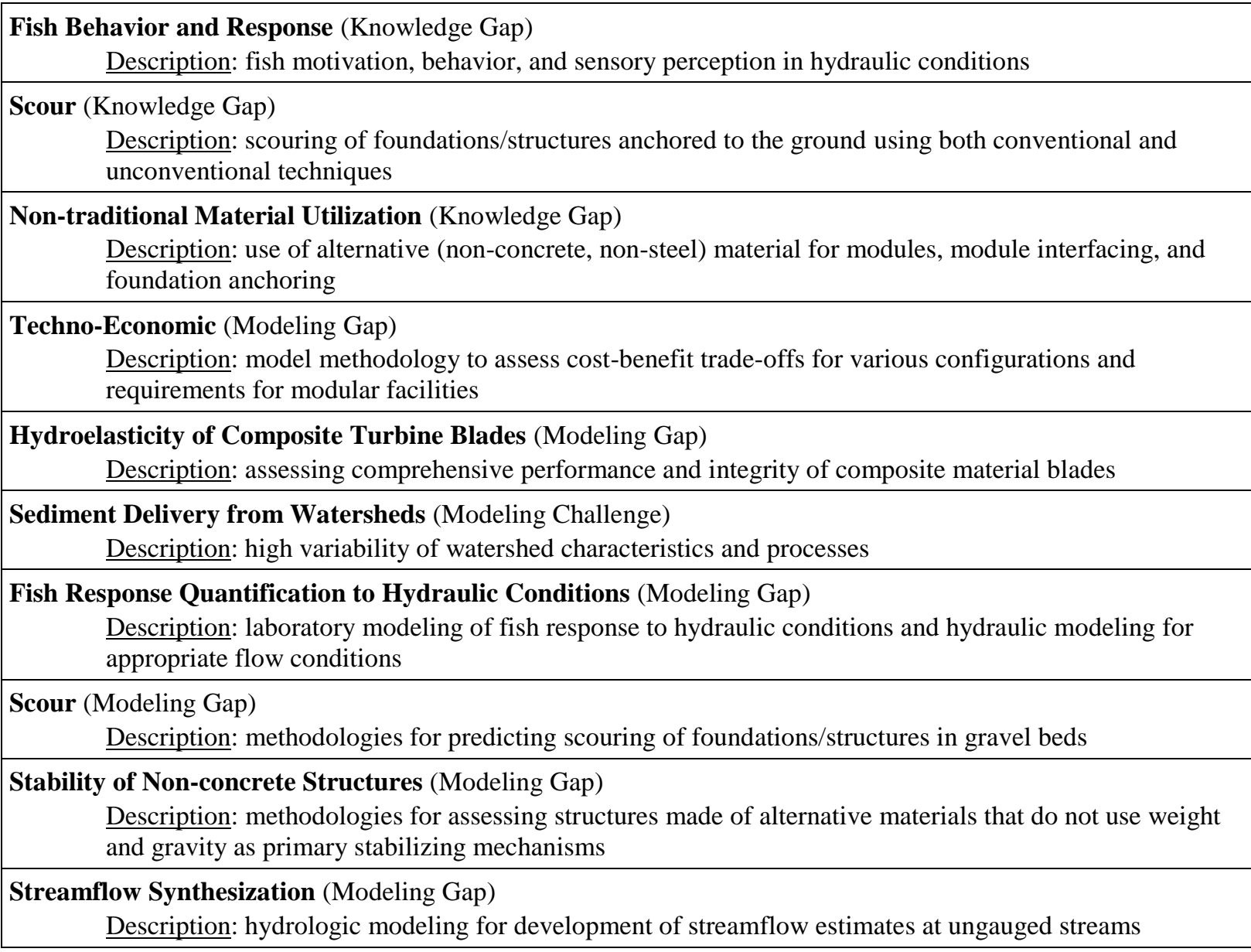





\section{REFERENCES}

Abban, B., Papanicolaou, A. N., Cowles, M. K., Wilson, C. G., Abaci, O., Wacha, K., Schilling, K., and Schnoebelen, D. 2016a. An enhanced Bayesian fingerprinting framework for studying sediment source dynamics in intensively managed landscapes, Water Resources Research 52, 4646-4673.

Abban, B., Papanicolaou, T., Cowles, K., Wilson, C., Abaci, O. and Wacha, K. 2016b. Towards a holistic model for simulating sediment dynamics at watershed scales: partitioning of sediment sources and uncertainty quantification, in EGU General Assembly Conference Abstracts 18, 912.

Abderrezzak, K. E. K., Moran, A. D., Tassi, P., Ata, R., and Hervouet, J. M. 2016. Modelling river bank erosion using a 2D depth-averaged numerical model of flow and non-cohesive, non-uniform sediment transport, Advances in Water Resources 93, 75-88.

Aksoy, H., and Kavvas, M. L. 2005. A review of hillslope and watershed scale erosion and sediment transport models, Catena 64(2), 247-271.

American Heritage 2005. American Heritage Science Dictionary, First Edition, Houghton-Mifflin Company, Boston.

Ashmore, P. 2013. Morphology and dynamics of braided rivers, pp. 289-312 in Volume 9, Fluvial Geomorphology, E. Wohl, ed., of Treatise on Geomorphology, J. Shroder, ed., Academic Press, San Diego.

Bailey, M. P., and Kemple, W. G. 1992. The scientific method of choosing model fidelity, in Proceedings of the 1992 Winter Simulation Conference, J. J. Swain, D. Goldsman, R. C. Crain, and J. R. Wilson, eds., Naval Postgraduate School.

Bennett, J. P. 1974. Concepts of mathematical modeling of sediment yield, Water Resources Research 10(3), 485-492.

Bensow, R., and Liefvendahl, M. 2008. Implicit and explicit subgrid modeling in LES applied to a marine propeller, 38th Fluid Dynamics Conference and Exhibit, Seattle, June 23-26.

Bevelhimer, M.S. 2002. A bioenergetics model for white sturgeon Acipenser transmontanus: Assessing differences in growth and reproduction among Snake River reaches. J. Applied Ichthyology 18(46):550 556.

Bevelhimer, M.S., and W.A. Bennett. 2000. Assessing cumulative thermal stress in fish during chronic intermittent exposure to high temperatures. Environmental Science and Policy 3:211-216.

Biswas, D. 2006. Studies on unsteady laminar-turbulent transition in a low pressure turbine flow Based on a higher order LES model, 36th AIAA Fluid Dynamics Conference and Exhibit, San Francisco, June 5-8.

Bonnet, M., Witt, A., Stewart, K., Hadjerioua, B., and Mobley, M. 2015. The Economic Benefits of Multipurpose Reservoirs in the United States-Federal Hydropower Fleet, ORNL/TM-2015/550, Oak Ridge National Laboratory, Oak Ridge, TN.

Brandt, A. 2000. A review of reservoir desiltation, International Journal of Sediment Research 15(3), 321-342.

Bridge, J. S. 2003. Rivers and Floodplains: Forms, Processes, and Sedimentary Record, John Wiley. 
Bunt, C. M., Castro-Santos, T., and Haro, A. 2012. Performance of fish passage structures at upstream barriers to migration, River Research and Applications 28(4), 457-478.

Campobasso, M. S., and Baba-Ahmadi, M. H. 2012. Analysis of unsteady flows past horizontal axis wind turbine airfoils based on harmonic balance compressible Navier-Stokes equations with low-speed preconditioning, Journal of Turbomachinery 134, 061020.

Castro-Santos, T., Cotel, A., and Webb, P. 2009. Fishway evaluations for better bioengineering: an integrative approach, American Fisheries Society Symposium 69, 557-575.

Chaluvadi, V. S. P., Kalfas, A. I., Banieghbal, M. R., Hodson, H. P., and Denton, J. D. 2001. Blade-row interaction in a high-pressure turbine, Journal of Propulsion and Power 17(4), 892-901.

Chen, J. P., and Whitfield, D. L. 1993. Navier-Stokes calculations for the unsteady flowfield of turbomachinery, AIAA Paper 93-0676, 31st Aerospace Sciences Meeting, Reno, Nevada, January 11-14.

Chen, J. P., Celestina, M. L., and Adamczyk, J. J. 1994. A new procedure for simulating unsteady flows through turbomachinery blade passages, paper 94-GT-151, ASME 1994 International Gas Turbine and Aeroengine Congress and Exposition, The Hague, Netherlands, July 13-16, American Society of Mechanical Engineers.

Cheng, G., Nichols, R., Neroorkar, K., and Radhamony, P. 2009. Validation and assessment of turbulence transition models, 47th AIAA Aerospace Sciences Meeting Including The New Horizons Forum and Aerospace Exposition, 29 volumes, Orlando, Florida, January 5-8, 1994.

Choi, W., Kim, J., and Park, G. 2016. Comparison study of some commercial structural optimization software systems, Structural and Multidisciplinary Optimization 685-699.

Chow, V. T. 1959. Open Channel Hydraulics, McGraw-Hill.

Coulthard, T. J., and Van De Wiel, M. J. 2013. Numerical modeling in fluvial geomorphology, pp. 694710 in Volume 9, Fluvial Geomorphology, E. Wohl, ed., of Treatise on Geomorphology, J. Shroder, ed., Academic Press, San Diego.

Cushman, R. M. 1985. Review of ecological effects of rapidly varying flows downstream from hydroelectric facilities, North American Journal of Fisheries Management 5(3A), 330-339.

Daly, C., Halbleib, M., Smith, J. I., Gibson, W. P., Doggett, M. K., Taylor, G. H., Curtis, J., and Pasteris, P. P. 2008. Physiographically sensitive mapping of climatological temperature and precipitation across the conterminous United States, International Journal of Climatology 28(15), 2031-2064. doi:10.1002/joc.1688.

Darby, S. E., Alabyan, A. M., and Van de Wiel, M. J. 2002. Numerical simulation of bank erosion and channel migration in meandering rivers, Water Resources Research 38(9).

Das, B. M. 1997. Principles of Geotechnical Engineering, PWS, Boston.

Denton, J. D. 1990. The calculation of three-dimensional viscous flow through multistage turbomachinery, paper 90-GT-19 in Volume 1, Turbomachinery, ASME 1990 International Gas Turbine and Aeroengine Congress and Exposition, American Society of Mechanical Engineers, Brussels, Belgium, June 11-14.

De Roo, A. P. J., Wesseling, C. G., and Ritsema, C. J. 1996. LISEM: A single-event physically based hydrological and soil erosion model for drainage basins, I: theory, input and output, Hydrological Processes 10(8), 1107-1117. 
Detert, M., Nikora, V., and Jirka, G. H. 2010. Synoptic velocity and pressure fields at the water-sediment interface of streambeds, Journal of Fluid Mechanics 660, 55-86.

Dey, S., and Raikar, R. V. 2005. Scour in long contractions, Journal of Hydraulic Engineering 131(12), 1036-1049.

Dinicola, R. S. 1990. Characterization and Simulation of Rainfall-Runoff Relations for Headwater Basins in Western King and Snohomish Counties, Report 89-4052, US Geological Survey, Washington, DC.

Diplas, P., and Papanicolaou, A. N. 1997. Batch analysis of slurries in zone settling regime, Journal of Environmental Engineering 123(7), 659-667.

Djeddi, R., Kaminsky, A., and Ekici, K. 2017. Convergence acceleration of fluid dynamics solvers using a reduced-order-model, AIAA Journal.

DNR (Department of Natural Resources). 2001. General Guidelines for New Dams and Improvements to Existing Dams in Indiana, Division of Water, Indianapolis, Indiana.

DoDD (Department of Defense Directive). 1995. DoD Modeling and Simulation (M\&S) Master Plan, Directive 5000.59-P.

DOE (Department of Energy). 2016. Hydropower Vision: A New Chapter for America's 1st Renewable Electricity Source, Office of Energy Efficiency and Renewable Energy Wind and Water Power Technologies Office, Washington, DC.

Eke, E. 2014. Numerical Modeling of River Migration Incorporating Erosional and Depositional Bank Processes, PhD dissertation, University of Illinois, Urbana-Champaign.

Ekici, K., and Hall, K. C. 2007. Nonlinear analysis of unsteady flows in multistage turbomachines using harmonic balance, AIAA Journal 45, 1047-1057.

Ekici, K., Hall, K.C., and Kielb, R. E. 2010. Harmonic balance analysis of blade row interactions in a transonic compressor, Journal of Propulsion and Power 26, 335-343.

Ettema, R., Nakato, T., and Muste, M. 2010. Estimation of Scour Depth at Bridge Abutments, report NCHRP 24-20, National Cooperative Highway Research Program, Transportation Research Board, Washington, DC.

Fancello, E. A., and Pereira, J. T. 2003. Structural topology optimization considering material failure constraints and multiple load conditions, Latin American Journal of Solids and Structures 1, $3-24$.

Feldman, A. D. 2000. Hydrologic Modeling System HEC-HMS Technical Reference Manual, US Army Corps of Engineers, Hydrological Engineering Center, Davis, CA.

FERC (Federal Energy Regulatory Commission). 2017. Engineering Guidelines for the Evaluation of Hydropower Projects, accessed online March 2017. https://www.ferc.gov/industries/hydropower/safety/guidelines/eng-guide/chap3.pdf

Ferro, C. E. 1999. Late Quaternary shift of mixed siliciclastic-carbonate environments induced by glacial eustatic sea-level fluctuations in Belize, pp. 385-411 in Advances in Carbonate Sequence Stratigraphy: Application to Reservoirs, Outcrops and Models, SEPM Special Publication 63, Society for Sedimentary Geology.

Flug, M., and R.H. Montgomery. 1988 Modeling instream recreational benefits. Water Resources Bulletin 24(5), 1073-1081. 
Font, R., Marcilla, A. F., and Zoffmann, C. 1992. Sedimentation batch test: application to deduce some parameters of aggregates in metal hydroxides suspensions, Powder Technology 71(3): 217-227.

Foster, G. R., and Meyer, L. D. 1975. Mathematical simulation of upland erosion by fundamental erosion mechanics, pp. 190-207 in Present and Prospective Technology for Predicting Sediment Yields and Sources, USDA Agricultural Service, Washington, DC.

Friswell, M. I., and Mottershead, J. E. 2013. Finite Element Model Updating in Structural Dynamics, Springer, Netherlands.

Garcia, M. H. 2008. Sedimentation Engineering: Processes, Measurements, Modeling and Practice, ASCE Manuals and Reports on Engineering Practice No. 110, American Society of Civil Engineers.

Gibson, R. E., Schiffman, R. L., and Cargill, K. W. 1981. The theory of one-dimensional consolidation of saturated clays. II. Finite nonlinear consolidation of thick homogeneous layers, Canadian Geotechnical Journal 18(2), 280-293.

Gibson, S., Simon, A., Langendoen, E., Bankhead, N. and Shelley, J. 2015. A physically-based channelmodeling framework integrating HEC-RAS sediment transport capabilities and the USDA-ARS bank-stability and toe-erosion model (BSTEM), Proceedings of the Joint Federal Interagency Conference 2015 (papers of the 5th Federal Interagency Hydrologic Modeling Conference and the 10th Federal Interagency Sedimentation Conference [SEDHYD 2015]).

Grams, P. E., Schmidt, J. C., and Topping, D. J. 2007. The rate and pattern of bed incision and bank adjustment on the Colorado River in Glen Canyon downstream from Glen Canyon Dam, 19562000, Geological Society of America Bulletin 119(5-6), 556-575.

Grant, G. E., Schmidt, J. C., and Lewis, S. L. 2003. A geological framework for interpreting downstream effects of dams on rivers, pp. 203-219 in A Peculiar River, J. E. O'Connor and G. E. Grant, eds., Water Science and Application Series Volume 7, American Geophysical Union.

Gulliver, J. S., Wilhelms, S. C., and Parkhill, K. L. 1998. Predictive capabilities in oxygen transfer at hydraulic structures, Journal of Hydraulic Engineering 124(7), 664-671.

Gulliver, J. S., and R. Arndt. 1991. Hydropower Engineering Handbook, McGraw-Hill.

Hagerty, D. J. 1991. Piping/sapping erosion, I: basic considerations, Journal of Hydraulic Engineering 17(8), 991-1008.

Hall, K. C., Thomas, J. P., and Clark, W. S. 2002. Computation of unsteady nonlinear flows in cascades using a harmonic balance technique, AIAA Journal 40(2002), 879-886.

Hallam, T.G., R.R. Lassiter, and S.M. Henson. 2000. Modeling fish population dynamics. Nonlinear Analysis 40, 227-250.

Hardy, F., Bariteau, L., Lorrain, S., Theriault, I., Gagnon, G., Messier, D. and Rougerie, J. F. 2010. Geochemical tracing and spatial evolution of the sediment bed load of the Romaine River, Quebec, Canada, Catena 81(1), 66-76.

He, L., and Ning, W. 1998. Efficient approach for analysis of unsteady viscous flows in turbomachines, AIAA Journal 36, 2005-2012.

Holmes, P., Lumley, J. L., and Berkooz, G. 1998. Turbulence, Coherent Structures, Dynamical Systems and Symmetry, Cambridge University Press. 
Holnbeck, S. R. 2011. Investigation of Pier Scour in Coarse-Bed Streams in Montana, 2001 through 2007, Scientific Investigations Report 2011-5107, US Department of the Interior, US Geological Survey.

Hooke, J. M. 2013. River meandering, pp. 260-288 in Volume 9, Fluvial Geomorphology, E. Wohl, ed., of Treatise on Geomorphology, J. F. Shroder, ed., Academic Press, San Diego.

Ikeda, M., 1987. Modeling interpretation of mesoscale meanders of the ice edge off the Labrador coast observed in NOAA satellite imagery, Journal of Physical Oceanography 17(9), 1468-1483.

Ikeda, S., Parker, G., and Sawai, I. 1981. Bend theory of river meanders, Part 1. Linear development, Journal of Fluid Mechanics 112, 363-377.

Jager, H., W. Van Winkle, K. Lepla, J. Chandler, and P. Bates. 2000. Population viability analysis of riverine fishes. Environmental Science \& Policy 3: S483-489

Jager, H.I., D.L. Peterson, D.Farrae, and M.S. Bevelhimer. 2013. A Population Model to Assess Influences on the Viability of the Shortnose Sturgeon Population in the Ogeechee River, Georgia. Transactions of the American Fisheries Society 142:731-746.

Johannesson, H. and Parker, G. 1989. Linear theory of river meanders, pp. 181-213 in River Meandering, Volume 12 of the Water Resources Monograph Series, American Geophysical Union.

Katopodis, C. 1992. Introduction to Fishway Design. Freshwater Institute, Canada Fisheries and Oceans, Winnipeg, MB, Canada, 68 p.

Kang, S., Borazjani, I., Colby, J. A., and Sotiropoulos, F. 2012. Numerical simulation of 3D flow past a real-life marine hydrokinetic turbine, Advances in Water Resources 39, 33-43.

Knighton, D. 1998. Fluvial Forms and Processes: A New Perspective, Routledge, New York.

Lagasse, P. F., Thompson, P. L., and Sabol, S. A. 1995. Guarding against scour, Civil Engineering 65(6), $56-59$.

Lane, E. W. 1955. Design of stable channels, Transactions of the American Society of Civil Engineers $120,1234-1260$.

Langendoen, E. J., Simon, A., and Thomas, R. E. 2001. CONCEPTS - a process-based modeling tool to evaluate stream-corridor restoration designs, pp. 1-11 in Wetlands Engineering and River Restoration, D. F. Hayes, ed., American Society of Civil Engineers.

Li, Y., and Mehta, A. J. 1998. Assessment of hindered settling of fluid mudlike suspensions, Journal of Hydraulic Engineering 124(2), 176-178.

Liang, X., Lettenmaier, D. P., Burges, S. J., and Wood, E. F. 1994. A simple hydrologically based model of land surface water and energy fluxes for general circulation models, Journal of Geophysical Research: Atmospheres 99, 14415-28. doi:10.1029/94JD00483.

Loper, M. L., and Register, A. 2015. Introduction to modeling and simulation, pp. 3-16 in Modeling and Simulation in the Systems Engineering Life Cycle, M. Loper, ed., Springer, Berlin.

Loperfido, J. V., Just, C. L., Papanicolaou, A. N., and Schnoor, J. L. 2010. In situ sensing to understand diel turbidity cycles, suspended solids, and nutrient transport in Clear Creek, Iowa, Water Resources Research 46(6).

Lucia, D. J., Beran, P. S., and Silva, W. A. 2004. Reduced-order modeling: new approaches for computational physics, Progress in Aerospace Sciences 40(1), 51-117. 
Luder, A. J., and Block-Jacobi, A. 2013. Time-Spectral Method for Incompressible Flow, PhD Dissertation, University of Michigan.

Magilligan, F. J., Nislow, K. H., and Renshaw, C. E. 2013. Flow regulation by dams, pp. 794-808 in Volume 9, Fluvial Geomorphology, E. Wohl, ed., of Treatise on Geomorphology, J. Shroder, ed., Academic Press, San Diego.

Marek, P., and Pustka, D. 2007. Probabilistic analysis of the durability of a concrete structure using the SBRA method, Slovak Journal of Civil Engineering 6(26), 6-12.

Martin, J. L., and McCutcheon, S. C. 1998. Hydrodynamics and Transport for Water Quality Modeling, Lewis Publishers, an imprint of CRC Press, Boca Raton, FL, p. 56.

Matsubara, Y., and Howard, A. D. 2014. Modeling planform evolution of a mud-dominated meandering river: Quinn River, Nevada, USA, Earth Surface Processes and Landforms 39(10), 1365-1377.

Melville, B. W., and Coleman, S. E. 2000. Bridge Scour, Water Resources Publications, Highlands Ranch, CO.

Merritt, W.S., Letcher, R. A., and Jakeman, A. J. 2003. A review of erosion and sediment transport models, Environmental Modelling \& Software 18(8), 761-799.

Millar, R. G. 1999. Grain and form resistance in gravel-bed rivers, Journal of Hydraulic Research 37(3), 303-312.

Morris, G. L., and Fan, J., 1998. Reservoir Sedimentation Handbook: Design and Management of Dams, Reservoirs, and Watersheds for Sustainable Use, McGraw Hill Professional.

Motta, D., Abad, J. D., Langendoen, E. J., and Garcia, M. H. 2012. A simplified 2D model for meander migration with physically-based bank evolution, Geomorphology 163, 10-25.

Munson, B. R., Young, D. F., and Okiishi, T. H. 1994. Fundamentals of Fluid Mechanics, 2nd edition, John Wiley.

NASA (National Aeronautics and Space Administration). 1996. Economic processes, Section 3.1 in Working Draft Framework, Version 2, Sustainable Development Indicator Group. https://www.hq.nasa.gov/iwgsdi/Economic_Processes.html

Nayfeh, A. H., and Pai, P. F. 2008. Linear and Nonlinear Structural Mechanics, Wiley-VCH.

Naz, B. S., Kao, S.-C., Ashfaq, M., Rastogi, D., Mei, R., and Bowling, L. C. 2016. Regional hydrologic response to climate change in the conterminous United States using high-resolution hydroclimate simulations, Global and Planetary Change 143, 100-117. doi:10.1016/j.gloplacha.2016.06.003.

Nestler, J. M., Goodwin, R. A., and Loucks, D. P. 2005. Coupling of engineering and biological models for ecosystem analysis, Journal of Water Resources Planning and Management 131(2), 101-109.

Nezu, I., and Nakagawa, H. 1993. Turbulence in Open-Channel Flows, IAHR/AIRH Monograph, CRC Press and several other publishers.

Nikora, V., Goring, D., McEwan, I., and Griffiths, G. 2001. Spatially averaged open-channel flow over rough bed, Journal of Hydraulic Engineering 1272, 123-133.

Nikora, V., McEwan, I., McLean, S., Coleman, S., Pokrajac, D., and Walters, R. 2007. Double-averaging concept for rough-bed open-channel and overland flows: theoretical background, Journal of Hydraulic Engineering 133(8), 873-883. 
NSF (National Science Foundation). 2006. Simulation-Based Engineering Science: Revolutionizing Engineering Science through Simulation, Report of the National Science Foundation Blue Ribbon Panel on Simulation-Based Engineering Science.

O'Connor, P. W., Zhang, Q. F., DeNeale, S. T., Chalise, D. R., and Centurion, E. 2015a. Hydropower Baseline Cost Modeling, ORNL/TM-2015/14, Oak Ridge National Laboratory, Oak Ridge, TN.

O'Connor, P. W., Zhang, Q. F., DeNeale, S. T., Chalise, D. R., Centurion, E., and Maloof, A. 2015 b. Hydropower Baseline Cost Modeling Version 2, ORNL/TM-2015/471, Oak Ridge National Laboratory, Oak Ridge, TN.

O'Connor, P. W., Chalise, D. R., and DeNeale, S. T. 2017. The Small Hydropower Integrated Design and Economic Assessment Model: Documentation and Selected Applications, ORNL/TM-2016/587, Oak Ridge National Laboratory, Oak Ridge, TN.

Odgaard, A. J. 1989. River-meander model, I: Economic feasibility assessment of small hydropower development, Journal of Hydraulic Engineering 115(11), 1433-1450.

Oñate, E. 2009. Basis and Solids, Volume 1 of Structural Analysis with the Finite Element MethodLinear Statics, Springer, Netherlands.

Osman, A. M., and Thorne, C. R. 1988. Riverbank stability analysis, I: Theory, Journal of Hydraulic Engineering 114(2), 134-150.

Oubeidillah, A. A., Kao, S.-C., Ashfaq, M., Naz, B. S., and Tootle, G. 2014. A large-scale, highresolution hydrological model parameter data set for climate change impact assessment for the conterminous US, Hydrology and Earth System Sciences 18, 67-84. doi:10.5194/hess-18-672014.

Papanicolaou, A. N., and Abaci, O. 2008. Upland erosion modeling in a semihumid environment via the water erosion prediction project model, Journal of Irrigation and Drainage Engineering 134(6), 796-806.

Papanicolaou, A. N., and Abban, B. 2016. Channel erosion and sediment transport, Chapter 65 in Handbook of Applied Hydrology, 2nd edition, V. P. Singh, ed., McGraw-Hill Education, ISBN-13:978-0071835091.

Papanicolaou, A. N., Bdour, A., and Wicklein, E. 2004. One-dimensional hydrodynamic/sediment transport model applicable to steep mountain streams, Journal of Hydraulic Research 42(4), 357-375.

Papanicolaou, A. T. N., Dermisis, D. C., and Elhakeem, M. 2011. Investigating the role of clasts on the movement of sand in gravel bed rivers, Journal of Hydraulic Engineering 137(9), 871-883.

Papanicolaou, A. N., Elhakeem, M., and Hilldale, R. 2007. Secondary current effects on cohesive river bank erosion, Water Resources Research 43, W12418. doi:10.1029/2006WR005763.

Papanicolaou, A. T. N., Elhakeem, M., Krallis, G., Prakash, S., and Edinger, J. 2008. Sediment transport modeling review-current and future developments, Journal of Hydraulic Engineering 134(1), $1-14$.

Parker, G. 1976. On the cause and characteristic scales of meandering and braiding in rivers, Journal of Fluid Mechanics 76(03), 457-480. 
Peck, E. L. 1976. Catchment Modeling and Initial Parameter Estimation for the National Weather Service River Forecast System, NOAA Technical Memorandum NWS HYDR0-31, Office of Hydrology, Washington, DC.

Poff, N. L., and Zimmerman, J. K. H. 2010. Ecological responses to altered flow regimes: a literature review to inform the science and management of environmental flows, Freshwater Biology 55(1), 194-205. http://www.wrb.state.ri.us/documents/Poff_Zimmerman_2009_FWB.pdf

Rajaratnam, N., Van der Vinne, G., Katopidis, C. 1986. Hydraulics of Vertical Slot Fishways, Journal of Hydraulic Engineering, 112(10), 909 - 927.

Recking, A., Frey, P., Paquier, A., Belleudy, P., and Champagne, J. Y. 2008. Feedback between bed load transport and flow resistance in gravel and cobble bed rivers, Water Resources Research 44, W05412. doi:10.1029/2007WR006219.

Richman, M., and Fleeter, S. 2000. Navier-Stokes simulation of IGV-rotor-stator interactions in a transonic compressor, AIAA Paper 2000-3379, 36th AIAA/ASME/SAE/ASEE Joint Propulsion Conference and Exhibit, Las Vegas, American Institute of Aeronautics and Astronautics.

Richmond MC and PDJ Romero-Gomez. 2014. "Fish passage through hydropower turbines: Simulating blade strike using the discrete element method." In IOP Conference Series: Earth and Environmental Science, vol. 22, no. 6, p. 062010. IOP Publishing.

Richmond MC, JA Serkowski, CL Rakowski, B Strickler, M Weisbeck, and CL Dotson. 2014. "Computational Tools to Assess Turbine Biological Performance." Hydro Review 33(6).

Rinaldi, M., and Darby, S. E. 2008. Modelling river-bank-erosion processes and mass failure mechanisms: progress towards fully coupled simulations, pp. 213-239 in Volume 11, Developments in Earth Surface Processes, H. Habersack et al., eds., of Gravel-Bed Rivers 6From Process Understanding to River Restoration, Elsevier, New York.

Rinaldi, M., Mengoni, B., Luppi, L., Darby, S. E., and Mosselman, E. 2008. Numerical simulation of hydrodynamics and bank erosion in a river bend, Water Resources Research 44(9).

Sanders, D., O’Brien, W., Sondergaard, R., Polanka, M., and Rabe, D. 2009. Turbulence model comparisons for mixing plane simulations of a multistage low pressure turbine operating at low Reynolds number, 45th AIAA/ASME/SAE/ASEE Joint Propulsion Conference and Exhibit, Denver, CO, American Institute of Aeronautics and Astronautics.

Schilt, C. 2007. Developing fish passage and protection at hydropower dams, Applied Animal Behaviour Science 104, 295-325.

Schmidt, J. C., and Wilcock, P. R. 2008. Metrics for assessing the downstream effects of dams, Water Resources Research 44(4).

Schumm, S. A. 1977. The Fluvial System, Wiley, New York, 338 pp.

Skalak, K., Benthem, A., Hupp, C., Schenk, E., Galloway, J., and Nustad, R. 2017. Flood effects provide evidence of an alternate stable state from dam management on the Upper Missouri River, River Research and Applications 33, 889-902.

Smith, B. T., Witt, A., Stewart, K. M., Lee, K., DeNeale, S., and Bevelhimer, M. 2017. A Multi-Year Plan for Research, Development, and Prototype Testing of Standard Modular Hydropower Technology, ORNL/TM-2016/102/R1, Oak Ridge National Laboratory, Oak Ridge, TN. 
Stewart, K. M., Smith, B. T., Witt, A., DeNeale, S., Bevelhimer, M., and Pries, J. 2017. Simulation and Modeling Capability for Standard Modular Hydropower Technology, ORNL/TM-2017/175, Oak Ridge National Laboratory, Oak Ridge, TN.

Sun, T., Meakin, P., and Jøssang, T. 2001. A computer model for meandering rivers with multiple bed load sediment sizes, 2. Computer simulations, Water Resources Research 37(8), 2243-58.

Sutarto, T., Papanicolaou, A. N., Wilson, C. G., and Langendoen, E. J. 2014. Stability analysis of semicohesive streambanks with CONCEPTS: coupling field and laboratory investigations to quantify the onset of fluvial erosion and mass failure, Journal of Hydraulic Engineering 140(9), 04014041. doi:10.1061/(ASCE)HY.1943-7900.0000899.

Suzen, Y., and Huang, G. 2005. Comprehensive validation of an intermittency transport model for transitional low-pressure turbine flows, The Aeronautical Journal 109(1093), 101-118.

Thornton, P. E., Running, S. W., and White, M. A. 1997. Generating surfaces of daily meteorological variables over large regions of complex terrain, Journal of Hydrology 190, 214-251. doi:10.1016/S0022-1694(96)03128-9.

Tian, W., Song, B., VanZwieten, J. H., Pyakurel, P., and Li, Y. 2016. Numerical simulations of a horizontal axis water turbine designed for underwater mooring platforms, International Journal of Naval Architecture and Ocean Engineering 8(1), 73-82.

Tootle, G. A., and Piechota, T. C. 2006. Relationships between Pacific and Atlantic Ocean sea surface temperatures and U.S. streamflow variability, Water Resources Research 42, W07411. doi:10.1029/2005WR004184.

Tsakiris, A. G., and Papanicolaou, A. N. 2016. Piping regimes in cohesive mud layers, American Geophysical Union Fall Meeting, San Francisco, December 12-16.

USACE (US Army Corps of Engineers). 1987. Flotation Stability Criteria for Concrete Hydraulic Structures, Engineering Technical Letter 1110-2-307.

USACE (US Army Corps of Engineers). 1992. Bearing Capacity of Soil, Engineering Manual 1110-1-1905.

USACE (US Army Corps of Engineers). 1993. Seepage Analysis and Control for Dams, Engineering Manual 1110-1-1901.

USACE (US Army Corps of Engineers). 1994. Rock Foundations, Engineering Manual 1110-1-2908.

USACE (US Army Corps of Engineers). 1995. Gravity Dam Design, Engineering Manual 1110-2-2200.

USACE (US Army Corps of Engineers). 2005. Stability Analysis of Concrete Structures, Engineering Manual 1110-1-2100.

Van Winkle, W., Rose, K.A., Shuter, B.J., Jager, H.I., Holcomb, B.D., 1997. Effects of climatic temperature change on growth, survival, and reproduction of rainbow trout: predictions from a simulation model. Canadian Journal of Fisheries and Aquatic Sciences 54, 2526-2542.

Venditti, J. G. 2013. Bedforms in sand-bedded rivers, pp. 137-162 in Volume 9, Fluvial Geomorphology, E. Wohl, ed., of Treatise on Geomorphology, J. Shroder, ed., Academic Press, San Diego.

Vesilind, P. A., and Jones, G. N. 1993. Channeling in batch thickening, Water Science and Technology 28(1), 59-65. 
Volmar, T. W., Brouillet, B., and Gallus, H. E. 2000. Time-accurate three-dimensional Navier-Stokes analysis of one-and-one-half stage axial-flow turbine, Journal of Propulsion and Power 6(2), $327-335$.

Walling, D. E. 1983. The sediment delivery problem, Journal of Hydrology 65(1-3), 209-237.

Wild, T. B., Loucks, D. P., Annandale, G. W., and Kaini, P. 2016. Maintaining sediment flows through hydropower dams in the Mekong River Basin, Journal of Water Resources Planning and Management 142(1), 05015004.

Williams, G. P., and Wolman, M. G. 1984. Downstream Effects of Dams on Alluvial Rivers, Professional Paper 1286, US Geological Survey.

Williams, J., Armstrong, G., Katopidis, C., Larinier, M., and Travade, F. 2012. Thinking like a fish: a key ingredient for development of effective fish passage facilities at river obstructions, River Research and Applications 28, 407-417.

Witt, A., Smith, B. T., Tsakiris, A., Papanicolaou, T., Lee, K., and Stewart, K. M. 2017. Exemplary Design Envelope Specification for Standard Modular Hydropower Technology, ORNL/TM2016/298/R1, Oak Ridge National Laboratory, Oak Ridge, TN.

Wu, W., and Wang, S. S. 2007. One-dimensional modeling of dam-break flow over movable beds, Journal of Hydraulic Engineering 133(1), 48-58.

Yershov, S., and Yakovlev, V. 2016. Influence of laminar-turbulent transition on 3D flow pattern in subsonic turbine cascade, presentation AIAA 2016-4552, 52nd AIAA/SAE/ASEE Joint Propulsion Conference, AIAA Propulsion and Energy Forum, American Institute of Aeronautics and Astronautics.

Zhang, Q. F., Smith, B., and Zhang, W. 2012. Small Hydropower Cost Reference Model, ORNL/TM2012/501, Oak Ridge National Laboratory, Oak Ridge, TN.

Zhang, Q. F., Uria-Martinez, R., and Saulsbury, B. 2013. Technical and Economic Feasibility Assessment of Small Hydropower Development in the Deschutes River Basin, ORNL/TM-2013/221, Oak Ridge National Laboratory, Oak Ridge, TN.

Zhang, Z., and Kleinstreuer, C. 2003. Low-Reynolds-number turbulent flows in locally constricted conduits: a comparison study, AIAA Journal 41(5), 831-40. 



\section{APPENDIX A. TOPIC DISCUSSION OF KNOWLEDGE GAPS AND MODELING GAPS AND CHALLENGES}

Following from the summary of the gaps and challenges presented in Sections 5.1. and 5.2, this appendix contains more comprehensive discussion regarding the specific gaps and challenges identified.

\section{Fish Behavior and Response for Fish Passage}

A prime example of the intersection of hydraulic, hydrologic, ecologic, and economic requirements is the challenge of fish passage design. The ideal fishway has been described as having the following characteristics

(1) any individual of any native species wishing to move upstream or downstream must be able to enter the fishway without experiencing any delay; (2) entry is immediately followed by successful passage, with (3) no temporal or energetic costs and (4) no stress, disease, injury, predation, or other fitness-relevant costs associated with passage. (CastroSantos et al. 2009)

These objectives are rarely achieved individually or in tandem in the field; fishway performance varies significantly among fishway types and among species within fishways (Bunt et al. 2012). Further, there are very few relevant empirical studies on fish motivation, behavior, and sensory perception that can be used to validate fish attraction and passage efficacy (Schilt 2007). Williams et al. (2012) suggest the greatest improvements in fish passage efficacy have come from research that identifies how fish react to well-defined hydraulic conditions - both those they avoid and those they seek. Effective fish passage module research and development must contain an element of laboratory testing to quantify fish reaction to hydraulic conditions, and it must be supported by detailed hydraulic modeling to assess how these conditions can be achieved through modular configurations.

\section{Scour}

Most past research on scour around hydraulic structures, such as those that would be encountered in an SMH facility, has been focused on sand bed river settings (Melville and Coleman 2000). Only a few studies have investigated scour around hydraulic structures in gravel bed rivers (Dey and Raikar 2005; Holnbeck 2011); the lack of research has created a significant knowledge gap and a lack of analytical models and formulas for scour prediction in gravel bed rivers. Because of this gap, some efforts have concentrated on correcting the predictions of scour formulae developed for sand bed rivers to provide more accurate scour depth estimates in gravel bed rivers. Despite these corrections, these predictions yield significant errors and typically overestimate the scour depth around hydraulic structures in gravel bed rivers. A key shortcoming of this approach is that the scour prediction formulae in sand bed streams are not parameterized to account for key processes that are encountered in gravel bed rivers but not in sand bed rivers. Such processes include the interactions between the differently sized gravel particles, including interlocking, hiding, and bed structure development, which increase the stability of the gravel particles. Further, existing scour prediction models gloss over the near-bed turbulent structures that result from the interaction with the bed gravel sediment and alter the near-bed flow characteristics. Finally, most existing studies have attempted to assess the maximum scour depth for a given set of flow conditions and hydraulic structure geometry, paying little attention to the 3D geometry of the scour and its temporal development. Yet, the 3D scour geometry, and especially its extent in plan view, is important for the stability of the adjacent SMH module structures. Further, the developing 3D scour geometry may interact with the turbulent flow hydraulics, which interactions are poorly documented. 


\section{Nontraditional Material Utilization}

Hydropower development has traditionally incorporated construction materials such as concrete and steel. The focus of SMH focus on modularity and standardization may encourage and necessitate the use of other construction materials because of their manufacturability, cost savings, and engineering properties. Composite materials and unique construction techniques with traditional materials may be used in SMH in applications that have not been implemented before - for example, composite turbine blades, unique construction methods for module structures with composite materials, or newer applications of traditional materials. The use of different materials and advanced construction techniques has little precedent in the field of hydropower; therefore, addressing this knowledge will require focused attention on research and material performance in use.

\section{Bank Erosion}

Bank erosion is a process integral to natural channel processes like meandering. It can also be a symptom of unchecked changes in the watershed causing incision and changes in channel cross-section geometry. This subject has bourgeoned as a research topic, as it is critical to the understanding of fluvial geomorphologic changes at the stream scale.

Early models calculated bank erosion and failure based on excess velocity near the bank and an empirically calibrated coefficient intended to capture bank characteristics, which are taken as homogeneous (Ikeda et al. 1981; Johannesson and Parker 1989). Physics-based models have improved upon this method and involve taking into consideration bedload movement, undercutting at the slope toe, and the episodic nature of mass planar and cantilever bank failure, as well as saturated effects from piping (Osman and Thorne 1988; Hagerty 1991; Darby et al. 2002; Motta et al. 2012; Abderrezzak et al. 2016; Sutarto et al. 2014; Gibson et al. 2015). Many of these models have started to consider the spatial heterogeneity of bank soil layers and are linked to existing hydraulic models like CONCEPTS or HEC-RAS (Sutarto et al. 2014; Motta et al. 2012; Gibson et al. 2015). Such models are beneficial in their detailed and process-based representation of bank erosion and failure mechanisms and their interaction with stream flow.

Despite the advances in physics-based models for bank erosion, several gaps exist. These include the effects of weathering and freeze-thaw cycles on bank material. Although piping has been considered theoretically, few models take into account this process or increased pore water pressure in the bank and their effects on erodibility. Understanding the effects of unsteady flows on bank erosion is another area of needed research. Furthermore, understanding of the effects of channel geometry changes and aggradation/degradation effects on bank erosion is needed.

\section{Techno-Economic}

Financial constraints on SMH facilities, which are fundamentally energy projects designed to generate revenue, limit the world of possibilities in equipment selection, structural design, mitigation measures, and development sites. A project will be viable only if the revenue available from power sales can offset the costs of all machines, structures, and operational strategies. Trade-offs between the energetic, hydraulic, structural, and environmental performance of modular facilities and the expected costs of installation and operation are not well understood. There is a need for techno-economic modeling that can set cost targets for modular facilities in different stream environments. For example, a site that requires fish, sediment, and recreation passage will have higher revenue generation requirements than a site that can sustain stream functions without multiple dedicated passage structures. A model that allows developers to assess potential cost-benefit trade-offs related to SMH facility design decisions is desired. 


\section{Hydroelasticity of Composite Materials}

As mentioned in Section 4.5.1, neither dynamic hydroelasticity (such as flutter) nor static hydroelasticity (such as divergence) has been a significant concern in hydropower applications because the runners (or the turbines) are traditionally made of solid metal with relatively high stiffness. However - given the possibilities for using advanced and additive manufacturing technologies via which complex blade shapes can be realized and materials such as composites can be used more commonly in SMH-designers need to ensure that phenomena such as flutter and forced excitation response do not occur as results of increased flexibility and the use of new materials. Therefore, simulation and modeling techniques that take hydroelastic modeling into account should be used to eliminate the possibility of such occurrences in future designs.

\section{Sediment Delivery from the Watersheds}

The need to understand sediment delivery from the watershed to the channel is an important process in understanding total sediment load and the resulting geomorphologic processes driven, in part, by sediment supply. Sediment delivery is highly varied, and no universal empirical or theoretical relationship exists for delivery ratios. Such ratios may vary greatly, depending on geographic and climactic factors (Walling 1983).

Models can generally be divided into two groups based on the way the model treats the input parameters and their application to the watershed. Lumped models assume the entire watershed is composed of soil with homogeneous properties. Many of these models are developed for use in modeling runoff and sediment transport from agricultural fields or catchments (De Roo et al. 1996). Distributed models do not assume homogeneity, and they apply different characteristics based on land use, soil type, topography, and so on to individual portions of the watershed. These models are applied against time scales, which vary from storm event duration (Water Erosion Prediction Project [WEPP], Soil and Water Assessment Tool [SWAT]) to annual periods. Some, like WEPP, are written to run continuous storm events for long periods, as in Papanicolaou and Abaci (2008). Such models use model inputs that include topography (linked to GIS platforms), rainfall characteristics, soil characteristics (e.g., soil type, minerology, pH), management practices, and crop type (Papanicolaou and Abaci 2008).

The application of such models is challenging, given the high variability of watershed characteristics and the processes that drive erosion and delivery to streams or retention within the watershed. Furthermore, these models typically are applicable only to small catchments. For example, WEPP is generally thought to be applicable to catchments of up to $2.6 \mathrm{~km}$, but it has been applied in long-term studies to catchments an order of magnitude larger (Papanicolaou and Abaci 2008).

\section{Streamflow Synthesization for Ungauged Stream-reaches}

The unavailability of streamflow estimates at various ungauged stream-reaches presents one of the biggest challenges to future SMH development and market acceleration. Given that most stream-reaches are not monitored (e.g., there are 23,000 National Water Information System [NWIS] gauge stations versus 3 million NHDPlus flowlines), efforts are needed to reconstruct long-term (over 30 years) and daily (or subdaily) historic streamflow time series and derive flow-duration curves to support SMH site identification, selection, and further engineering design. However, given the geographical variability and data availability, the most suitable streamflow synthesization model is likely to be different across various regions. Issues such as hydrologic model comparison, selection, calibration, and data assimilation need study for the development of credible streamflow estimates to support SHM needs. 


\section{Coupling Upland Erosion and In-Stream Hydraulic and Morphodynamic Models}

Despite the notable development of upland erosion and in-stream hydraulic and morphodynamic models that has occurred in recent years, the two types of models are typically developed separately from one another with no framework for their coupling. In nature, however, river systems are intimately related to their adjacent watersheds, which supply runoff and sediment to the river as lateral contributions. These contributions affect the sediment transport capacity and supply in the rivers; therefore, failure to account for these factors may lead to large errors in their estimation. Because all geomorphological processes examined in Section 4.5 are based on this balance between sediment transport capacity and supply, neglecting these lateral contributions would result into significant errors in the prediction of morphodynamic river models. Coupling between upland erosion and in-stream models is therefore an active research topic; and new coupling frameworks are being proposed, such as the recent work of Abban et al. (2016a,b). The development of analogous frameworks for coupling upland erosion and instream models is a key challenge for the SMH simulation and modeling capability. Key considerations for addressing this challenge are the compatibility of the spatiotemporal scales of the processes that are represented in the various upland erosion and in-stream models, and the communication and interface protocols between the inputs and outputs from the different models.

\section{Generator and Power Converter}

Although SMH generator design is possible using common design methods, those methods may not be suitable for the development of the low-cost, high-power-density, high-efficiency generators needed in SMH installations. With respect to electromechanical processes, the most pronounced gaps and challenges are modeling of losses, the effects of manufacturing on steel magnetic processes, and the convective thermal processes for generator and power electronics cooling. These are key issues for accurately modeling generator efficiency and power output capability. Although there are commonly used techniques to roughly model all of these effects, considerable gaps are still observed even between most state-of-the-art generator models and test data. Newer methods to increase the fidelity of generator and power converter simulations are discussed in the preceding sections of this report. It is also common to build and test generator prototypes to validate or provide feedback for improving modeling accuracy.

\section{Ensemble Averaging Approaches}

An analysis of the processes examined in Section 4 reveals that the individual processes within each class of processes occur on different spatiotemporal scales that may range over several orders of magnitude (Figure 5). As a result, it may not be possible to account for all processes because of limitations in model resolution, parameterization, and computational cost. To overcome this limitation and account for the effects of processes occurring at different spatiotemporal scales, it is often necessary to average ensembles, or upscale the effects of processes occurring on smaller scales. At present, the upscaling of the effects of processes is an active field of research and a key challenge for the simulation and modeling capability. Research in this topic has yielded theoretical frameworks for upscaling processes such as the double averaging approach (Nikora et al. 2001; Nikora et al. 2007), which is focused on upscaling turbulent flow hydrodynamics while accounting for roughness caused by large roughness elements. 